\title{
COMPUTER MODEL OF RARITAN RIVER BASIN WATER-SUPPLY SYSTEM IN CENTRAL NEW JERSEY
}

by Paul Dunne and Gary Tasker

U.S. GEOLOGICAL SURVEY

Open-File Report 96-360

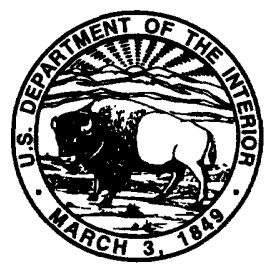

Prepared in cooperation with the NEW JERSEY WATER SUPPLY AUTHORITY

West Trenton, New Jersey 


\section{U.S. DEPARTMENT OF THE INTERIOR \\ BRUCE BABBITT, Secretary}

\section{U.S. GEOLOGICAL SURVEY}

Gordon P. Eaton, Director

For additional information write to:

District Chief

U.S. Geological Survey Mountain View Office Park 810 Bear Tavern Road, Suite 206 West Trenton, NJ 08628
Copies of this report can be obtained from:

U.S. Geological Survey

Branch of Information Services

Box 25286

Denver, CO 80225-0286 


\section{CONTENTS}

Page

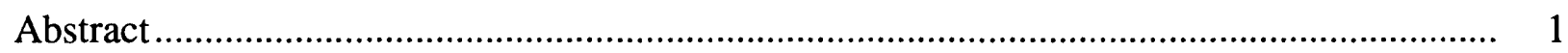

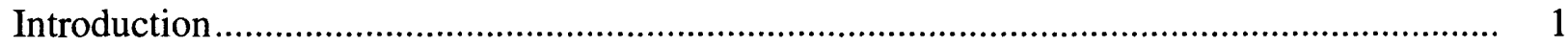

Purpose and scope ................................................................................................. 1

Description of the study area .................................................................................... 2

Raritan River Basin water-supply-system model ............................................................... 2

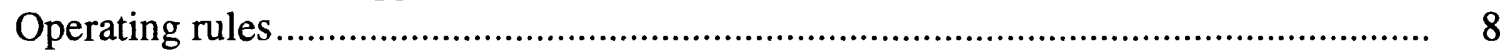

Delaware-Raritan Canal ........................................................................... 8

Spruce Run Reservoir ............................................................................... 9

Round Valley Reservoir............................................................................... 9

Combined storage ………………………................................................... 9

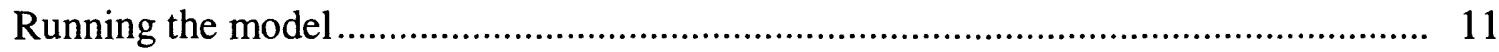

General risk analysis model ................................................................... 11

Position analysis model ............................................................................ 11

Model derivation .............................................................................. 11

Error components in historical sequence ......................................... 13

Program structure .............................................................................................. 15

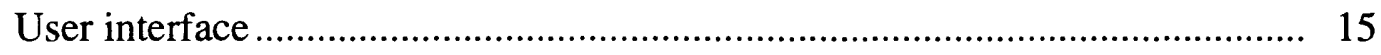

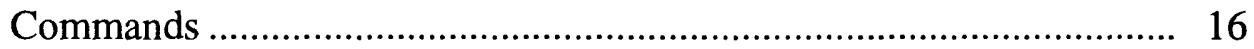

Assistance panel.............................................................................. 18

Instruction panel.......................................................................... 19

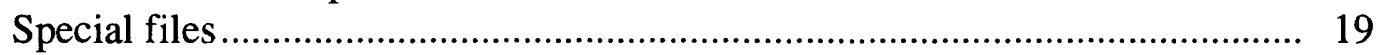

Session record--RARRIV.LOG ................................................... 19

Error and warning messages--ERROR.FIL ........................................ 19

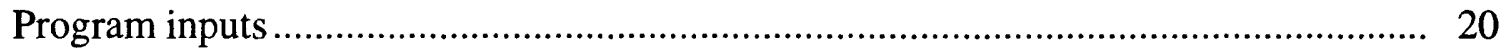

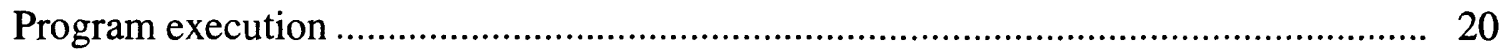

Program options ......................................................................................... 20

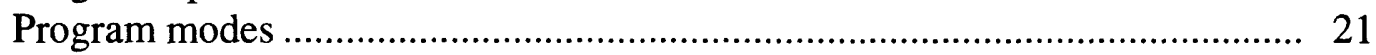

Modification of operating rules ................................................................... 24

Depletive water-use rates................................................................. 26

Spruce Run Reservoir .................................................................. 28

Round Valley Reservoir.................................................................. 30

New York City reservoirs .................................................................... 33

Combined reservoir system.............................................................. 35

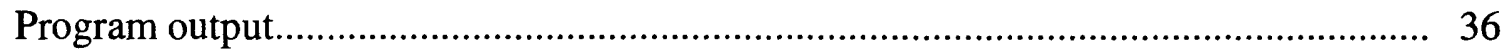

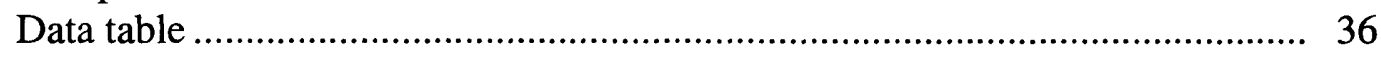

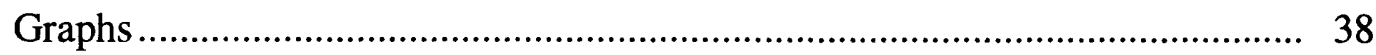

Time-series plots .......................................................................... 40

Percentile plots ........................................................................... 40

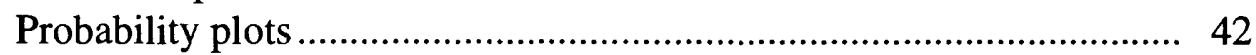

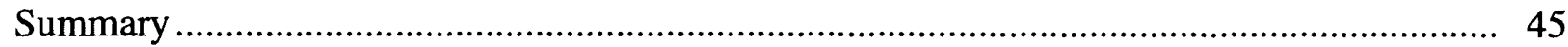

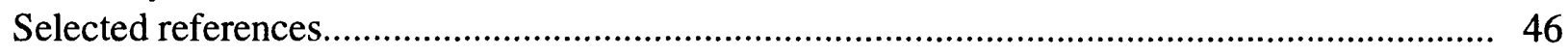

Appendix 1. Observed error components of stochastic runoff model ................................... 47 


\section{ILLUSTRATIONS}

Page

Figure 1. Map showing Raritan River Basin water-supply system, central New Jersey.

2. Map showing relation between New York City reservoirs and the Raritan River Basin, central New Jersey

3. Flow diagram of model of Raritan River Basin water-supply system, central New Jersey

4. Graph showing relation between the ratio of average monthly unregulated runoff to required runoff and the ratio of average monthly release to required runoff, Raritan River Basin model, central New Jersey ....

5. Flow diagram of bootstrap method applied to a water-supply storage and delivery system, Raritan River Basin model, central New Jersey

6. Diagram showing basic screen layout and commands for the computer program, Raritan River Basin model, central New Jersey

7. Diagram showing RARRIV opening screen, Raritan River Basin model, central New Jersey

8. Diagram showing the branches of the RARRIV option tree, Raritan River Basin model, central New Jersey

9. Diagram showing run option menu, Raritan River Basin model, central New Jersey

10. Diagram showing input field screens of the position analysis mode, Raritan River Basin model, central New Jersey .

11. Diagram showing input/output menu, Raritan River Basin model, central New Jersey

12. Diagram showing create option menu, Raritan River Basin model, central New Jersey

13. Diagram showing water-use option menu, Raritan River Basin model, central New Jersey

14. Diagram showing depletive water-use rate tables, Raritan River Basin model, central New Jersey

15. Diagram showing Spruce Run Reservoir menu, Raritan River Basin model, central New Jersey

16. Diagram showing Spruce Run Reservoir tables and forms, Raritan River Basin model, central New Jersey

17. Diagram showing Round Valley Reservoir menu, Raritan River Basin model, central New Jersey

18. Diagram showing Round Valley Reservoir tables and forms, Raritan River Basin model, central New Jersey

19. Diagram showing New York City reservoirs menu, Raritan River Basin model, central New Jersey

20. Diagram showing New York City reservoirs tables and forms, Raritan River Basin model, central New Jersey 


\section{ILLUSTRATIONS--Continued}

Figure 21. Diagram showing operate option table, Raritan River Basin model, central New Jersey

22. Example data table produced by the Raritan River Basin model, central New Jersey

23. Diagram showing graph option menu, Raritan River Basin model, central New Jersey.....

24. Diagram showing plot type menu, Raritan River Basin model, central New Jersey 38

25. Diagram showing plot menu, Raritan River Basin model, central New Jersey... 39

26. Diagram showing modify option menu, Raritan River Basin model, central New Jersey.

27. Graph showing time-series plot produced by the Raritan River Basin model, central New Jersey

28. Graph showing percentile plot produced by the Raritan River Basin model, central New Jersey

29. Graph showing probability plot produced by the Raritan River Basin model, central New Jersey

\section{TABLES}

Table 1. Gaging stations and periods of record used to reconstruct values of unregulated runoff for indicated regions of the Raritan and Delaware River Basins, central New Jersey

2. Storage threshold limits for indicated condition of reservoirs for the combined New York City Delaware River reservoirs

3. Prescribed withdrawals for New York City, passing-flow requirements for Delaware River, and diversions for Delaware-Raritan Canal for indicated condition of reservoirs

4. Reservoir contents that define the condition of the Raritan River Basin water-supply system, central New Jersey

5. Passing-flow requirements and minimum releases from Spruce Run Reservoir for various conditions of the Raritan River Basin water-supply system, central New Jersey

6. Parameters for the PARMA $(1,1)$ model for the indicated regions, Raritan River Basin model, central New Jersey 


\section{CONVERSION FACTORS}

Multiply

inch (in.)

square mile $\left(\mathrm{mi}^{2}\right)$

billion gallons (Ggal)

cubic foot per second $\left(\mathrm{ft}^{3} / \mathrm{s}\right)$

million gallons per day (Mgal/d)
By

25.4

2.590

$3,785,412$

0.02832

0.04381
To obtain

millimeter

square kilometer

cubic meter

cubic meter per second

cubic meter per second 


\title{
COMPUTER MODEL OF RARITAN RIVER BASIN WATER-SUPPLY SYSTEM IN CENTRAL NEW JERSEY
}

\author{
by Paul Dunne and Gary Tasker
}

\begin{abstract}
This report describes a computer model of the Raritan River Basin water-supply system in central New Jersey. The computer model provides a technical basis for evaluating the effects of alternative patterns of operation of the Raritan River Basin water-supply system during extended periods of below-average precipitation.

The computer model is a continuity-accounting model consisting of a series of interconnected nodes. At each node, the inflow volume, outflow volume, and change in storage are determined and recorded for each month. The model runs with a given set of operating rules and water-use requirements including releases, pumpages, and diversions. The model can be used to assess the hypothetical performance of the Raritan River Basin water-supply system in past years under alternative sets of operating rules. It also can be used to forecast the likelihood of specified outcomes, such as the depletion of reservoir contents below a specified threshold or of streamflows below statutory passing flows, for a period of up to 12 months. The model was constructed on the basis of current reservoir capacities and the natural, unregulated monthly runoff values recorded at U.S. Geological Survey streamflow-gaging stations in the basin.
\end{abstract}

\section{INTRODUCTION}

The reservoirs and pumping station that comprise the Raritan River Basin water-supply system and its interconnections to the Delaware-Raritan Canal water-supply system supply potable water to central New Jersey communities. This combined system includes Spruce Run Reservoir, Round Valley Reservoir, Hamden pumping station, and the Delaware-Raritan Canal. The system can easily be strained by an extended period of below-average precipitation. Efficient operation of the combined system during such periods is vital to meeting the water- supply needs of central New Jersey communities. The New Jersey Water Supply Authority (NJWSA) is responsible for the management of the water resources in the system. The U.S. Geological Survey (USGS), in cooperation with NJWSA, developed a computer model that provides a technical basis for evaluating the effects of alternative patterns of past or future operation of the Raritan River Basin water-supply system given current streamflow conditions and current reservoir contents.

\section{Purpose and Scope}

This report documents a model of the Raritan River Basin water-supply system. It describes the structure and execution of the computer program, input requirements, and program output. 


\section{Description of the Study Area}

The Raritan River Basin water-supply system is located in central New Jersey and encompasses Hunterdon, Mercer, Middlesex, Monmouth, Morris, and Somerset Counties (fig. 1). Features of the water-supply system include Spruce Run Reservoir, Round Valley Reservoir, Hamden pumping station, Delaware-Raritan Canal, and several streamflow-gaging stations. The New York City reservoirs supply water to the Delaware-Raritan Canal by way of the Delaware River (fig. 2). These features are used for storage and release of surface waters to supply the demands of public and private water utilities and to meet statutory passing-flow requirements within the Raritan River Basin.

Spruce Run Reservoir is located on Spruce Run Creek, a tributary of the South Branch Raritan River, in Hunterdon County. The reservoir has a drainage area of $41.3 \mathrm{mi}^{2}$ and a usable capacity of $11 \mathrm{Ggal}$ (called BG in the program).

Round Valley Reservoir is located on Prescott Brook, a branch of the South Branch Rockaway Creek, in Hunterdon County. The reservoir has a drainage area of $5.7 \mathrm{mi}^{2}$ and a capacity at the spillway level of $55 \mathrm{Ggal}$.

To augment water storage, water is pumped into Round Valley Reservoir during most of the year because its drainage area is too small to provide sufficient runoff. Water is pumped from the South Branch Raritan River at Hamden pumping station, which has a drainage area of 147 $\mathrm{mi}^{2}$ (Michael McRee, New Jersey Water Supply Authority, written commun., 1994). Water releases from Round Valley Reservoir are made through a 108-in.-diameter pipeline, which discharges to the South Branch Rockaway Creek at Whitehouse Station.

The Delaware-Raritan Canal is an integral part of the Raritan River Basin water-supply system. The canal begins on the Delaware River in Hunterdon County and flows south to Trenton and then northeast to New Brunswick, where it empties into the Raritan River. The canal is connected to the water-supply system through the Millstone River near Bound Brook. Water can be released into the Millstone River from the canal or pumped from the river into the canal.

The Raritan River Basin water-supply system must meet statutory passing-flow requirements at three locations. A passing-flow requirement is the minimum volume of water required to be maintained at a selected point to ensure adequate water-quality conditions after consideration of the needs of downstream users. These requirements are $40 \mathrm{Mgal} / \mathrm{d}$ in the South Branch Raritan River at Stanton, $70 \mathrm{Mgal} / \mathrm{d}$ in the Raritan River at Manville, and $90 \mathrm{Mgal} / \mathrm{d}$ in the Raritan River at Bound Brook below Calco Dam.

\section{RARITAN RIVER BASIN WATER-SUPPLY-SYSTEM MODEL}

The Raritan River Basin water-supply-system model (RARRIV) is a continuityaccounting model consisting of a series of interconnected nodes that represent reservoirs, canals, and other water supplies, and flow paths that connect the nodes (fig. 3). At each node the inflow volume, outflow volume, and change in storage are determined and recorded for each month. RARRIV is based on the natural inflows into each node. Because RARRIV runs with a monthly time step and because natural inflows can fluctuate greatly within the course of a month, releases 


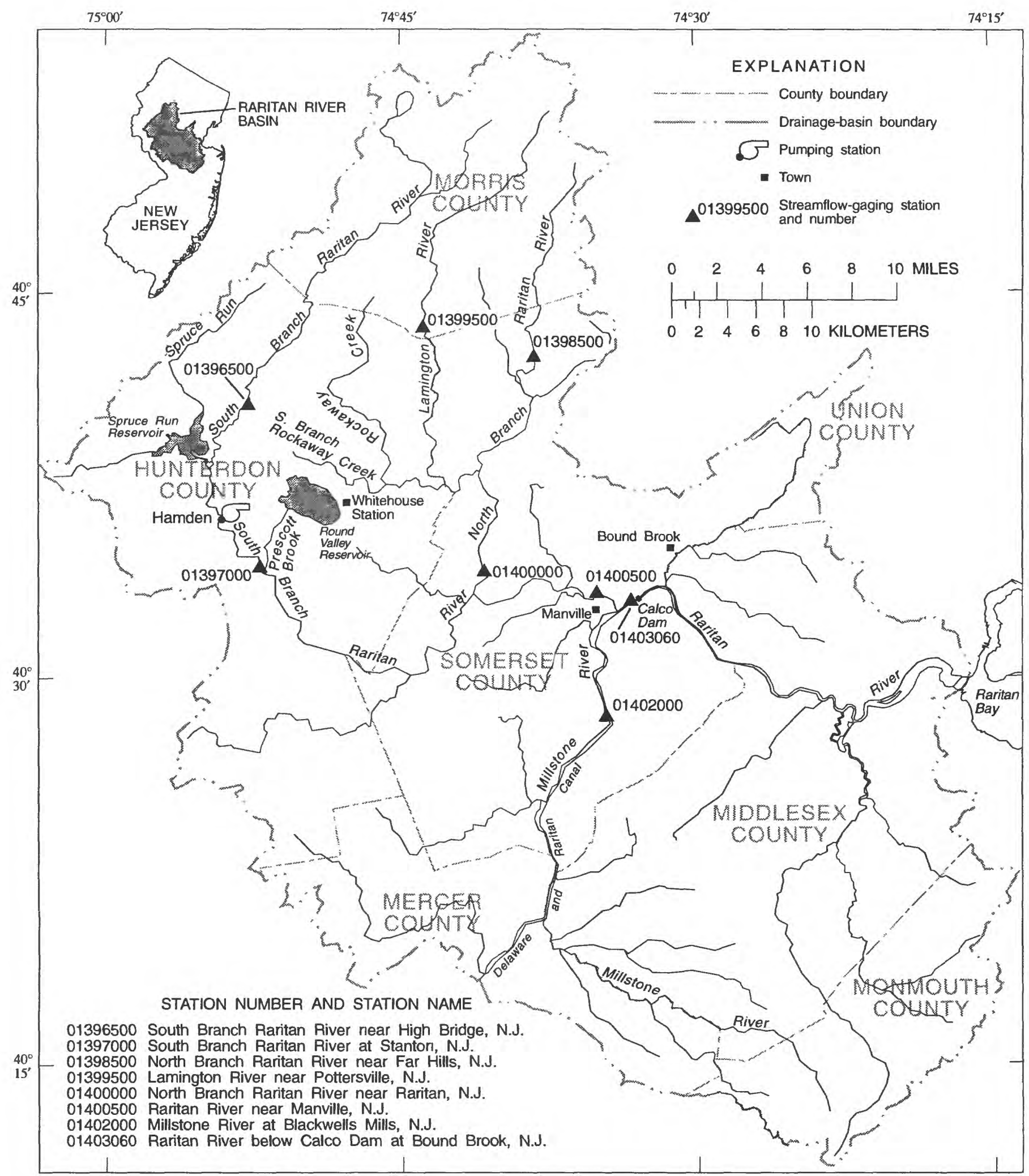

Figure 1. Raritan River Basin water-supply system, central New Jersey. 


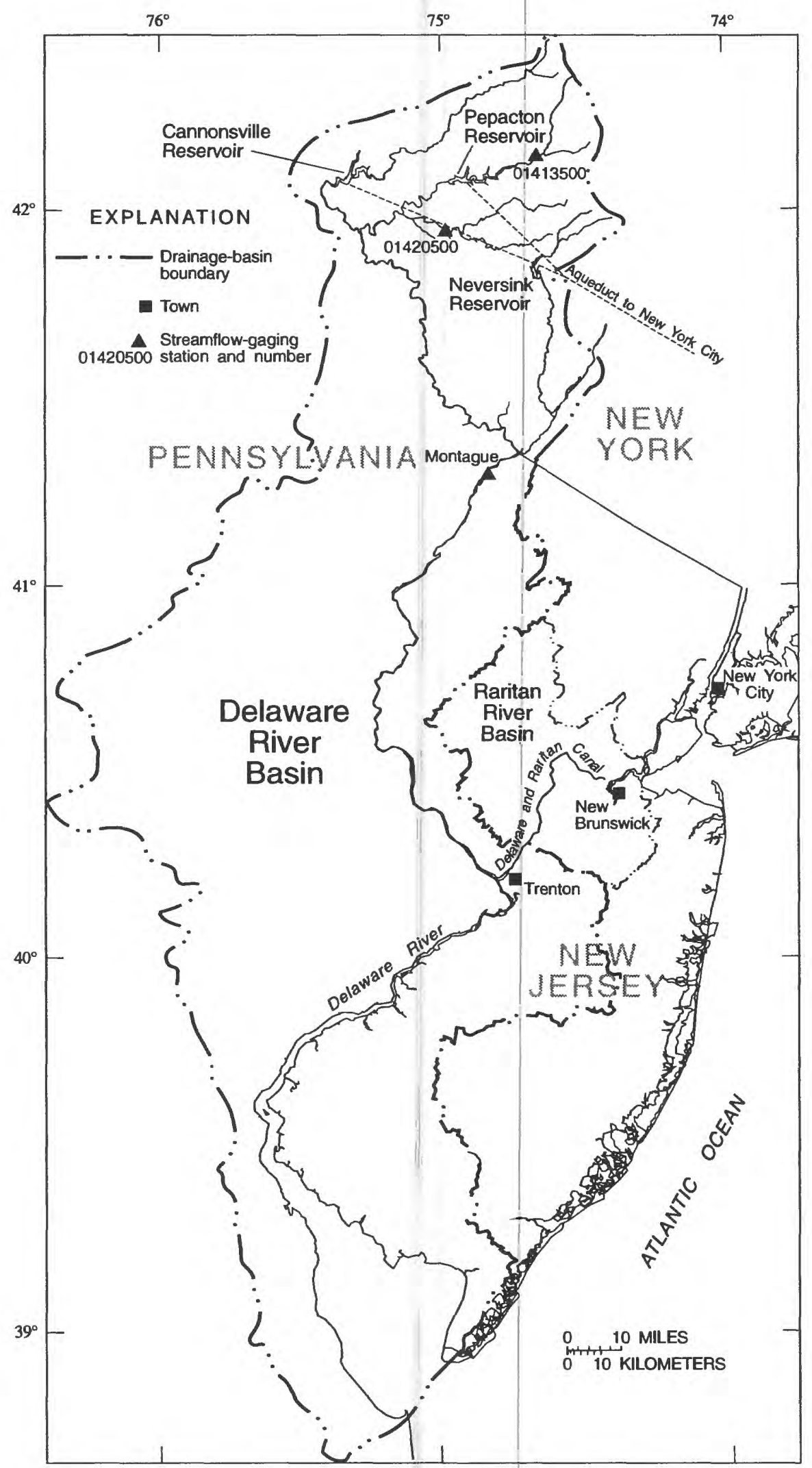

Figure 2. Relation between New York City reservoirs and the Raritan River Basin, central New Jersey. 


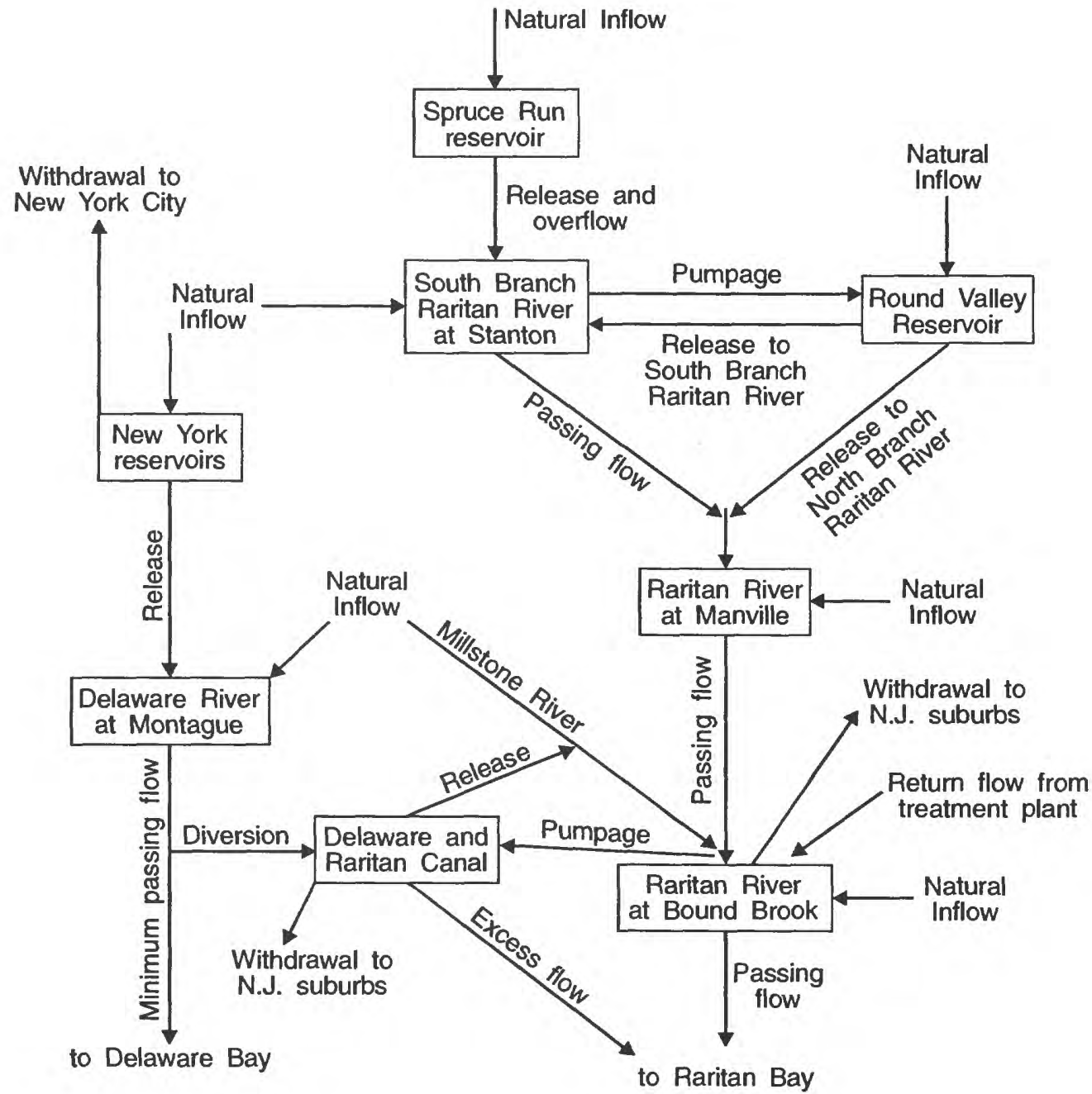

Figure 3. Flow diagram of model of Raritan River Basin water-supply system, central New Jersey (Boxes represent model nodes and arrows represent inflows and outflows). 
to meet daily passing-flow and water-withdrawal requirements in the model need to be adjusted upward to account for periods of low flow within a month. This is done by using an empirical formula (fig. 4) developed by the New York State Department of Environmental Conservation and reported in Hirsch (1981b).

RARRIV is based on natural, unregulated monthly runoff values. Records from USGS streamflow-gaging stations in the study area (table 1) were used to estimate these values. Only those records representing natural, unregulated streamflow were included. The longest record spanned 75 years, from October 1918 to September 1993. Records of shorter length were reconstructed and extended to a length of 75 years by regression using the MOVE. 1 technique (Hirsch, 1982). These reconstructed flow records were then adjusted on a regional yield basis to account for ungaged basin area, resulting in a time series of monthly runoff data for three regions in the Raritan River Basin and two regions in the Delaware River Basin. The three regions in the Raritan River Basin are the South Branch Raritan River, the North Branch Raritan River, and the remaining drainage area upstream from the streamflow-gaging station on the Raritan River at Bound Brook (which includes the Millstone River Basin). The two regions in the Delaware River Basin are the area above the three New York City reservoirs and the area between the reservoirs and the streamflow-gaging station at Montague, N.J.

Table 1. Gaging stations and periods of record used to reconstruct values of unregulated runoff for indicated regions of the Raritan and Delaware River Basins, central New Jersey [mi ${ }^{2}$, square miles; NYC, New York City]

\begin{tabular}{|c|c|c|c|c|}
\hline $\begin{array}{l}\text { Station } \\
\text { number }\end{array}$ & Station name & $\begin{array}{c}\text { Drainage } \\
\text { area } \\
\left(\mathrm{mi}^{2}\right)\end{array}$ & $\begin{array}{c}\text { Period of record } \\
\text { used }\end{array}$ & Model region \\
\hline 01396500 & $\begin{array}{l}\text { South Branch Raritan River near } \\
\text { High Bridge, N.J. }\end{array}$ & 65.3 & $10 / 1918$ to $9 / 1993$ & $\begin{array}{l}\text { South Branch Raritan } \\
\text { River }\end{array}$ \\
\hline 01397000 & $\begin{array}{l}\text { South Branch Raritan River at } \\
\text { Stanton, N.J. }\end{array}$ & 147 & $10 / 1919$ to $9 / 1963$ & $\begin{array}{l}\text { South Branch Raritan } \\
\text { River }\end{array}$ \\
\hline 01398500 & $\begin{array}{l}\text { North Branch Raritan River near } \\
\text { Far Hills, N.J. }\end{array}$ & 26.2 & $\begin{array}{l}10 / 1921 \text { to } 9 / 1975 \\
10 / 1977 \text { to } 9 / 1993\end{array}$ & $\begin{array}{l}\text { North Branch Raritan } \\
\text { River }\end{array}$ \\
\hline 01399500 & $\begin{array}{l}\text { Lamington River near } \\
\text { Pottersville, N.J. }\end{array}$ & 32.8 & $10 / 1921$ to $9 / 1993$ & $\begin{array}{l}\text { North Branch Raritan } \\
\text { River }\end{array}$ \\
\hline 01400000 & $\begin{array}{l}\text { North Branch Raritan River near } \\
\text { Raritan, N.J. }\end{array}$ & 190 & $6 / 1923$ to $9 / 1993$ & $\begin{array}{l}\text { North Branch Raritan } \\
\text { River }\end{array}$ \\
\hline 01402000 & $\begin{array}{l}\text { Millstone River at Blackwells } \\
\text { Mills, N.J. }\end{array}$ & 258 & $8 / 1921$ to $9 / 1993$ & $\begin{array}{l}\text { Millstone-Raritan } \\
\text { Rivers }\end{array}$ \\
\hline 01413500 & $\begin{array}{l}\text { East Branch Delaware River at } \\
\text { Margeretteville, N.Y. }\end{array}$ & 163 & $4 / 1937$ to $9 / 1993$ & $\begin{array}{l}\text { Delaware River above } \\
\text { NYC reservoirs }\end{array}$ \\
\hline 01420500 & Beaver Kill at Cooks Falls, N.Y. & 241 & $10 / 1918$ to $9 / 1993$ & $\begin{array}{l}\text { Delaware River above } \\
\text { and below NYC } \\
\text { reservoirs }\end{array}$ \\
\hline
\end{tabular}




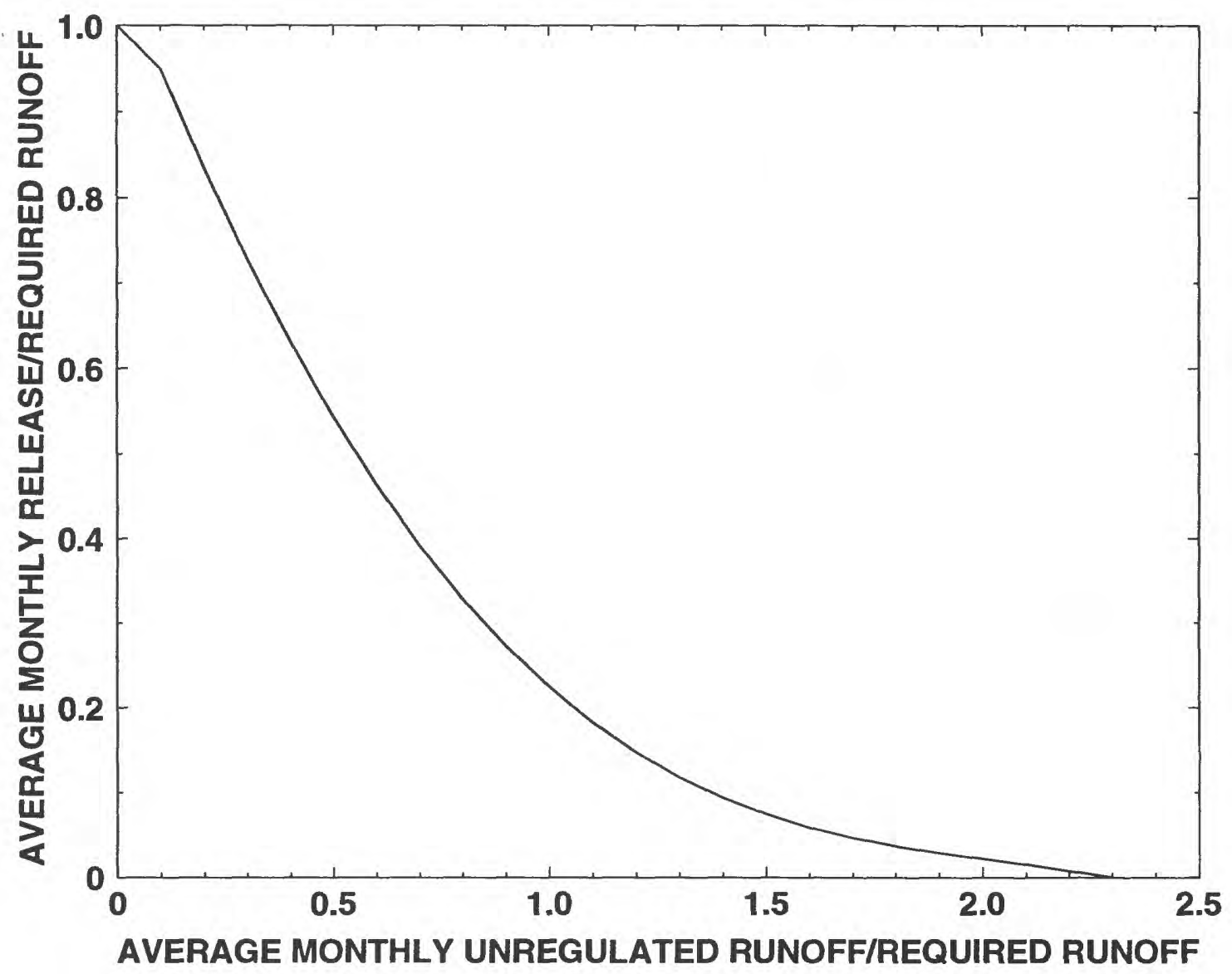

Figure 4. Relation between the ratio of average monthly unregulated runoff to required runoff and the ratio of average monthly release to required runoff, Raritan River Basin model, central New Jersey (Modified from Hirsch, 1981b, fig. 2). 


\section{Operating Rules}

In RARRIV, a set of operating rules mimics the timing and rate of reservoir and canal releases and pumpages that are required of the real system to meet passing-flow requirements and withdrawal demands. These operating rules can be changed to simulate the effects of alternative sets of rules and to evaluate their usefulness and attendant risks. The following report sections describe the model's operating rules, default specifications, and user options.

\section{Delaware-Raritan Canal}

The amount of diversion allowed from the Delaware River to the Raritan River, the amount of withdrawals allowed to New York City, and the passing-flow requirements for the Delaware River at Montague streamflow-gaging station depend on the condition of the New York City reservoirs and the month of year. For any month, the reservoirs can be in one of four conditions--normal, drought warning, drought emergency, or drought (table 2). Default values for diversions, withdrawals, and passing-flow requirements are associated with each condition of the reservoirs (table 3). In RARRIV, the user can change the monthly thresholds of each condition and the default values for diversions, withdrawals, and passing-flow requirements.

Table 2. Storage threshold limits for indicated condition of reservoirs for the combined New York City Delaware River reservoirs

[If storages are below drought emergency level, basin is in drought state. Values are in billion gallons]

\begin{tabular}{|c|c|c|c|}
\hline Month & Normal & $\begin{array}{c}\text { Drought } \\
\text { warning }\end{array}$ & $\begin{array}{c}\text { Drought } \\
\text { emergency }\end{array}$ \\
\hline \hline January & 130 & 110 & 90 \\
\hline February & 145 & 125 & 105 \\
\hline March & 165 & 145 & 115 \\
\hline April & 180 & 160 & 140 \\
\hline May & 190 & 170 & 150 \\
\hline June & 190 & 170 & 150 \\
\hline July & 175 & 155 & 135 \\
\hline August & 150 & 130 & 110 \\
\hline September & 120 & 100 & 80 \\
\hline October & 110 & 90 & 70 \\
\hline November & 110 & 90 & 70 \\
\hline December & 120 & 100 & 80 \\
\hline
\end{tabular}


Table 3. Prescribed withdrawals for New York City, passing-flow requirements for Delaware River, and diversions for Delaware-Raritan Canal for indicated condition of reservoirs

\begin{tabular}{|l|c|c|c|c|}
\hline \multicolumn{1}{|c|}{ Operating rule } & Normal & $\begin{array}{c}\text { Drought } \\
\text { warning }\end{array}$ & $\begin{array}{c}\text { Drought } \\
\text { emergency }\end{array}$ & Drought \\
\hline \hline $\begin{array}{l}\text { Withdrawals to New York City, in million gallons } \\
\text { per day }\end{array}$ & 800 & 680 & 560 & 520 \\
\hline $\begin{array}{l}\text { Passing flow for Delaware River at Montague, in } \\
\text { cubic feet per second }\end{array}$ & 1,750 & 1,655 & 1,550 & 1,350 \\
\hline $\begin{array}{l}\text { Diversions to Delaware-Raritan Canal, in million } \\
\text { gallons per day }\end{array}$ & 100 & 85 & 70 & 50 \\
\hline
\end{tabular}

\section{Spruce Run Reservoir}

The normal monthly minimum capacity for Spruce Run Reservoir is $3 \mathrm{Ggal}$. As long as storage in the reservoir is above this capacity, releases are made from Spruce Run as needed to meet the withdrawal demands and passing-flow requirements at Stanton, Manville, and Bound Brook. If storage falls below the minimum in a specified month, then releases are made only to meet demands for passing flow at Stanton until storage rises above the minimum once again. In RARRIV, the user can change the minimums, the reservoir capacity (default $11 \mathrm{Ggal}$ ), and the minimum-flow release (default $5 \mathrm{ft}^{3} / \mathrm{s}$ ).

\section{Round Valley Reservoir}

Releases from Round Valley Reservoir to South Branch Raritan River are made to meet passing-flow requirements at Stanton that cannot be met by unregulated flows or by releases from Spruce Run. Releases to North Branch Raritan River are made to meet withdrawal demands and passing-flow requirements at Manville and Bound Brook that cannot be met by unregulated flows, by releases from Spruce Run, or by diversions from the Delaware-Raritan Canal. Inflow into Round Valley Reservoir comes from natural runoff supplemented by water pumped from the Hamden pumping station above the Stanton streamflow-gaging station. Pumping is done only when statutory passing-flow requirements at Stanton are met and when storage in Round Valley Reservoir is below the target capacity. In RARRIV, the user can set the target storage capacity for each month (default $50 \mathrm{Ggal}$ ). The user can also change the reservoir capacity (default $55 \mathrm{Ggal}$ ).

\section{Combined Storage}

The Raritan River Basin water-supply system can be in one of three conditions--normal, drought warning, or drought emergency--depending on the current storage available in Spruce Run and Round Valley Reservoirs during a specified month (table 4). For each condition, passing-flow requirements and withdrawal rates have been established (table 5). In RARRIV, the user can change these conditions. In addition, the user can set storage thresholds that trigger a simulated pumpage of water from Hamden to Round Valley if sufficient water is available in the stream. The default pumping triggers for each month are the "normal" values in table 4. Unless 
the user sets new thresholds, simulated pumping will start when reservoir contents fall below default levels (table 4). The user can also modify the maximum pumping rate from Hamden to Round Valley Reservoir (default $70 \mathrm{Mgal} / \mathrm{d}$ ).

Table 4. Reservoir contents that define the condition of the Raritan River Basin water-supply system, central New Jersey

[Values are in billion gallons]

\begin{tabular}{|c|c|c|c|}
\hline Month & Normal & $\begin{array}{c}\text { Drought } \\
\text { warning }\end{array}$ & $\begin{array}{c}\text { Drought } \\
\text { emergency }\end{array}$ \\
\hline \hline January & 47.7 & 42.7 & 32.8 \\
\hline February & 49.1 & 44.1 & 34.7 \\
\hline March & 50.5 & 45.5 & 37.4 \\
\hline April & 52.0 & 47.0 & 39.5 \\
\hline May & 54.7 & 49.7 & 41.8 \\
\hline June & 56.5 & 51.5 & 44.0 \\
\hline July & 54.4 & 49.4 & 41.0 \\
\hline August & 48.1 & 43.1 & 34.3 \\
\hline September & 42.0 & 37.0 & 26.0 \\
\hline October & 39.5 & 34.5 & \\
\hline November & 43.1 & 38.1 & 23.3 \\
\hline December & 45.7 & 40.7 & 27.9 \\
\hline
\end{tabular}

Table 5. Passing-flow requirements and minimum releases from Spruce Run Reservoir for various conditions of the Raritan River Basin watersupply system, central New Jersey

[Values are in million gallons per day]

\begin{tabular}{|l|c|c|c|}
\hline \multicolumn{1}{|c|}{ Operating rule } & Normal & $\begin{array}{c}\text { Drought } \\
\text { warning }\end{array}$ & $\begin{array}{c}\text { Drought } \\
\text { emergency }\end{array}$ \\
\hline \hline Passing-flow requirement at Stanton & 40.0 & 40.0 & 40.0 \\
\hline $\begin{array}{l}\text { Passing-flow requirement at } \\
\text { Manville }\end{array}$ & 70.0 & 70.0 & 70.0 \\
\hline $\begin{array}{l}\text { Passing-flow requirement at Bound } \\
\text { Brook }\end{array}$ & 90.0 & 90.0 & 90.0 \\
\hline $\begin{array}{l}\text { Minimum release from Spruce Run } \\
\text { Reservoir }\end{array}$ & 5.0 & 5.0 & 5.0 \\
\hline
\end{tabular}




\section{Running the Model}

RARRIV can be run in one of two modes-- General Risk Analysis Model (GRAM) or Position Analysis Model (PAM). These models are explained in this section.

\section{General Risk Analysis Model}

General risk analysis (Hirsch, 1978) is based on the reconstructed historical flow records for the base period of 75 years. GRAM can be used to estimate the probabilities of certain events --such as the depletion of reservoir storage below a critical level-- given an assumed set of operating rules and withdrawal rates. It provides an alternative to a traditional "safe yield" analysis (Rippl, 1883) and its outputs can be compared with those from other models such as that of Dresnack and others (1985). GRAM can help water managers assess the hypothetical performance of a water-supply system in past years under alternative sets of operating rules. Because most water-system managers are familiar with the hydrologic history of the systems they operate, GRAM provides a readily understood simulation of various operating alternatives.

\section{Position Analysis Model}

Of course, water-system managers are vitally interested in the potential effects of future hydrologic conditions on system performance and on the risks of water shortages. Position analysis (Hirsch, 1978) is a tool that can be used to forecast the likelihood of specified outcomes, such as the depletion of reservoir storage below a specified level or of streamflows below statutory passing-flow requirements, that would result from a specific operating plan for the basin over a projected period of a few months. It can be used as an aid in selecting a plan of operation to implement from the current period forward by providing a means of evaluating and ranking each proposed plan of operation in terms of future water-shortage risks. RARRIV allows the user to specify future operating rules, current streamflows, and current reservoir contents, and draws upon streamflow statistics to project the likelihood of possible outcomes.

\section{Model derivation}

Unlike general risk analysis, position analysis relies on the generation of a large number of possible future flow traces, a few months in length, that have been initialized with the current reservoir storages and current streamflows. These traces can be derived from a stochastic model of streamflows based on the historical record as described in Hirsch (1981a). Use of a stochastic model allows observed runoff to be separated into a carryover component and a random-error component. The stochastic runoff model used for this model is the log-transformed autoregressive moving-average (LT-ARMA(1,1)) cyclic model (Hirsch, 1981a). It is also referred to as a periodic ARMA(1,1) or PARMA $(1,1)$ model (Salas, 1993). The model is derived as follows: 
Denote the runoff in year $\mathrm{i}$ and month $\mathrm{j}$ as $X_{i, j}$, and let $Y_{i, j}=\log \left(X_{i, j}\right)$. Define the variable

$$
Z_{i, j}=\frac{\left(Y_{i, j}-\bar{Y}_{j}\right)}{S_{j}}
$$

where $Y_{j}$ and $S_{j}$ are the sample mean and standard deviation, respectively, of the logarithms of the observed runoff values for month $j$. Therefore, $Z_{i, j}$ represents the standard deviation for year $i$ and month $\mathrm{j}$ of the $\log$-transformed mean runoff for month $\mathrm{j}$. form:

The serial dependence is a periodic-moving-average process or PARMA(1,1) model of the

$$
Z_{i, j}=\phi Z_{i, j-1}+E_{i, j}-\theta_{j} E_{i, j-1}
$$

where $E_{i, j}$ are independent errors with a mean of zero. The thirteen parameters, $\phi$ and $\theta_{j}$, are estimated by the method described in Hirsch (1979). Note that when $\mathrm{j}=1, \mathrm{Z}_{\mathrm{i}, \mathrm{j}-1}$ is taken to be $\mathrm{Z}_{\mathrm{i}-1,12^{--}}$ in other words, the month before January in a given year is taken to be December of the previous year.

In the LT-ARMA $(1,1)$ model, the lag 1 serial correlations between the runoff values in adjacent months for all 12 months are exactly preserved in the long run and the lag 2 through 12 serial correlations are preserved in a least-squares sense (Hirsch, 1981a). The first and third terms on the right-hand side of equation 2 can be thought of as the carryover components of runoff due to antecedent moisture and delayed runoff in a basin, whereas $E_{\mathrm{i}, \mathrm{j}}$ is the random component due to weather conditions in the current month, $\mathrm{j}$.

Equation (2) can be written as

$$
E_{i, j}=Z_{i, j}-\phi Z_{i, j-1}+\theta_{j} E_{i, j-1}
$$

Given an observed long record of monthly runoff values, $\mathrm{Z}_{\mathrm{i}, \mathrm{j}}$; the parameters for the model, $\phi$ and $\theta_{j}$; and a reasonable starting value for the first value of $E_{i, j}$, a long record of "observed error components" can be computed from equation 3 . These observed $E_{i, j}$ values represent the random component of monthly runoff for the period of record. Breaking up the standardized runoff values into carryover and random components allows synthetic runoff sequences to be generated either by using the error components in their historical sequence or by random resampling, with replacement, from the observed error components. The method of randomly resampling with replacement from the sample itself is called a bootstrap sampling method (Efron, 1979). Random resampling means to create a new sample of values by drawing at random from a reference sample. Random resampling with replacement means that each value drawn from the reference sample is immediately replaced in the reference sample so that it can be drawn again. 


\section{Error components in historical sequence}

A position-analysis trace 11 months in length can be generated by setting the starting value of $Z$ and sequentially computing $Z$ values by using a series of 12 error components. The $Z$ values can then be converted to runoff through use of equation 1 . The number of possible position-analysis traces that can be generated depends on the length of the error-component time series. In this model, because 75 years of monthly error components are available, 75 independent, equally likely 11 -month traces of synthetic runoff can be generated with each trace, starting with the current runoff value. The error components in the original historical sequence allow the user to see what would happen if meteorological conditions during one of the years in the base period were to occur under current conditions. For example, one may wish to see what would be likely to happen if the rainfall and temperature for the next few months were similar to those in 1965, a particularly dry year in central New Jersey.

Hirsch (1981a) generated stochastic traces for a single site by using a random-number generator to produce normally distributed errors. However, the assumption of normality of errors may not exploit all the information in the sample. The advantage of the bootstrap method is that it does not rely on the unverifiable assumption of normality of the error components. Instead, it relies on the nonparametric assumption that the maximum likelihood estimate of the population of error components is the sample of error components itself (Efron, 1982). The number of runoff traces that can be generated by the bootstrap method is not limited by the length of the base period. In addition, the bootstrap method provides a means of including long-range weather forecasts in the data used to generate the runoff values.

The results of either the historical sequence method or the bootstrap sequence method for generating runoff traces can be used as inputs to control a model simulation of a water-supply storage and delivery system for drought management. For a given set of system operating rules and water-use requirements, water managers can use such a model to forecast the likelihood of specified outcomes, such as the depletion of reservoir storage below a specified level or of streamflows below statutory passing-flow requirements, a few months in advance. Thus, RARRIV can be used to determine the effectiveness of specified changes in operating rules or drought restrictions. The flow chart in figure 5 shows the relation between the bootstrap runoff traces and a basin model.

The bootstrap method can be used to generate more sequences of runoff values than are available in the observed sequence. Each month of a bootstrap sequence of random components is selected by randomly selecting a year with replacement of the year and inputting the error component for the month for that year. Many sequences can be generated in this manner. This is possible because the components are independent random observations. Thus, 300,400 , 500 , or more 11-month bootstrap position-analysis traces can be generated from the 75 years of observed data. Because multiple runoff sites are needed for this model, the same randomly selected year is chosen for both sites; thus, the cross-correlation in error components is preserved. 

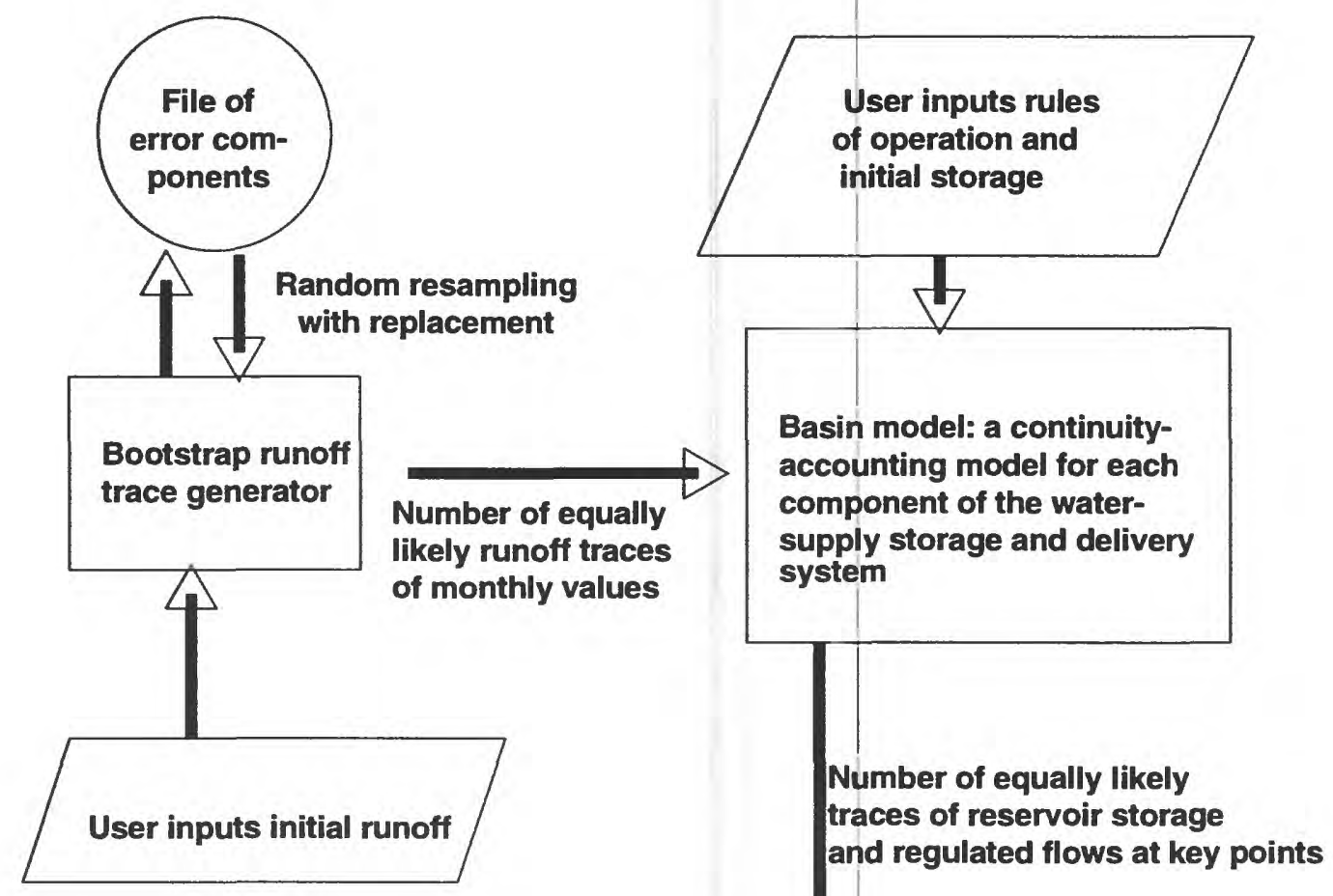

Figure 5. Flow diagram of bootstrap method applied to a water-supply storage and delivery system, Raritan River Basin model, central New Jersey. 
The bootstrap method also allows one to include the effects of long-range (90 days or more) forecasts of weather. Suppose that a 90 -day forecast predicts a 5 percent more likely than normal probability that conditions will be drier than normal. Then the bootstrap selection process can be modified to make it 5 percent more likely than normal to select a large negative error component, which would make it more likely that a "dry" position-analysis trace would be generated. RARRIV allows the user to specify the probabilities of occurrence of normal weather, wetter-than-normal weather, and drier-than-normal weather.

Five reconstructed time series of monthly runoff were used to develop five stochastic runoff models for the five portions of the Raritan and Delaware River Basins described earlier. The parameters of these PARMA $(1,1)$ models are given in table 6 . By using the reconstructed runoff values for the five portions of the basins and the model parameters, error components for the 75-year base period were computed by using equation 3 . These error components are given in appendix 1 for the five areas in the Raritan and Delaware River Basins.

Table 6. Parameters for the PARMA $(1,1)$ model for the indicated regions, Raritan River Basin model, central New Jersey

$[\phi$, autoregressive parameter; $\theta$, moving-average parameter; NYC, New York City]

\begin{tabular}{|l|c|c|c|c|c|}
\hline Parameter & $\begin{array}{c}\text { Delaware } \\
\text { River above } \\
\text { NYC } \\
\text { reservoirs }\end{array}$ & $\begin{array}{c}\text { Delaware } \\
\text { River } \\
\text { below NYC } \\
\text { reservoirs }\end{array}$ & $\begin{array}{c}\text { South } \\
\text { Branch } \\
\text { Raritan } \\
\text { River }\end{array}$ & $\begin{array}{c}\text { North } \\
\text { Branch } \\
\text { Raritan } \\
\text { River }\end{array}$ & $\begin{array}{c}\text { Raritan and } \\
\text { Millstone } \\
\text { Rivers }\end{array}$ \\
\hline \hline$\phi$ & 0.50 & 0.45 & 0.75 & 0.70 & 0.60 \\
\hline$\theta_{1}$ & .13 & .05 & .18 & .14 & .07 \\
\hline$\theta_{2}$ & .46 & .32 & .83 & .83 & .93 \\
\hline$\theta_{3}$ & .71 & .62 & .91 & .83 & .94 \\
\hline$\theta_{4}$ & .74 & .76 & .25 & .22 & .19 \\
\hline$\theta_{5}$ & .51 & .53 & .41 & .40 & .51 \\
\hline$\theta_{6}$ & -.06 & -.13 & .11 & .04 & .03 \\
\hline$\theta_{7}$ & -.31 & -.30 & .26 & .09 & .15 \\
\hline$\theta_{8}$ & -.02 & -.20 & .31 & .23 & .22 \\
\hline$\theta_{9}$ & -.12 & -.18 & .11 & .03 & .24 \\
\hline$\theta_{10}$ & -.22 & -.32 & .04 & .06 & .07 \\
\hline$\theta_{11}$ & -.19 & -.25 & .28 & .20 & .21 \\
\hline$\theta_{12}$ & .19 & .22 & .22 & .19 & .20 \\
\hline
\end{tabular}

\section{Program Structure}

\section{User Interface}

Program interaction takes place in a computer screen 80 characters wide by 24 characters high (fig. 6). Each screen consists of a list of available commands displayed at the bottom of the screen and one or more boxed-in areas that are referred to as panels. Commands are used to obtain additional information and to move between screens. There are three types of panels—data, assis- 
tance, and instruction. The data panel displayed at the top of the screen is always present. Data panels contain menus, forms, tables, and text to permit user interaction with the program. An assistance panel may be present depending on user or program assignments. When present, the assistance panel is displayed below the data panel (usually as the middle panel) and contains textual information, such as help messages, valid range of values, and details on program status. The instruction panel is displayed above the available commands when the user is expected to interact with the program. When present, the instruction panel contains information on the keystrokes that are required to interact with the program.

Each screen can be identified by a name and the path selected to reach the screen. The screen name appears in the upper left corner of the data panel, where the words "screen name" appear (fig. 6). The first screen displayed by the program is named "Opening screen." All subsequent screen names are based on the menu option or program sequence that caused the current screen to be displayed. Screen names are followed by "(path)," a string of characters (most recent from left to right) consisting of the first letter(s) of the menu options selected in order to arrive at the current screen. The path can aid the user in keeping track of the position of the current screen in the menu hierarchy. For example, "Operate (RC)" indicates that the menu option Operate was selected previously and that the path to this screen from the "Opening screen" consisted of two menu selections-Run, executed first; and Create, executed second.

\section{Commands}

The screen commands and their associated keystrokes are described in figure 6. A subset of the screen commands is available for any given screen. Most commands can be executed by pressing a single function key. (The designation for a function key is " $F \#$ " where \# is the number of the function key.) All of the commands can be executed in "command mode." Command mode is toggled on and off by pressing the semicolon (;) $\mathrm{key}^{1}$. In command mode, any command can be executed by pressing the first letter of the command name--for example, "o" or "O" for the Oops command. When commands are discussed in this report, the command name is spelled out with the function key or keystroke given in parentheses. For example, Accept $(F 2)$ is the most frequently used command.

Use Help (F1) and Limits (F5) to obtain additional information about the current screen and use Status (F7) to obtain information on the state of the program. Cmhlp (;c) will display information on the available commands. Use Quiet (F8) to close the assistance panel. To move between screens, use Accept (F2), Prev (F4), Intrpt (F6), Dnpg (;d), Uppg (;u), or Top (F10). To reset the values in the data panel, use Oops (;o). Xpad (F9) is used to save typed information in a file called XPAD.DAT.

There are four types of data panels---menu, form, table, and text. Menus offer a choice of two or more options. Data values are entered or modified in one or more data fields of a form or table. General or specific information, program progress, messages, and results of analyses may be displayed in a text data panel. The data panel appears at the top of the screen, as shown in figure 6 . There are 16 rows in the data panel when the assistance panel is closed and 10 rows when the assistance panel is open.

${ }^{1}$ On some systems the F3 key and (or) the escape key (Esc) may also work. 


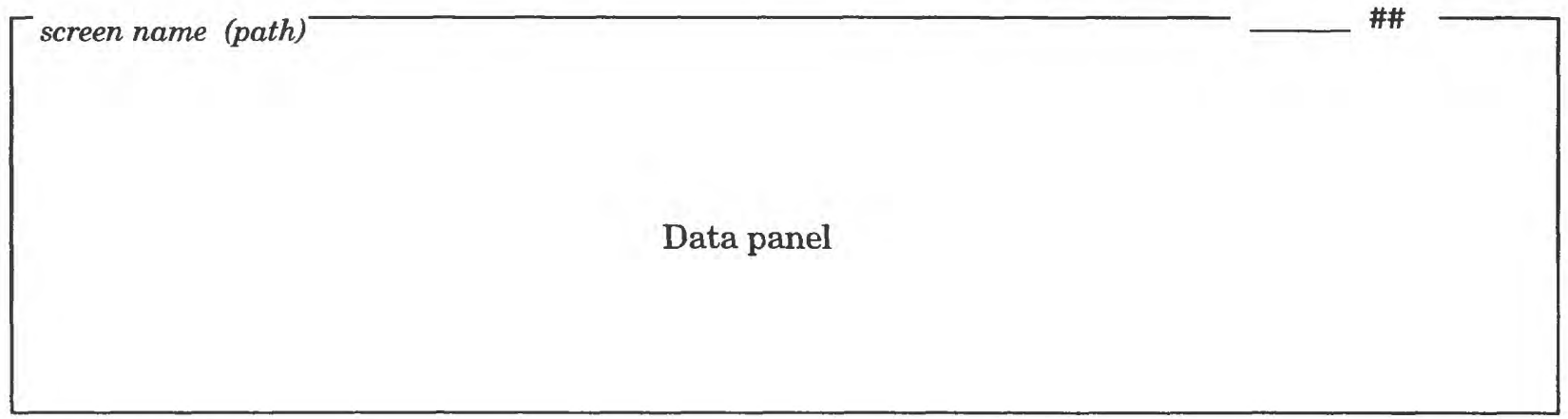

\begin{tabular}{|l|} 
assistance type- Assistance panel \\
\end{tabular}

\begin{tabular}{|l|} 
instruction type \\
Instruction panel
\end{tabular}

Help:F1 Accept:F2 Prev:F4 Limits:F5 Status:F7 Intrpt:F6 Quiet:F8 Cmhlp Oops

\begin{tabular}{|c|c|c|}
\hline Command & $\begin{array}{l}\text { Associated } \\
\text { keystrokes }^{\mathrm{a}}\end{array}$ & Description \\
\hline Help & $\begin{array}{c}\mathrm{F} 1 \\
\text { or } ; \mathrm{h}\end{array}$ & $\begin{array}{l}\text { Displays help information in the assistance panel. The help information is updated as the user } \\
\text { moves from field to field in the data panel or to a different screen. The program automatically clos- } \\
\text { es the assistance panel if a screen is displayed for which no help information is available. }\end{array}$ \\
\hline Accept & $\begin{array}{c}\text { F2 } \\
o r ; a\end{array}$ & $\begin{array}{l}\text { Indicates that you have "accepted" the input values, menu option currently highlighted, or text mes- } \\
\text { sage in the data panel. Selection of this command causes program execution to continue. }\end{array}$ \\
\hline Cmhlp & $\begin{array}{l}\text { F3c } \\
o r ; c\end{array}$ & Displays brief descriptions of the commands available on the screen. \\
\hline Oops & $\begin{array}{l}\text { F3o } \\
o r ; 0\end{array}$ & Resets all data fields in an input form to their initial values. \\
\hline Dnpg & $\begin{array}{l}\text { F3d } \\
\text { or } ; \mathrm{d}\end{array}$ & $\begin{array}{l}\text { Displays next "page" of text in data panel. Available when all of the text cannot be displayed at one } \\
\text { time. }\end{array}$ \\
\hline Uppg & $\begin{array}{l}\mathrm{F} 3 \mathrm{u} \\
\text { or } ; \mathrm{u}\end{array}$ & Redisplays previous "page" of text in data panel. Available after execution of Dnpg (F3d). \\
\hline Prev & $\begin{array}{l}\mathrm{F} 4 \\
\text { or } ; \mathrm{p}\end{array}$ & $\begin{array}{l}\text { Redisplays a previous screen. Any modifications in the data panel are ignored. Which screen is the } \\
\text { previous one may be ambiguous in some cases. }\end{array}$ \\
\hline Limits & $\begin{array}{l}\text { F5 } \\
\text { or } ; 1\end{array}$ & $\begin{array}{l}\text { Displays valid ranges for numeric fields and valid responses for character fields. As with the Help } \\
\text { command, information on field limits is updated as the user moves from field to field in the data } \\
\text { panel or to a different screen by using the arrow keys or the Enter (Return) key. }\end{array}$ \\
\hline Intrpt & $\begin{array}{l}\mathrm{F} 6 \\
\text { or } ; \mathrm{i}\end{array}$ & $\begin{array}{l}\text { Interrupts current processing. Depending on the process, returns the program to the point of exe- } \\
\text { cution prior to the current process or advances to the next step in the process. }\end{array}$ \\
\hline Status & $\begin{array}{l}\text { F7 } \\
\text { or } ; \mathrm{s}\end{array}$ & Displays program status information. \\
\hline Quiet & $\begin{array}{l}\mathrm{F} 8 \\
\text { or } ; \mathrm{q}\end{array}$ & Closes the assistance panel. Available when the assistance panel is open. \\
\hline Xpad & $\begin{array}{l}\text { F9 } \\
o r ; \mathrm{x}\end{array}$ & $\begin{array}{l}\text { Opens the assistance panel as a "scratch pad." Text entered in the scratch pad is saved in a file } \\
\text { called "XPAD.DAT." }\end{array}$ \\
\hline
\end{tabular}

a. The function keys will execute the commands on most computer systems. On all computer systems, the semicolon key (";") followed by the first letter (upper or lower case) of the command can be used to execute the commands. The F3 function key may not be available on some systems.

Figure 6. Basic screen layout and commands for the computer program, Raritan River Basin model, central New Jersey. 
A single option is selected from a menu that consists of two or more options. There are two ways to select a menu option. Either press the first letter (not case-sensitive) of the menu option (if more than one menu option begins with the same letter, press in sequence enough characters to uniquely identify the option), or use the arrow keys to move the cursor to the option and then execute Accept (F2).

Forms can contain any number and combination of character, numeric, file-name, or option fields. Character fields may be a variable entry, such as a descriptive text string (case-sensitive), or may require a specific entry, such as "yes" or "no" (not case-sensitive). The text string "none" in a field indicates that the field is currently undefined. Option fields are activated and deactivated by positioning the cursor in the option field and pressing any key, such as the space bar. Use arrow keys to move up, down, and laterally between fields. The Enter (Return) key is used to move forward through fields. Use Accept (F2) to accept the entered and modified data and continue with the program. Executing Oops $(; 0)$ sets all fields in the current screen to their initial values. Executing Prev (F4) will cause the data values entered on the current screen to be ignored and the previous screen to be redisplayed.

Tables can contain any number and combination of character, numeric, and file-name columns. Character fields, like forms, may require a specific entry or a variable entry. Use arrow keys to move up, down, and laterally between fields. The Enter (Return) key is used to move forward across rows and to the next row. Some tables may contain more rows than can be displayed in the 10 or 16 rows of the data panel. In these cases, the table is divided into multiple screens. Use Accept (F2) to move forward through each of the screens for the table and to continue the program after the last screen of the table. Executing Oops $(; 0)$ sets all fields in the current screen to their initial values. Executing Prev (F4) causes the data values entered on the current screen to be ignored and the previous screen to be redisplayed. Executing Intrpt (F6) causes the data values entered on the current screen to be ignored and the remaining screens in the table to be skipped. Use Quiet (F8) to close the assistance panel and view the 16 lines of the data panel.

A text data panel may contain a warning or error message, a tabular list of data, a progress message for an activity that may take more than a few seconds, or other general information. Execute Accept (F2) to continue to the next screen. In cases where the displayed text requires more lines than the number available in the data panel, the Prev (F4), Dnpg (;d), and Uppg (;u) commands may be available to move forward and backward (scroll) through the screens. Note that the up and down arrows also may be used to move through the screens. Intrpt (F6) may be available to permit skipping the remaining screens of text.

\section{Assistance panel}

The assistance panel provides information to help the user enter data in the data panel or to allow note-taking during a program session. The panel appears in the middle of the screen below the data panel. A name corresponding to the type of assistance being provided displays in the upper left corner of the panel, where the words "assistance type" appear in figure 6. The Help (F1), Limits (F5), Status (F7), Cmhlp (;c), and Xpad (F9) commands open the assistance panel. The program may open the assistance panel to display status information. Help and Limits provide information about the current screen and data fields; Status provides information about 
the current process; Cmhlp provides information about the available commands; and Xpad provides a "note pad" for making notes in the file XPAD.DAT. Use Quiet (F8) to close the assistance panel.

Assistance panels display four lines at a time. In cases where the assistance information is more than four lines long, the cursor moves into the assistance panel. Use the up and down arrow keys to scroll through the information. If available, the Page Down and Page Up keys can be used to page through the information. Use the command-mode toggle (;) to put the cursor back in the data panel.

\section{Instruction panel}

The instruction panel is present whenever the program requires input from the user. The instruction panel provides information on how to interact with the current screen, such as how to enter data or how to advance to another screen. This panel appears at the bottom of the screen just above the screen commands (fig. 6). Up to four lines of text are displayed in an instruction panel. If an invalid keystroke is entered, the information in the instruction panel is replaced with an error message. In this case, the panel name (upper left corner) changes from the usual "INSTRUCT" to "ERROR." When a valid keystroke is entered, the Instruct panel is redisplayed.

\section{Special Files}

Two files are associated with the interaction between the user and the program. A session record is written to the RARRIV.LOG file each time the program is run; all or parts of this file can be used as input to the program at a later time. Error and warning messages, as well as some additional information, may be written to the file ERROR.FIL.

\section{Session record--RARRIV.LOG}

The keystrokes entered during a program session are recorded in the RARRIV.LOG file. Each time the program is run, a RARRIV.LOG file is created; if one already exists in the current directory, it is overwritten. All or part of this file can be used as input to the program as a means of repeating the same or similar tasks. To do this, first save the RARRIV.LOG file under a different name. Modify the file to contain only the sequence of commands that needs to be repeated. Then, at any point in a subsequent program session, press "@"; a small file-name panel appears. Type the name of the log file and press the Enter key.

\section{Error and warning messages--ERROR.FIL}

Any error or warning messages produced during a program session are written to the ERROR.FIL file. Each time the program is run, an ERROR.FIL file is created; if one already exists in the current directory, it is overwritten. Diagnostic and summary reports also may be written to this file. Examine ERROR.FIL if an unexpected program response is encountered. 


\section{Program Inputs}

In addition to the current operating rules, two input files are built into the program. The first file, named "ystats.dat," contains sample means and standard deviations of the logarithms of monthly streamflow at seven streamflow-gaging stations. Each streamflow gage corresponds to one part of the water-supply system, including (1) East Branch of the Delaware River at Margaretville, N.Y.; (2) Beaver Kill at Cooks Falls, N.Y.; (3) South Branch Raritan River at Stanton, N.J.; (4) North Branch Raritan River near Raritan, N.J.; (5) Millstone River at Blackwells Mills, N.J.; (6) South Branch Raritan River near High Bridge, N.J.; and (7) North Branch Raritan River near Far Hills, N.J.

The second file, named "rcomp.obs", contains the observed random component of runoff computed from the PARMA $(1,1)$ model of streamflow at five streamflow-gaging stations, each corresponding to a different area. The five stations are (1) East Branch of the Delaware River at Margaretville, N.Y.; (2) Beaver Kill at Cooks Falls, N.Y.; (3) South Branch Raritan River at Stanton, N.J.; (4) North Branch Raritan River near Raritan, N.J.; and (5) Millstone River at Blackwells Mills, N.J. These random components of runoff are used to generate a sequence of runoff values either for the historical sequence (the components are taken in order) or the bootstrap sequence (the components are drawn at random with replacement).

\section{Program Execution}

\section{Program Options}

Typing "rarriv" at the operating-system prompt starts the program. The opening screen (fig. 7) will appear. The data panel contains the Opening screen menu options, and the instruction panel explains how to select the menu items. The following options are available:

Help Choose the Help option to read instructions on how to run the program.

File An output file name must be specified here. This option must be chosen before the run option is chosen.

Run Choosing this option initiates execution of the program. This option is chosen after the output file name is specified.

Graphs Choose this option to specify plots after completing the run option.

Query Select Query to display information on whom to contact for technical support.

Exit Choose this option to terminate the program. 


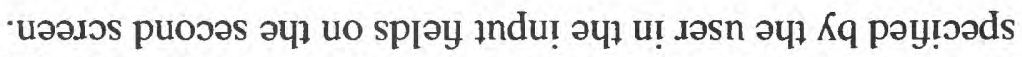

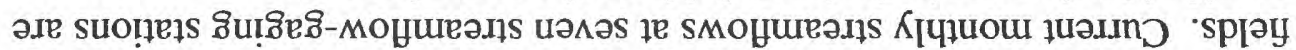

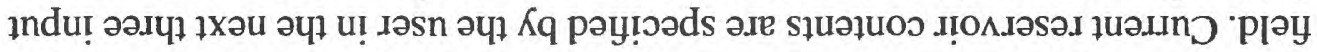

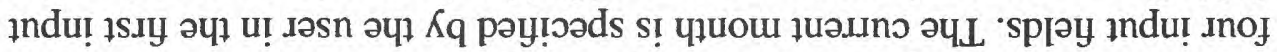

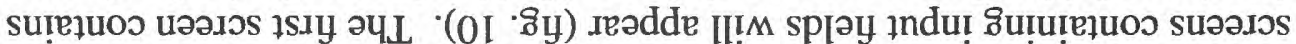

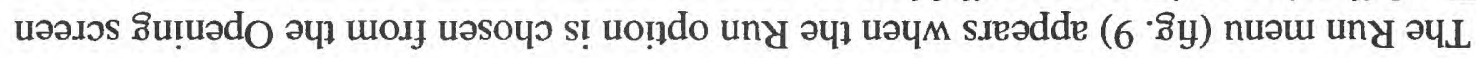

\section{sepow wos6old}

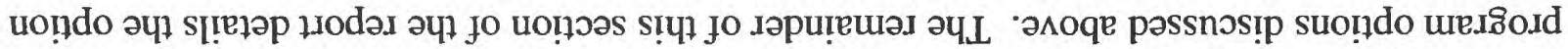

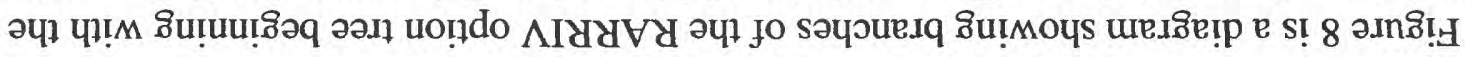

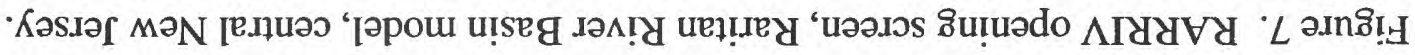

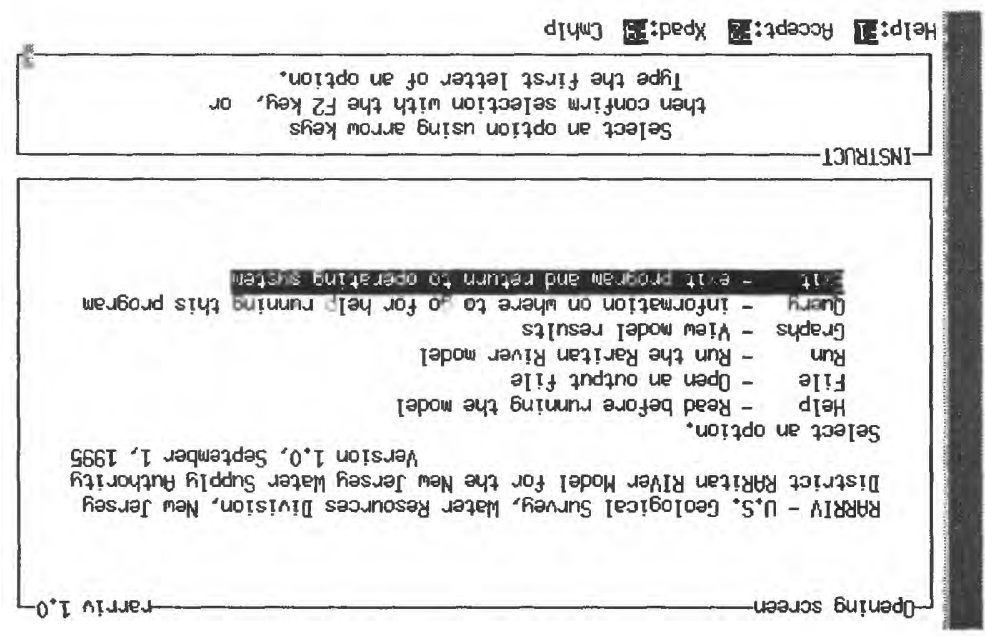



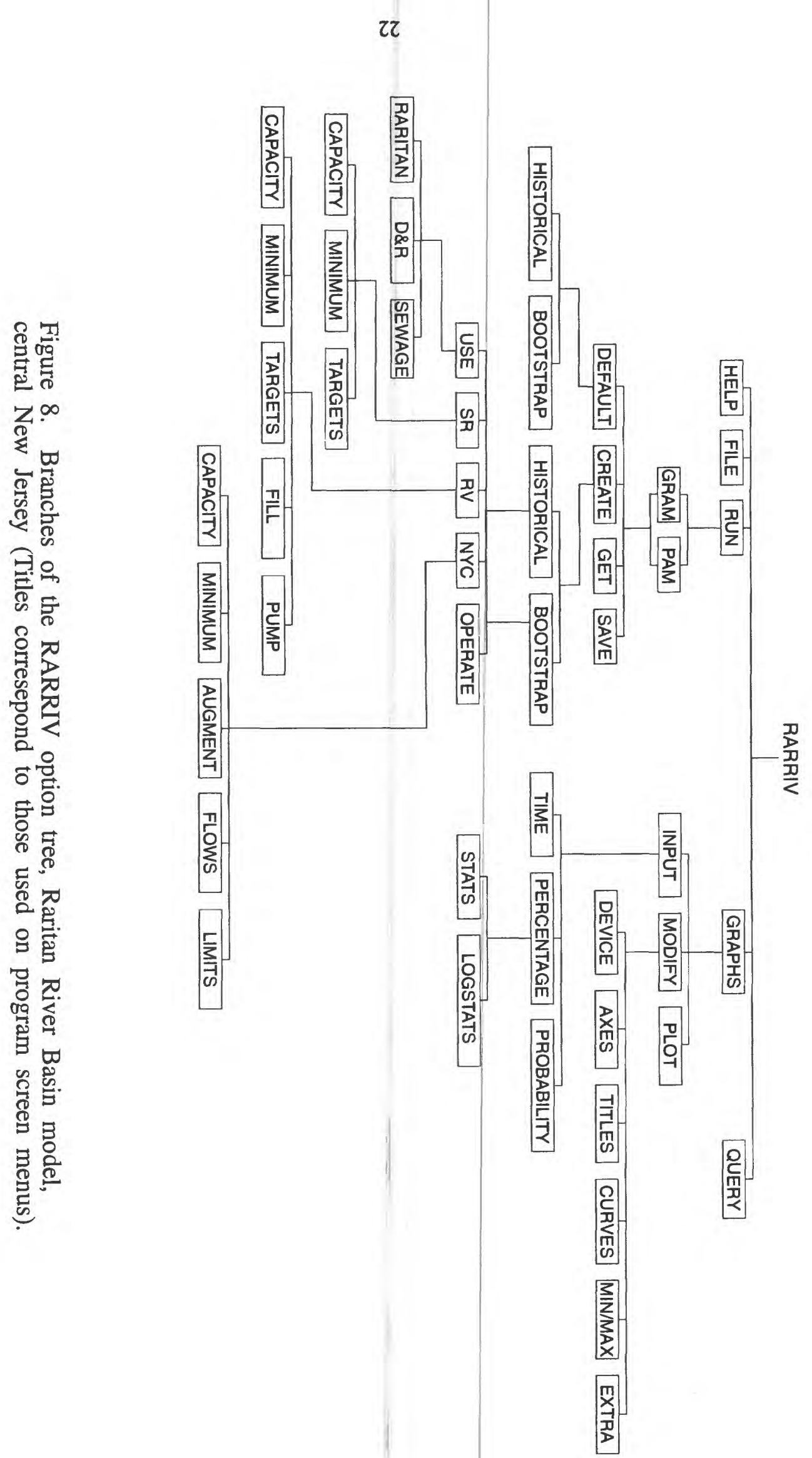

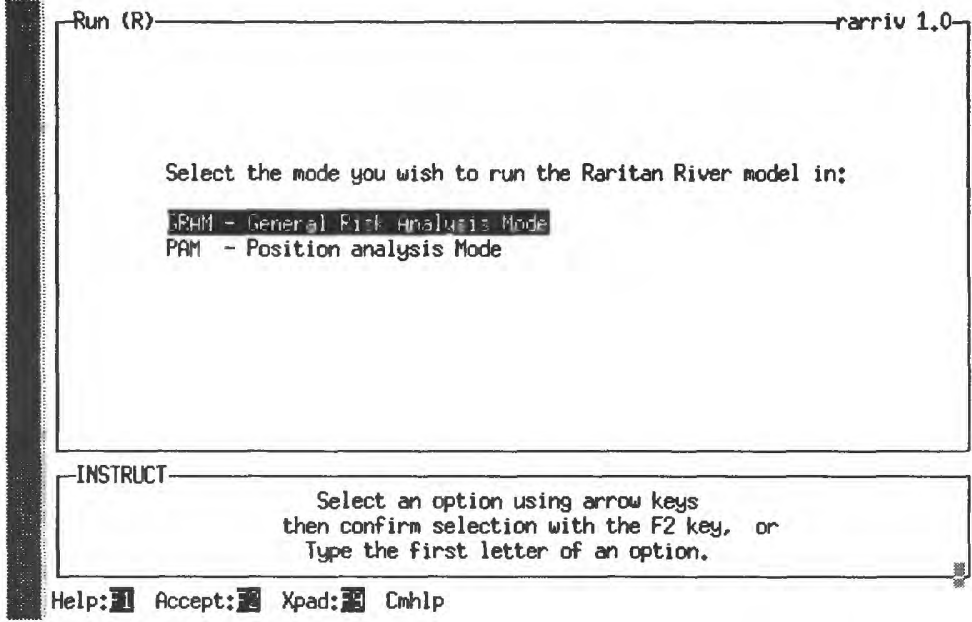

-INSTRUCT-

Select an option using arrow keys

then confirm selection with the F2 key, or

Type the first letter of an option.

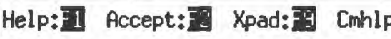

Figure 9. Run option menu, Raritan River Basin model, central New Jersey.

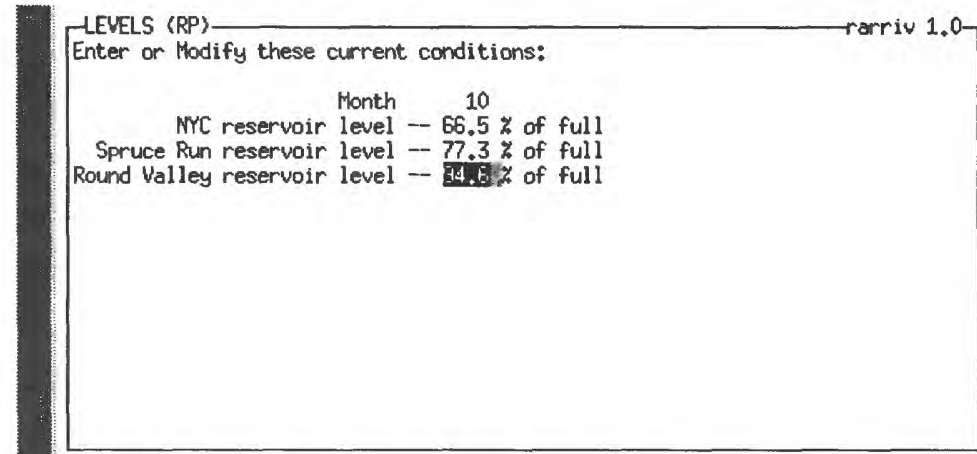

[INSTRUCT- Enter data in highlighted field\{s\}.

Use carriage return or arrow keys to enter data and move between fields. Use 'Accept' command to go to next screen when done entering data.

Help:F1 Accept:F Limits:F Xpad:F Cmhlp Oops

FLOWS 〈RP >

ENTER current monthly flow, in cfs, for:

Beaver Kill at Cooks Falls, NY: 112

South Branch Raritan River near High Bridge, NJ: 65

North Branch Raritan River near Far Hills, NJ: 26

Millstone River at Blackwells Mills, NJ: 100

ENTER most recent monthly flow, in MGD, for:

South Branch Raritan River at Stanton, NJ: 123

Raritan River at Manville, NJ: 176

Raritan River below Calco Dam at Bound Brook, NJ: 263

( 


\section{Modification of Operating Rules}

Operating rules can be modified and saved for future program executions. The Input/ Output menu (fig. 11) contains the following options:

Default Choose this option to run the program with the current operating-rule inputs.

Create Choose Create to modify any or all of the current operating-rule inputs.

Save This option presents text explaining how to save a session record containing modified operating-rule inputs to a file for future program executions.

Get This option presents text explaining how to implement a file containing a session record of modified operating-rule inputs for future program executions.

Figure 11. Input/output menu, Raritan River Basin model, central New Jersey.

Two forms will follow the Default or Create option of the Input/Output menu. The flow sequence can be chosen on the first form by typing a " 0 " or " 1 " in the corresponding input field. A "0" indicates that the historical flow sequence (1918-93) is to be used. A " 1 " indicates that the bootstrap flow sequence is to be used. The pumping station can be chosen on the second form. A " 0 " indicates the Hamden pumping station is to be used. A " 1 " indicates the Confluence pumping station (a proposed pumping station that would be located at the confluence of the North and South Branches of the Raritan River) is to be used.

Other forms will follow if the bootstrap flow sequence is chosen. A random seed (negative integer) must be entered to begin the bootstrap process. A " 0 " indicates that the random seed will be computer-generated. This number will be saved to a file named "r.seed." This saved number can then be used as the seed if a program execution is to be duplicated. A " 1 " indicates that the user will enter the seed in a subsequent form. 
The precipitation probabilities forecast for the next few months by the National Weather Service can be entered on another form for the following categories: wetter than normal, normal, and drier than normal.

If the Create option has been chosen, a menu will follow that indicates operating-rule options; this menu is shown in figure 12:

Use Choose this menu item to display a menu pertaining to depletive water-use rates.

SR Choose this menu item to display a menu pertaining to Spruce Run Reservoir.

RV Choose this menu item to display a menu pertaining to Round Valley Reservoir.

NYC Choose this menu item to display a menu pertaining to the New York City reservoirs.

Operate Choose this menu item to display the monthly operating-rule curve values for the combined storage of Spruce Run and Round Valley Reservoirs. Values are displayed for three conditions: initial pumping to Round Valley Reservoir, drought warning, and drought emergency.

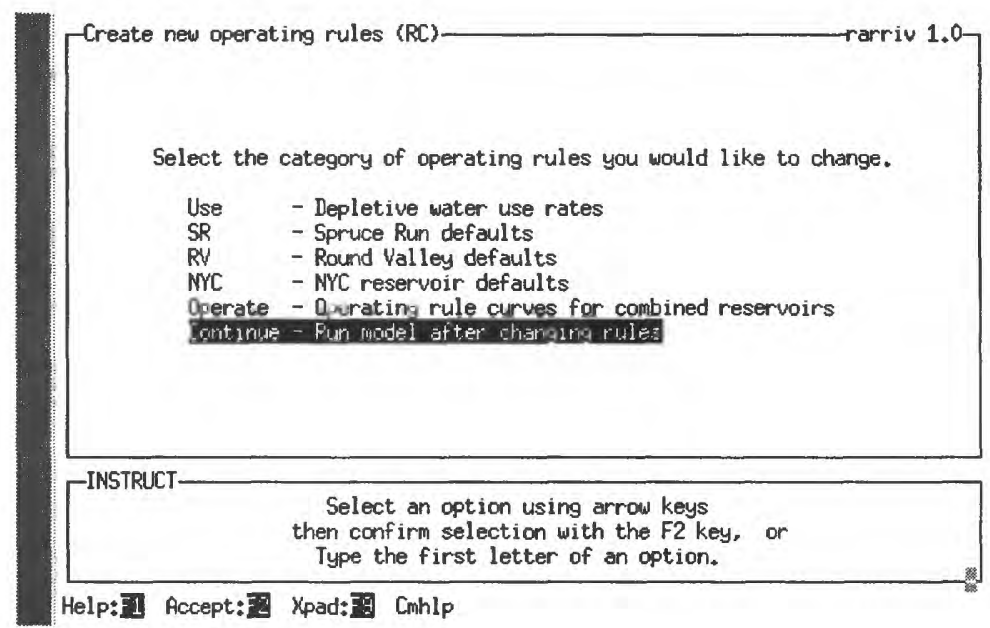

Figure 12. Create option menu, Raritan River Basin model, central New Jersey. 


\section{Depletive water-use rates}

The depletive water-use rates menu (fig. 13) will appear when the Use option is chosen. The following options are available:

Raritan Choose this option to modify the monthly depletive water-use rates for the Raritan River at Bound Brook. Values are displayed for three conditions: normal, drought warning, and drought emergency.

$\mathrm{D}+\mathrm{R}$ Choose this option to modify the monthly depletive water-use rates for the Delaware and Raritan Canal. Values are displayed for three conditions: normal, drought warning, and drought emergency.

Sewage Choose this option to modify the monthly sewage return rates for the Raritan River above Bound Brook.

Tables (fig. 14) will appear when these options are chosen.

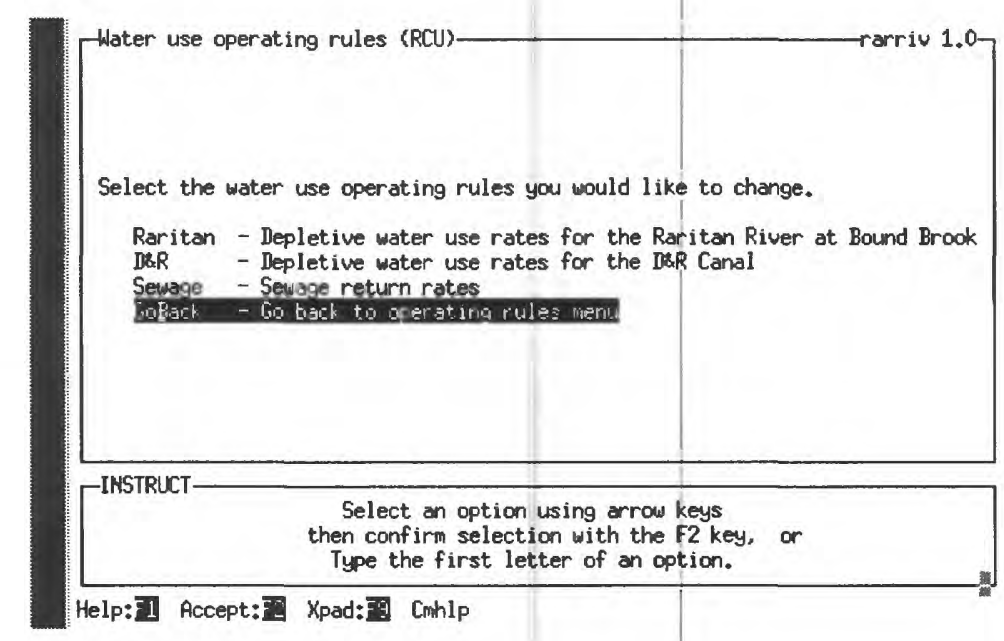

Figure 13. Water-use option menu, Raritan River Basin model, central New Jersey. 
Raritan (RCUR)

HONTH

CONDITION JAN FEB MAR APR MAY JUN JUL AUG SEP OCT NOV DEC

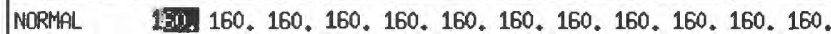

WARNING 160, 160, 160, 160, 160, 160, 160, 160, 160, 160, 160, 160

EMERGENCY $160.160,160,160,160,160,160,160,160,160 * 160.160$.

INSTRUCT- Enter data in highlighted field(s).

Use carriage return or arrow keys to enter data and move between fields. Use 'Accept' command to go to next screen when done entering data.

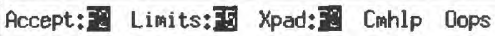

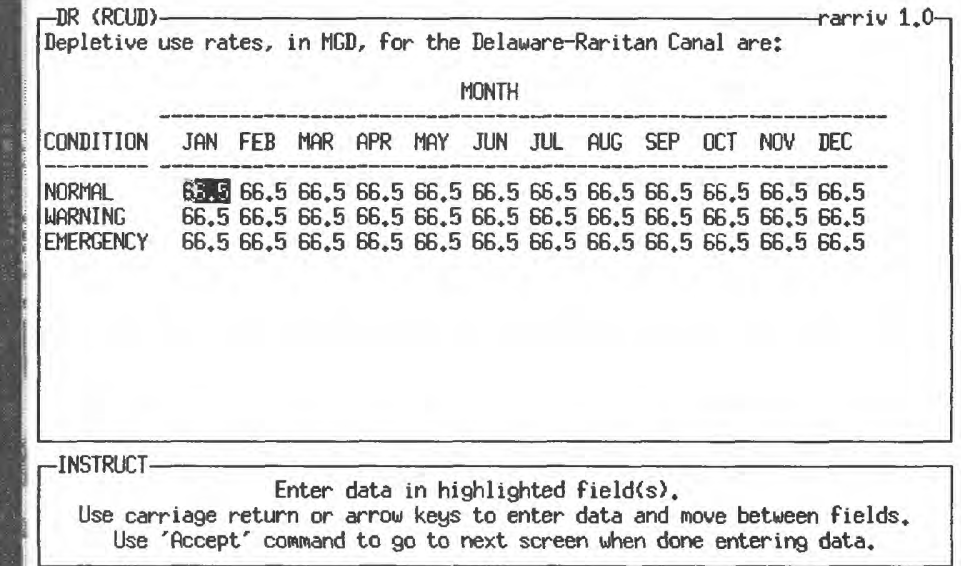

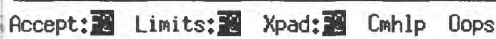

SEWAGE (RCUS)

Enter or modify sewage return rates, in MGD.

for Raritan River above Bound Brook:

MONTH

$\frac{\text { JAN FEB MAR APR MAY JUN JUL AUG SEP OCT NOV DEC }}{20.120 .020 .020 .020 .020 .020 .020 .020 .020 .020 .020 .0}$

IINSTRUCT- Enter data in highlighted field(s).

Use carriage return or arrow keys to enter data and move between fields. Use 'Accept' command to go to next screen when done entering data.

Accept:Fin Limits:F Xpad:F Cmalp Dops

Figure 14. Depletive water-use rate tables, Raritan River Basin model, central New Jersey. 


\section{Spruce Run Reservoir}

User options related to Spruce Run Reservoir operating rules (fig. 15) will appear when the SR option is chosen. The following options are available:

Capacity Choose this option to modify the usable capacity of the reservoir.

Minimum Choose this option to modify the monthly minimum desirable capacity of the reservoir.

Targets Choose this option to modify the statutory passing-flow requirements at Stanton, Manville, and Bound Brook and the minimum-release requirement at the reservoir. Values are displayed for three conditions: normal, drought warning, and drought emergency.

Tables or forms (fig. 16) will appear when these options are chosen.

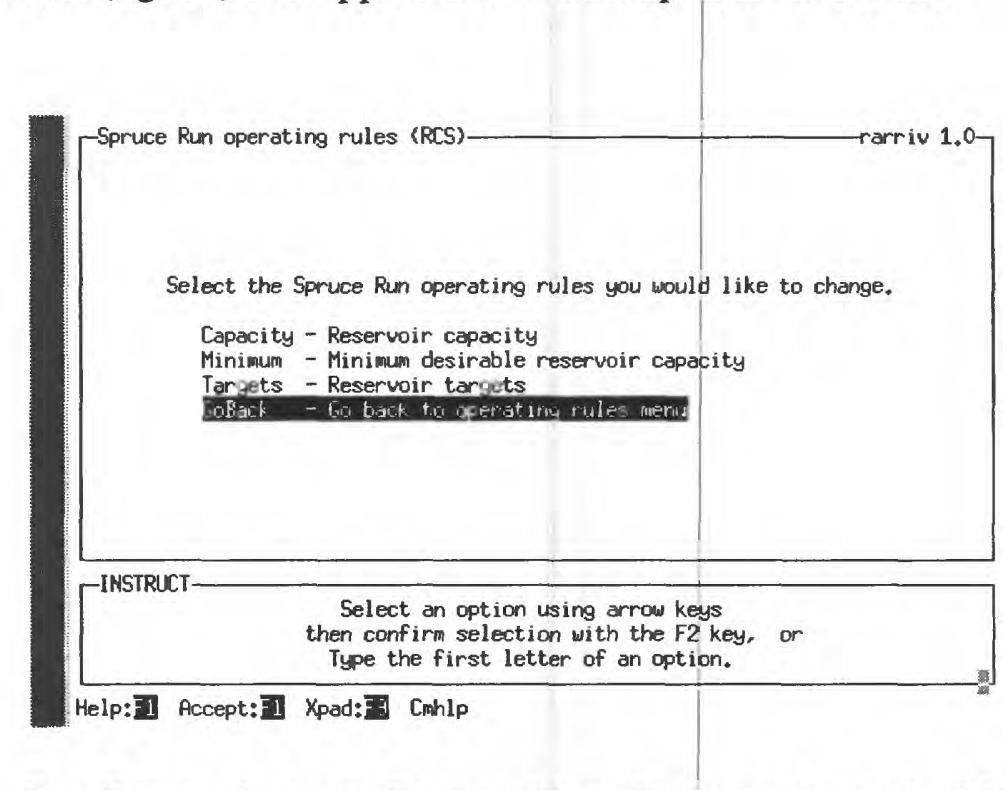

Figure 15. Spruce Run Reservoir menu, Raritan River Basin model, central New Jersey. 
Capacity (RCSC)

rarriv, 1.0

Enter or modify the capacity for Spuce Run reservoir: $11.0 \mathrm{BG}$

INSTRICT

Enter data in highlighted field(s)

Use carriage return or arrow keys to enter data and move between fields. Use 'Accept' command to go to next screen when done entering data.

Rccept:Fi Limits: F Xpad:F Comhlp Dops

Minimum (RCRM)

Round Valley default minimum desirable capacities $(B G)$ :

MONTH

\begin{tabular}{|c|c|c|c|c|c|c|c|c|c|c|c|}
\hline JAN & FEB & MAR & APR & MAY & JUN & JUL & AUG & SEP & DCT & NON & $\mathrm{DEC}$ \\
\hline
\end{tabular}

[INSTRUCT- Enter data in highlighted field(s).

Use carriage return or arrow keys to enter data and move between fields. Use 'Accept' command to go to next screen when done entering data.

Accept:Fin Limits: Fin Xpad;: Cmhlp Dops

Targets (RCST)

Spruce Run Reservoir Targets (MCD):

Node

\begin{tabular}{rcr} 
Normal & Warning & Drought \\
\hline 40.0 & 40.0 & 40.0 \\
\hline 70.0 & 70.0 & 70.0 \\
90.0 & 90.0 & 90.0 \\
5.0 & 5.0 & 5.0
\end{tabular}

STANTON

WANUILLE

BOUND BROON

5.0

5,0

rarriv 1.0

MIN,RELERSE

5,0

INSTRUCT

Enter data in highl ighted field(s).

Use carriage return or arrow keys to enter data and move between fields. Use 'Accept' command to go to next screen when done entering data.

Accept:F Limits; Xpad; Cmhlp Dops

Figure 16. Spruce Run Reservoir tables and forms, Raritan River Basin model, central New Jersey. 


\section{Round Valley Reservoir}

User options related to Round Valley Reservoir operating rules (fig. 17) will appear when the RV option is chosen. The following options are available:

Capacity Choose this option to modify the usable capacity of the reservoir.

Minimum Choose this option to modify the monthly minimum desirable contents of the reservoir.

Targets Choose this option to modify the statutory passing-flow requirements at Stanton, Manville, and Bound Brook and the minimum-release requirement at the reservoir. Values are displayed for three conditions: normal, drought warning, and drought emergency.

Fill Choose this option to modify the monthly reservoir storage level that can be reached by pumping. When the reservoir is filled to this level, pumping will cease.

Pump Choose this option to modify pump capacity at the Hamden pumping station.

Tables or forms (fig. 18) will appear when these options are chosen.

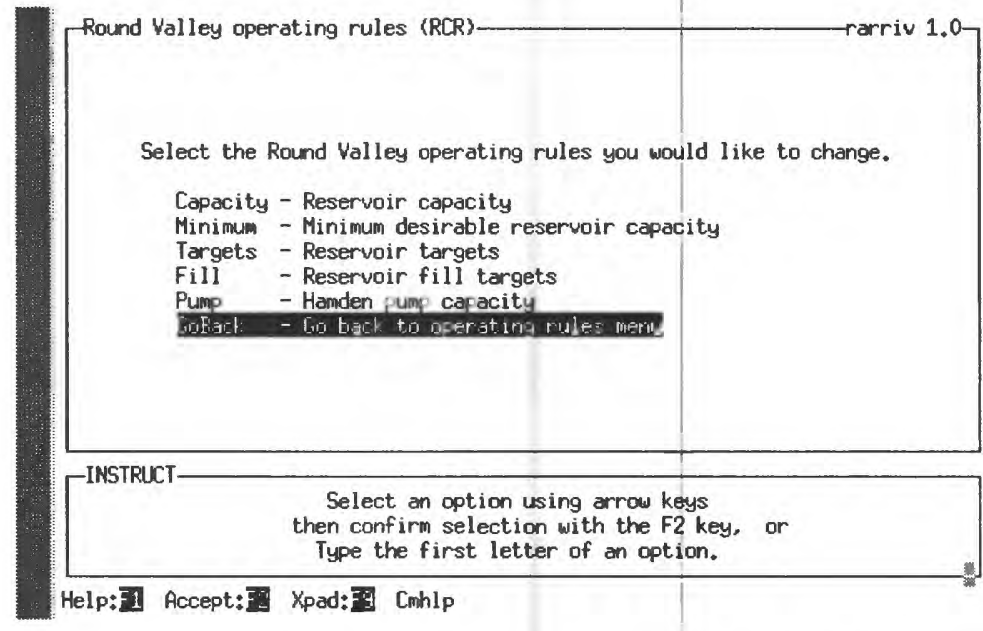

Figure 17. Round Valley Reservoir menu, Raritan River Basin model, central New Jersey. 
Capacity $\{\mathrm{RCRC}$ )

rarriv 1.0

Enter or modify the capacity for Round Valley reservoir: 5 an BG

[INSTRUCT- Enter data in highlighted field(s).

Use carriage return or arrow keys to enter data and move between fields. Use 'Accept' command to go to next screen when done entering data.

Accept:Fin Limits: F Xad: 7 Comlp Dops

Minimum (RCRM)

Round Valley default minimum desirable capacities (BG):

MONTH

JAN FEB MAR APR MAY JUN JUL AUG SEP OCT NOV DEC

FINSTRUCT

Enter data in highlighted fieldis\}.

Use carriage return or arrow keys to enter data and move between fields. Use 'Accept' command to go to next screen when done entering data.

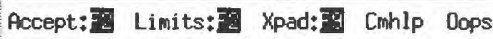

Targets (RCRT)

Round Valley Reservoir Targets (MCD):

Node

STANTON

MANVILLE

BOUND BROOK

MIN.RELEASE

\begin{tabular}{rcc} 
Normal & Warning & Irought \\
\cline { 2 - 3 } A11. & 40.0 & 40.0 \\
70.0 & 70.0 & 70.0 \\
90.0 & 90.0 & 90.0 \\
0.0 & 0.0 & 0.0
\end{tabular}

IINSTRUCT

Enter data in highlighted field(s).

Use carriage return or arrow keys to enter data and move between fields. Use 'Accept' command to go to next screen when done entering data,

Accept:配 Limits:F Xpad:F Cmhlp Dops

Figure 18. Round Valley Reservoir tables and forms, Raritan River Basin model, central New Jersey. 
Fill (RCRF)

Enter or modify Round Valley fill targets:

MONTH

JAN FEB MAR APR MAY JUN JUL AUG SEP OCT NOV DEC

5I.1. 50.050 .050 .050 .050 .050 .050 .050 .050 .050 .050 .0

$$
\text { -INSTRUCT }
$$

Enter data in highlighted field\{s\}.

Use carriage return or arrow keys to enter data and move between fields. Use 'Accept' command to go to next screen when done entering data,

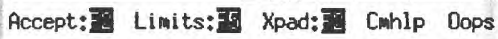

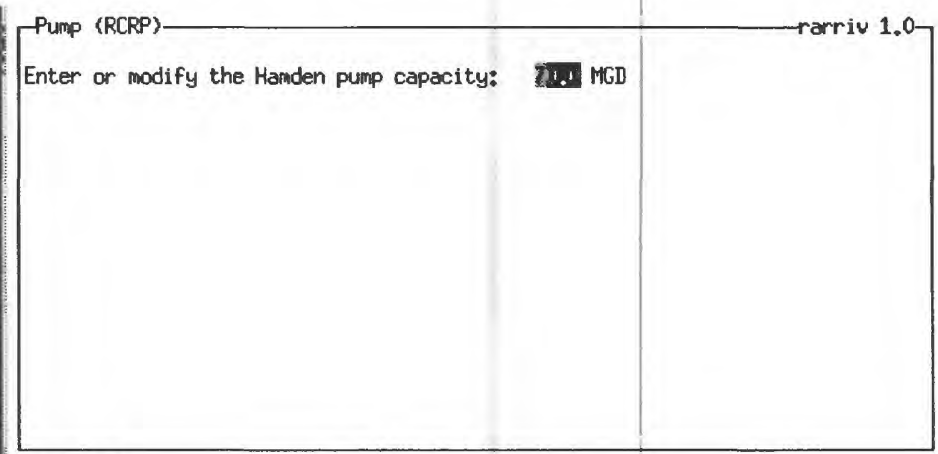

INSTRUCT

Use carriage return or arrow keys to enter data and move between fields. Use 'Accept' command to go to next screen when done entering data.

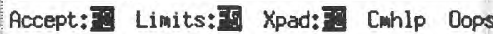

Figure 18. Round Valley Reservoir tables and forms, Raritan River Basin model, central New Jersey--Continued. 


\section{New York City reservoirs}

User options related to New York City reservoir operating rules (fig. 19) will appear when the NYC option is chosen. The following options are available:

Capacity Choose this option to modify the usable capacity of the reservoir.

Minimum Choose this option to modify the monthly minimum release from the reservoir.

Augment Choose this option to modify the monthly augmented release amounts (the amounts released for recreational purposes). Under drought conditions these releases are equal to minimum-release values.

Flows Choose this option to modify the statutory passing-flow requirements at Montague to New York City and to the Delaware and Raritan Canal. Values are displayed for three conditions: normal, drought warning, and drought emergency.

Limits Choose this option to display the monthly operating-rule curve values for the New York City reservoirs. Values are displayed for three conditions: normal, drought warning, and drought emergency.

Tables or forms (fig. 20) will appear when these options are chosen.

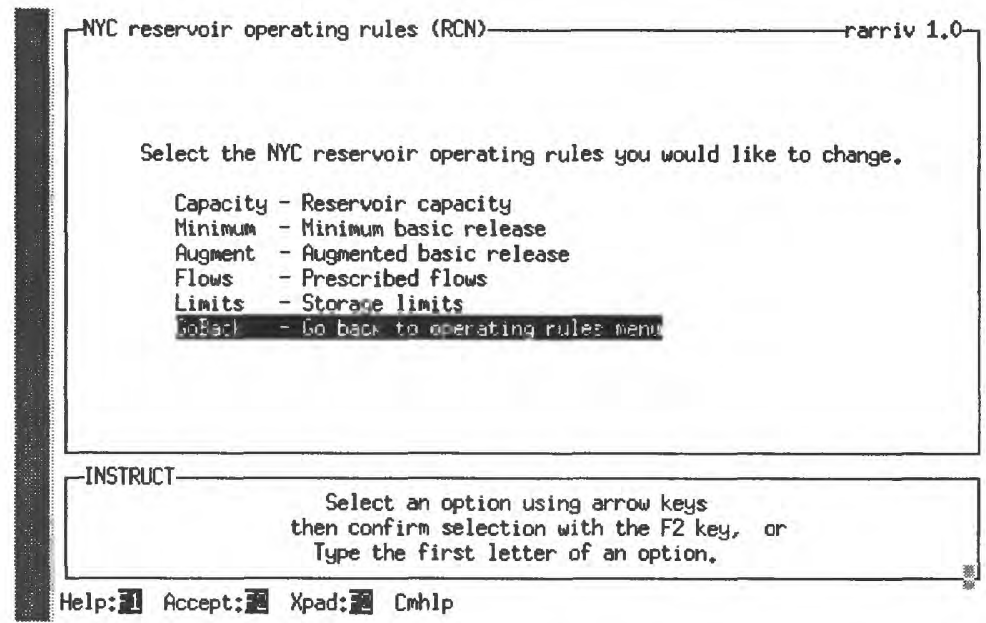

Figure 19. New York City reservoirs menu, Raritan River Basin model, central New Jersey. 


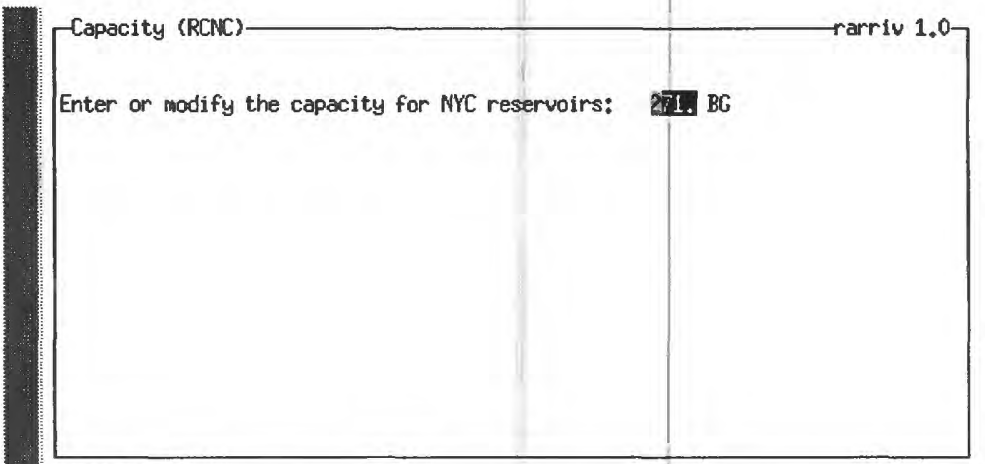

[INSTRUCT- Enter data in highlighted field (s).

Use carriage return or arrow keys to enter data and move between fields, Use 'Accept' command to go to next screen when done entering data.

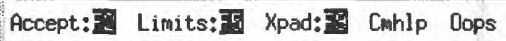

Minimum (RCNH)

NYC minimum basic release, in cfs:

JAN FEB MAR APR MAY JUN JUL AUG SEP OCT NOV DEC

16.518 .518 .541 .857 .357 .357 .357 .357 .357 .334 .018 .5

-INSTRUCT

Enter data in highlighted field $s$ ).

Use carriage return or arrow keys to enter data and move between fields. Use 'Accept' command to go to next screen when done entering data.

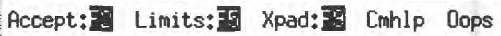

AUGMENT (RCNA)

Enter or modify MYC augmented basic release, in cfs:

MONTH

JAN FEB MAR APR MAY JUN JUL AUG SEP OCT NOW DEC

119. $108,108,160,160,440,440,440,160,160,108,108$.

Figure 20. New York City reservoirs tables and forms, Raritan River Basin model, central New Jersey. 


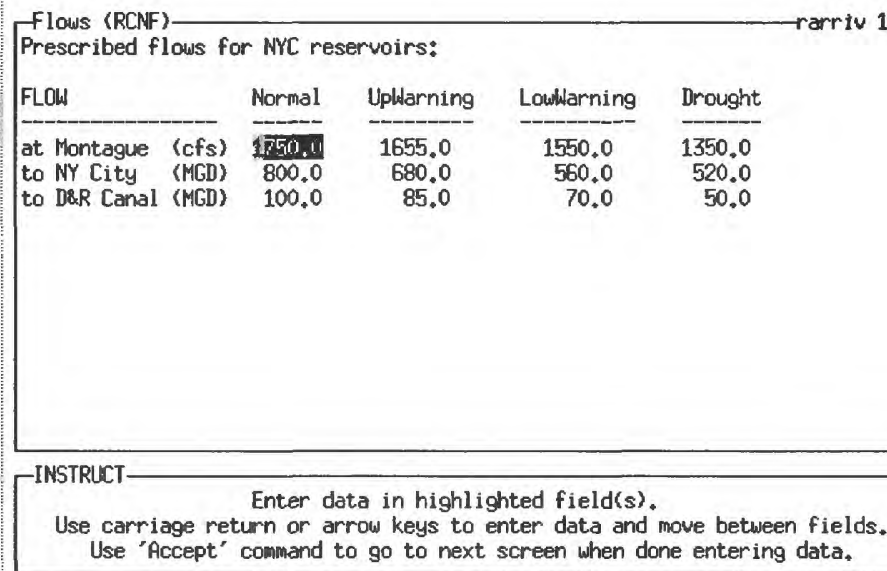
Use 'Accept' command to go to next screen when done entering data.

Accept:政 Limits:国 Xpad:国 Cmhlp Oops

Limits (RCNL)

Storage limits, in BG, for the NYC Reservoirs are:

MONTH

CONDITION

NORMAL

UPPER WARNING JAN FEB MAR APR MAY JUN JUL AUG SEP OCT NOU DEC

LOUR $180,145,165,180,190,190,175,150,120,110,110,120$. $110,125,145,160,170,170,155,130,100,90,090.0100$ LOWER WARNIN $90.0105,115,140,150,150,135,110,80,070,070,080.0$

IINSTRUCT

Enter data in highlighted field(s). carriage return or arrow keys to enter data and move between fields. Use 'Accept' command to 90 to next screen when done entering data.

Accept:瓶 Limits:国 Xpad:国 Cmhlp Oops

Figure 20. New York City reservoirs tables and forms, Raritan River Basin model, central New Jersey--Continued.

\section{Combined reservoir system}

A table will appear when the Operate option is chosen (fig. 21). This table lists the operating-rule curves for the combined reservoir system for three threshold capacities: when to begin pumping to Round Valley Reservoir, drought warning, and drought emergency. 


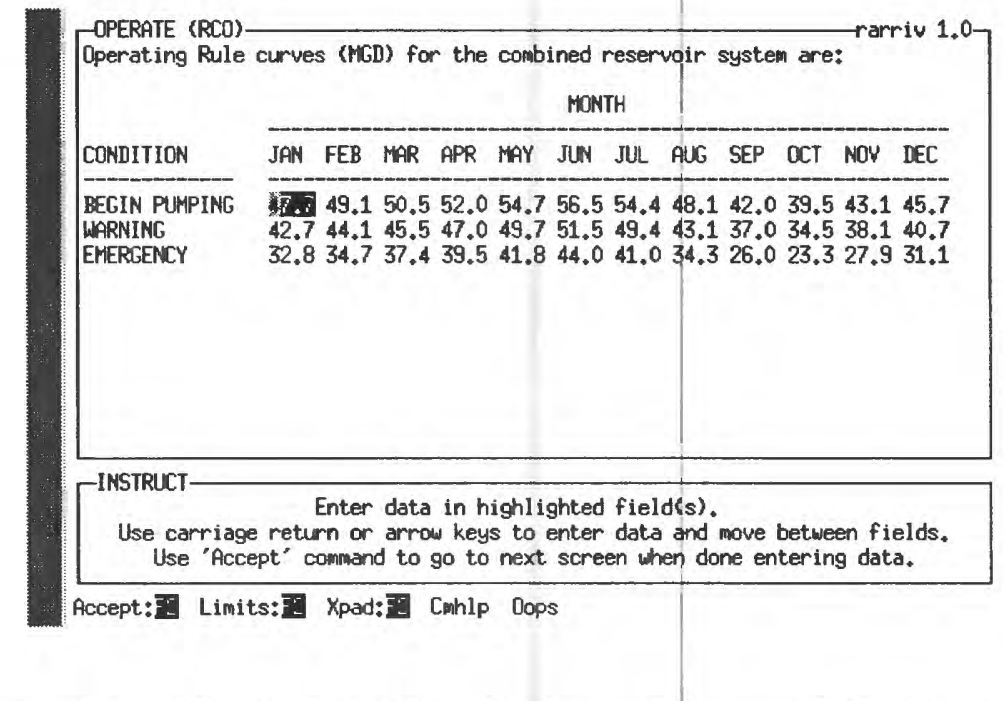

Figure 21. Operate option table, Raritan River Basin model, central New Jersey.

\section{Program Output}

Program output includes a data table and graphs as described in the following sections. The data table is produced automatically with each program execution. Graph format is specified through program interaction. Graphs can be plotted on the computer screen or sent to a printer.

\section{Data Table}

The data table is written to the output file specified during program interaction and lists values for storages, releases, streamflows, diversions, and basin condition. For each program execution, the data table (fig. 22) differs according to the flow sequence chosen. For the historical sequence, a table of monthly values is produced for the years 1918-93, inclusive. The bootstrap sequence produces a table covering a 300-year period.

The program output includes streamflows, diversions, and reservoir releases in million gallons per day, storage in billion gallons, and a numeric reservoir-condition indicator. Streamflow values are listed for South Branch Raritan River at Stanton, Raritan River at Manville, Raritan River below Calco Dam at Bound Brook, Delaware-Raritan Canal, and Delaware-Raritan Canal to the Millstone River. Diversions are listed for Delaware-Raritan Canal and Millstone River. Releases are listed for Spruce Run Reservoir, Round Valley Reservoir to Hamden pùmping station, and Round Valley Reservoir to North Branch Rockaway Creek. Storage values are listed for Spruce Run Reservoir, Round Valley Reservoir, and the combination of both reservoirs. The basin condition is listed as a $0,1,2$, or 3 . Zero indicates a normal condition (no pumping to Round Valley Reservoir is needed), 1 indicates pumping to Round Valley Reservoir, 2 indicates a drought-warning condition, and 3 indicates a drought- emergency condition. 


\section{Graphs}

The graphics menu (fig. 23) includes the following options:

Input Choose this option to select the type of plot to be viewed. Plot types include time-series, percentile, and probability and are chosen from the menu shown in figure 24. A form follows if the time-series option is chosen. The starting and ending dates can be chosen on this form. A plot menu appears after choosing any of the plots to be viewed (fig. 25). The plot menu lists all storages, releases, streamflows, and diversions that can be plotted.

Modify Choose this option to modify plot characteristics.

Plot Choose this option to make the plot.

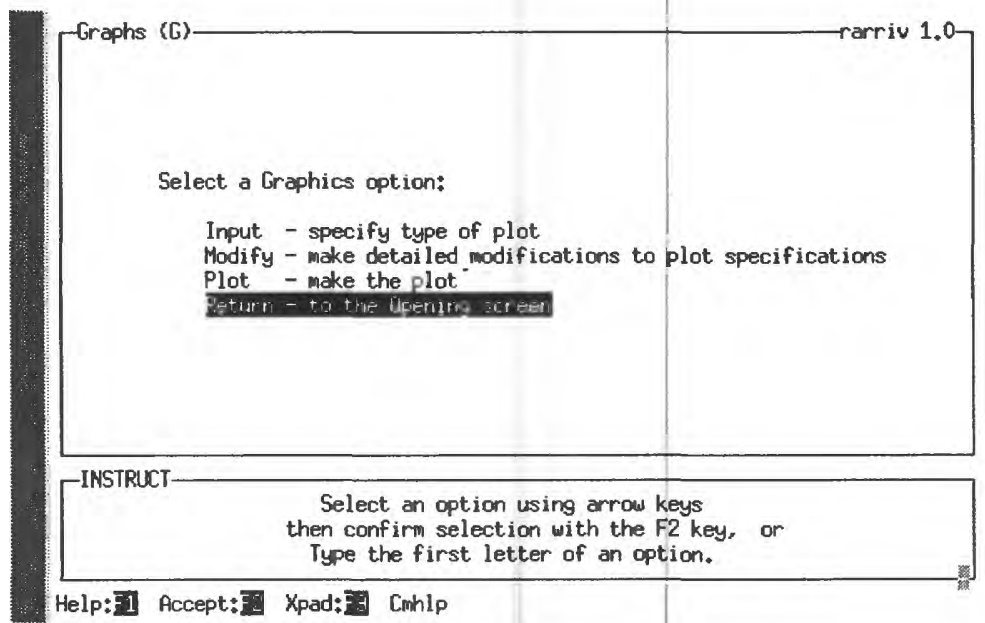

Figure 23. Graph option menu, Raritan River Basin model, central New Jersey.

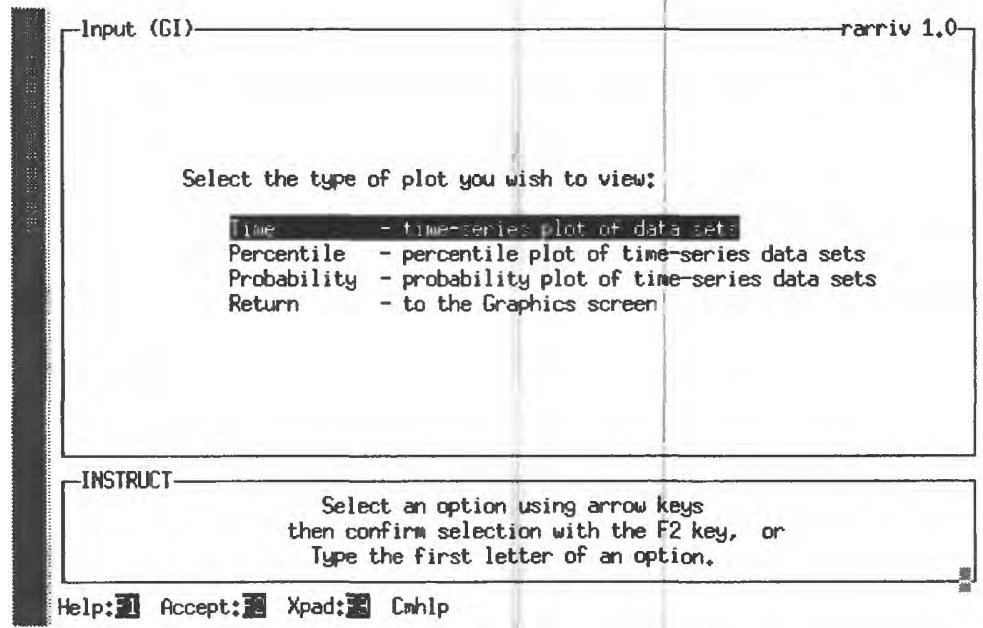

Figure 24. Plot type menu, Raritan River Basin model, central New Jersey. 


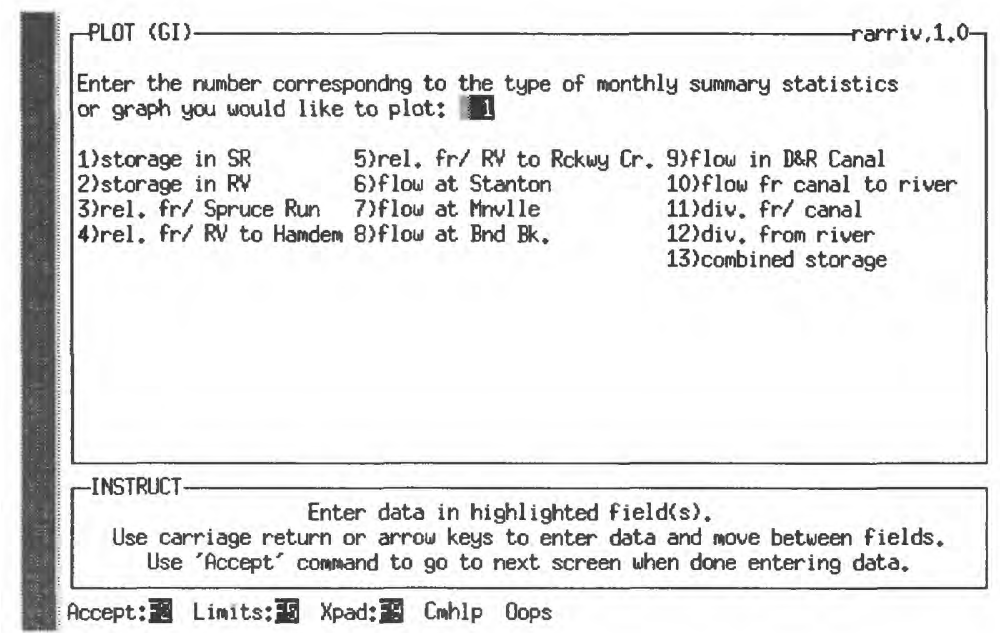

Figure 25. Plot menu, Raritan River Basin model, central New Jersey.

Choosing Modify will display the modify menu options (fig. 26). These options allow modification of the following plot characteristics:

Device An optional output device can be selected by choosing this option.

Axes Axis types, such as arithmetic, logarithmic, or probability, can be specified. Additional axes, such as a right $y$-axis or an auxiliary axis, can be added or eliminated.

Titles The plot title and all axis labels can be modified.

Curves Curve characteristics, such as color, line type, or symbol used, can be changed.

Min/Max The minimum and maximum value plotted on each axis can be modified.

Extra Text can be added to the graph. The placement of that text, the number of lines of text, and the number of characters per line of text can be specified. The location of the explanation can be changed.

Size The plotting-space dimensions, axis lengths, location of the origin within the plotting space, and size of text lettering can be modified. 


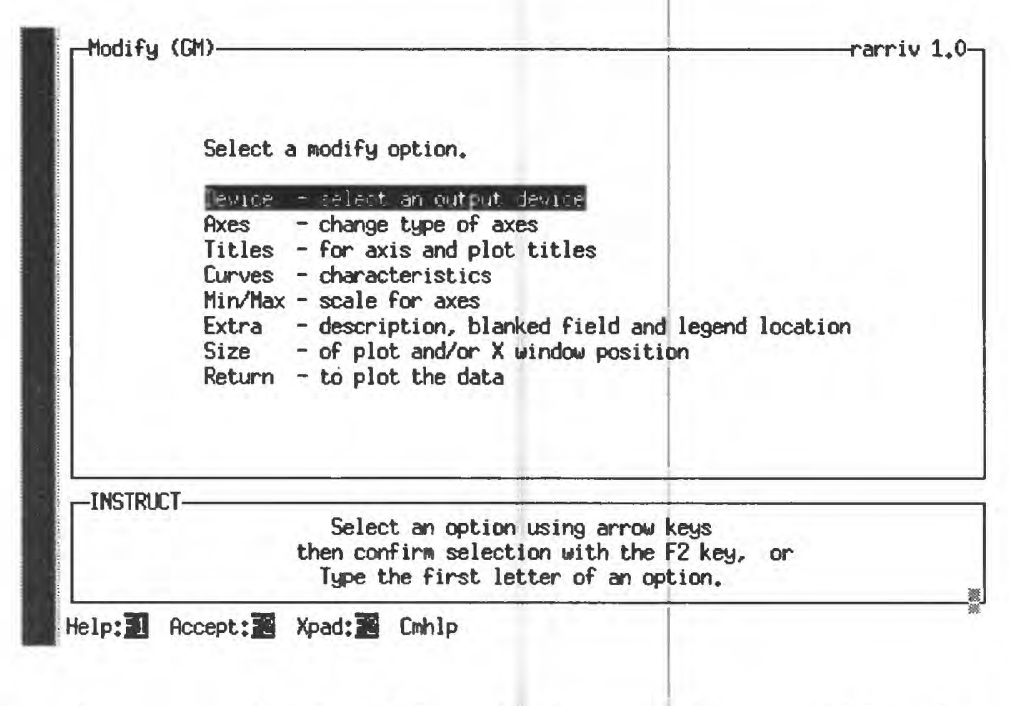

Figure 26. Modify option menu, Raritan River Basin model, central New Jersey.

\section{Time-series plots}

Storages, releases, streamflows, and diversions can be plotted for any time period within the historical record (fig. 27). The time period can be entered on a form after choosing the timeseries plot option.

\section{Percentile plots}

Storage and streamflow values can be plotted as a function of their probability of occurrence over the 12 months following initial basin conditions. Seven percentile lines are plotted, including greater than $1,12.5,25,50,75,87.5$, and less than 98 . The 50-percent, or median, line indicates values of storage and streamflow that will occur under normal hydrologic and climatologic conditions. Percentile lines greater than 50 indicate values of storage and streamflow that will occur under the assumption that wetter-than-normal conditions will occur. Percentile values less than 50 indicate values of storage and streamflow that will occur under the assumption that drier- than-normal conditions will occur. The 25 - and 75-percentile lines indicate that corresponding storage and streamflow values have a 1 in 4 chance of occurrence, the 12.5- and 87.5percentile lines indicate those that have a 1 in 8 chance of occurrence, and the less-than- 1 and greater-than-98-percentile lines indicate those that have a 1 in 10 chance of occurrence. For example, if wetter-than-normal conditions are likely to occur, the 75-percentile line could be used as an indicator of future storage and streamflow values. 


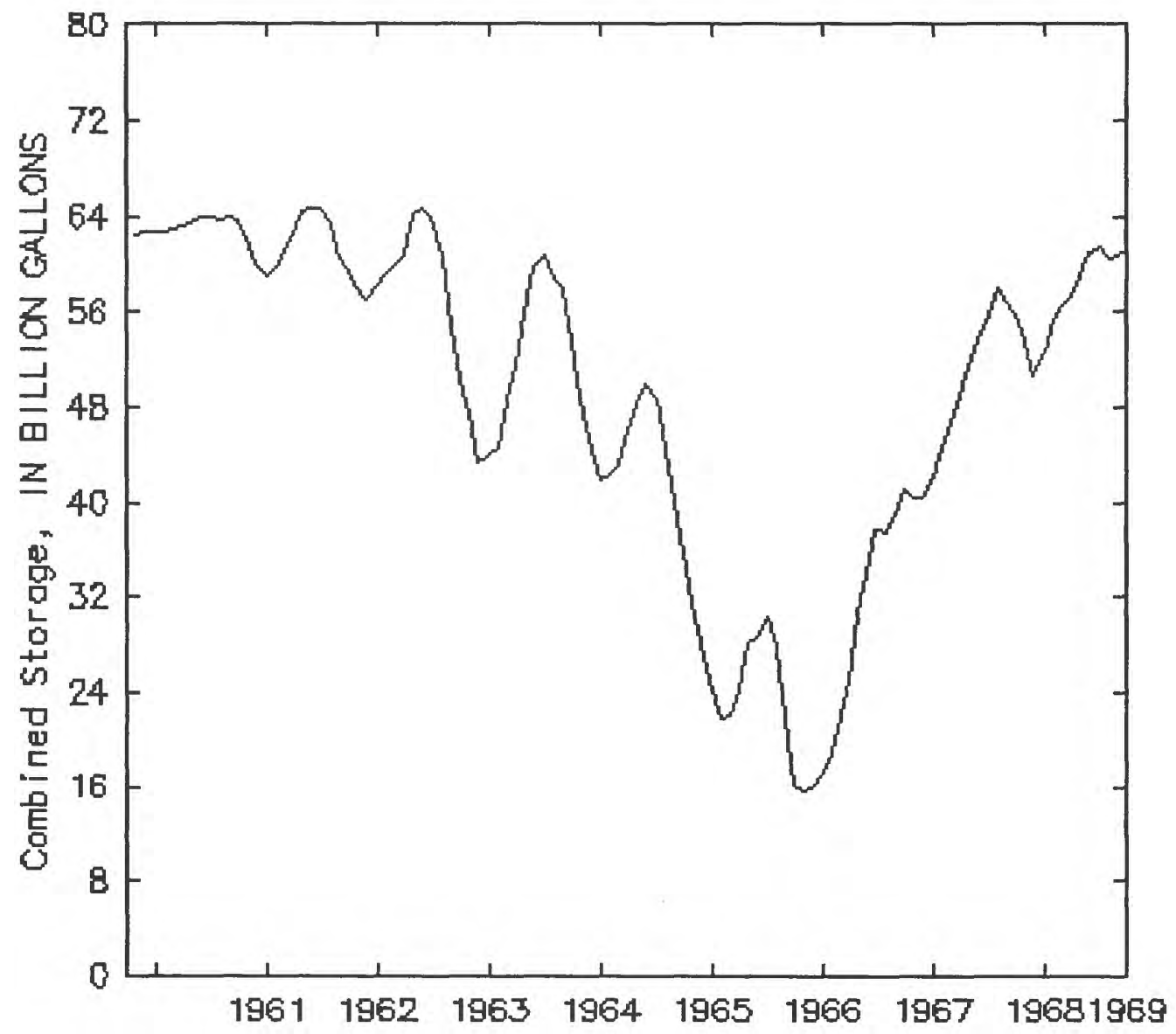

Figure 27. Time-series plot produced by the Raritan River Basin model, central New Jersey. 
An example percentile plot is shown in figure 28. Drought-warning conditions for each month are indicated by the light shaded area. Drought-emergency conditions are indicated by the dark shaded area. On the computer screen, these areas will appear as orange and red vertical lines for drought-warning and drought-emergency conditions, respectively. These conditions are indicated only on the combined-storage plot (number 13 on the plot menu shown in figure 25). Figure 28 illustrates a hypothetical plot of the combined reservoir storage for Spruce Run Reservoir and Round Valley Reservoir for a 12-month period beginning in August. Note that if drier-thannormal conditions occur during the next 12 months, there is a 1 in 10 chance that drought-warning conditions would occur during May, June, and July.

\section{Probability plots}

Storage and flow values also can be plotted as a probability of occurrence not to be exceeded during any month or all months. The months to be plotted can be entered on a form after choosing the probability-plot option. An example probability plot is shown in figure 29. This plot shows the percentage of time that streamflow at Bound Brook was not exceeded during May for a particular model run. For example, streamflow at Bound Brook would not exceed $1,100 \mathrm{Mgal} / \mathrm{d}$ approximately 70 percent of the time. 


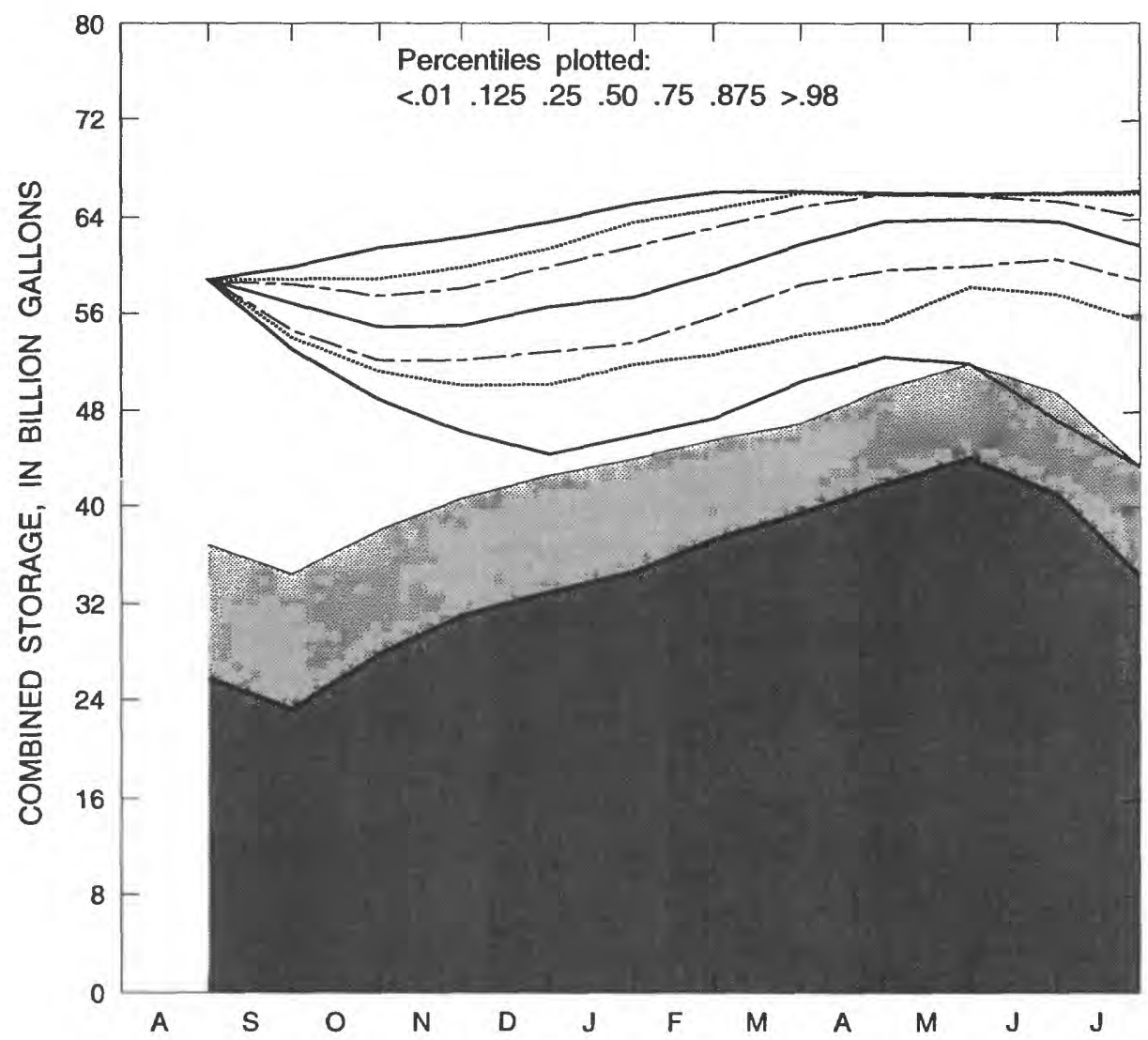

Figure 28. Percentile plot produced by the Raritan River Basin model, central New Jersey. 


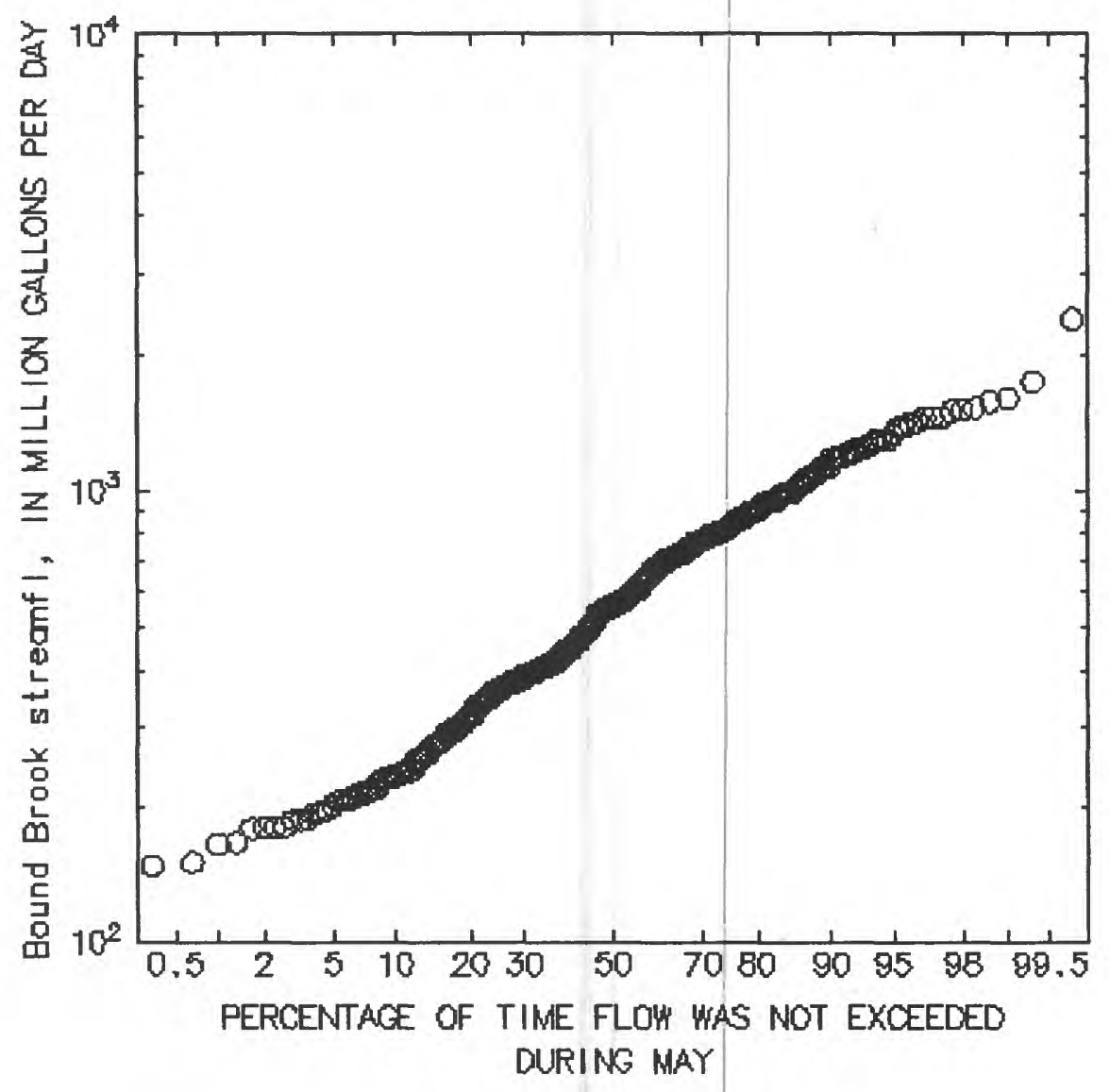

Figure 29. Probability plot produced by the Raritan River Basin model, central New Jersey. 


\section{SUMMARY}

The computer model described in this report provides a technical basis for evaluating the effects of alternative patterns of operation for the Raritan River Basin water-supply system during extended periods of below-average precipitation. For a given set of system operating rules and water-use requirements, the model can be used to assess the performance of the Raritan River Basin water-supply system in past years under alternative sets of operating rules. The model also can be used to forecast the likelihood of specified outcomes, such as a decrease in reservoir contents below a specified threshold or in streamflows below statutory passing flows, for a period of up to 12 months. 


\section{SELECTED REFERENCES}

Dresnack, Robert, Golub, Eugene, and Salek, Franklin, 1985, Hydrologic and economic efficient operations Raritan River Basin reservoir system supported by the Delaware and Raritan Canal water-supply system: New Jersey Institute of Technology, Civil and Environmental Engineering Department, 41 p., 4 app.

Efron, Bradley, 1979, Bootstrap methods: Another look at the jackknife: The Annals of Statistics, v. 7, no. 1, p. 1-26.

Efron, Bradley, 1982, The jackknife, the bootstrap and other resampling plans: Society for Industrial and Applied Mathematics, Philadelphia, Pa., 92 p.

Hirsch, R.M., 1978, Risk analysis for a water-supply system--Occoquan Reservoir, Fairfax and Prince William Counties, Virginia: Hydrological Sciences Bulletin, v. 23, no. 4, p. 476-505.

Hirsch, R.M., 1979, Synthetic hydrology and water supply reliability: Water Resources Research, v. 15 , no. 6 , p. $1603-1615$.

Hirsch, R.M., 1981a, Stochastic hydrologic model for drought management: Journal of Water Resources Planning and Management Division, American Society of Civil Engineers, v. 107 , no. WR2, p. 303-313.

Hirsch, R.M., 1981b, Estimating the probabilities of reservoir storage for the upper Delaware River basin: U.S. Geological Survey Open-File Report 81-478, 18 p.

Hirsch, R.M., 1982, A comparison of four streamflow record extension techniques: Water Resources Research, v. 18, no. 4, p. 1081-1088.

Rippl, W., 1883, The capacity of storage reservoirs for water supply: Proceedings of Institute of Civil Engineers, v. 71, p. 270-278.

Salas, J.D., 1993, Analysis and modeling of hydrologic time series, in Maidment, D.R., ed., Handbook of hydrology: New York, McGraw-Hill, Inc., p. 19.1-19.72. 


\section{APPENDIX 1. Observed error components of stochastic runoff model.}

[Region 1 is the Delaware River drainage area above NYC reservoirs; region 2 is the Delaware River drainage area between the NYC reservoirs and the gage at Montague, N.J.; region 3 is the South Branch Raritan River drainage area; region 4 is the North Branch Raritan River drainage area; and region 5 is the remainder Raritan River drainage area including the Millstone River. A -1 value for INDEX indicates that the sum across regions of the errors for the month is in the lowest 33.3 percent for all months; a 0 value for INDEX indicates that it is in the middle 33.3 percent for all months, and a +1 value indicates that it is in the top 33.3 for all months]

\begin{tabular}{|c|c|c|c|c|c|c|c|}
\hline YEAR & MONTH & 1 & 2 & 3 & 4 & 5 & IND \\
\hline 1918 & 10 & 0.000000 & 0.000000 & 0.000000 & 0.000000 & 0.000000 & \\
\hline 1918 & 11 & -0.776143 & -0.758057 & -0.394578 & -0.446877 & -0.551475 & -1 \\
\hline 1918 & 12 & 0.463676 & 0.414606 & 0.793342 & 0.736289 & 0.548877 & 1 \\
\hline 1919 & 1 & 0.384246 & 0.360373 & 0.410249 & 0.370320 & 0.305246 & 1 \\
\hline 1919 & 2 & -1.057416 & -1.094814 & -0.206329 & -0.230355 & -0.227408 & -1 \\
\hline 1919 & 3 & -0.018969 & 0.003322 & 0.900720 & 0.879650 & 0.821813 & 1 \\
\hline 1919 & 4 & -0.576155 & -0.547849 & -0.652281 & -0.642740 & -0.597722 & -1 \\
\hline 1919 & 5 & 0.196770 & 0.178015 & -0.197635 & -0.200270 & -0.273961 & 0 \\
\hline 1919 & 6 & -0.642038 & -0.639960 & -0.763950 & -0.756461 & -0.769151 & -1 \\
\hline 1919 & 7 & 1.693977 & 1.662129 & 2.528643 & 2.617397 & 2.486524 & 1 \\
\hline 1919 & 8 & 0.334723 & 0.098522 & 1.345002 & 1.268145 & 1.423219 & \\
\hline 1919 & 9 & -0.364889 & -0.292853 & -0.431662 & -0.434747 & 0.082424 & \\
\hline 1919 & 10 & -0.119161 & -0.097159 & 0.272026 & 0.341984 & 0.476109 & 0 \\
\hline 1919 & 11 & 0.895579 & 0.891538 & 0.411444 & 0.457157 & 0.597140 & 1 \\
\hline 1919 & 12 & -0.216237 & -0.149457 & 0.104831 & 0.078018 & 0.273111 & 0 \\
\hline 1920 & 1 & -1.887977 & -1.866257 & -0.850401 & -1.180019 & -1.092380 & -1 \\
\hline 1920 & 2 & -2.043906 & -1.865091 & -2.028360 & -2.180953 & -2.280935 & -1 \\
\hline 1920 & 3 & 0.948291 & 1.138109 & 1.016011 & 1.281179 & 0.782699 & \\
\hline 1920 & 4 & 1.107440 & 1.338142 & 0.018886 & -0.286214 & -0.225439 & \\
\hline 1920 & 5 & -0.4676 & -0.269229 & -0.695103 & -0.230458 & -0.152008 & 0 \\
\hline 1920 & 6 & 0.321906 & 0.304234 & -0.147072 & -0.056503 & -0.008185 & 0 \\
\hline 1920 & 7 & 1.646856 & 1.657763 & 1.257805 & 1.134969 & 1.164660 & 1 \\
\hline 1920 & 8 & 0.002853 & -0.207237 & 0.587445 & 0.537851 & 0.665122 & 1 \\
\hline 1920 & 9 & 0.187661 & 0.271358 & -0.443797 & -0.672096 & -0.408460 & 0 \\
\hline 1920 & 10 & 0.372029 & 0.358906 & 0.297542 & 0.591639 & 0.618649 & \\
\hline 1920 & 11 & 0.411291 & 0.429129 & 0.009261 & 0.349021 & 0.434500 & \\
\hline 1920 & 12 & 1.063462 & 1.12226 & 338666 & 1.037372 & 1.167511 & \\
\hline & 1 & -0.8 & -0.911080 & -0.284712 & -0.045373 & 0.040581 & 0 \\
\hline 1921 & 2 & -1.068263 & -0.962668 & -1.064867 & -0.657470 & -0.496508 & -1 \\
\hline 1921 & 3 & 0.971282 & 1.091861 & 0.349686 & 0.623616 & 0.700511 & 1 \\
\hline 1921 & 4 & -0.364309 & -0.187274 & -0.729728 & -0.544509 & -0.433138 & -1 \\
\hline 1921 & 5 & -0.573173 & -0.507798 & 0.529853 & 0.460475 & 0.470037 & 0 \\
\hline 1921 & 6 & -0.868458 & -0.866787 & -1.313077 & -1.720118 & -1.647747 & -1 \\
\hline 1921 & 7 & 0.746569 & 0.677264 & 0.078150 & 0.269554 & 0.057031 & 1 \\
\hline 1921 & 8 & 0.489913 & 0.363199 & -0.113608 & -0.145244 & -0.236378 & 0 \\
\hline 1921 & 9 & 0.035541 & 0.051101 & -0.643266 & -0.580972 & -0.683248 & \\
\hline 1921 & 10 & 0.295334 & 0.302591 & -0.655409 & -0.494586 & 0.168018 & 0 \\
\hline 1921 & 11 & 0.837941 & 0.841459 & 0.246659 & 0.106070 & -0.357773 & 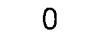 \\
\hline 1921 & 12 & 0.156393 & 0.238534 & -0.522589 & -0.680310 & 0.030529 & 0 \\
\hline 1922 & 1 & -1.256226 & -1.236657 & -1.481843 & -1.120847 & -1.940283 & -1 \\
\hline 1922 & 2 & -0.124206 & 0.008086 & 1.040195 & 1.224469 & 0.569305 & 1 \\
\hline 1922 & 3 & 1.168480 & 1.259442 & 0.552143 & 1.371740 & 0.714352 & \\
\hline
\end{tabular}




\begin{tabular}{|c|c|c|c|c|c|c|c|}
\hline 1922 & 4 & 0.338440 & 0.492655 & 0.090986 & -0.385406 & -0.361974 & \\
\hline 1922 & 5 & 0.193844 & 0.286892 & -0.203369 & -0.038557 & -0.138982 & \\
\hline 1922 & 6 & 1.107846 & .085515 & -0.116842 & 0.339186 & 0.524624 & \\
\hline 1922 & 7 & 053371 & 022048 & 1.702 & 18717 & & \\
\hline 1922 & 8 & .023782 & 0.061628 & -0.811130 & -0.31 & 19 & \\
\hline 1922 & 9 & -0.224475 & -0.209917 & 0.751469 & 0.234602 & -0.31 & \\
\hline 1922 & 10 & -0.440058 & -0.421952 & -0.998407 & -0.688046 & -0.521677 & \\
\hline 1922 & 11 & -1.817402 & -1.819838 & -1.179071 & -1.278767 & -0.756578 & \\
\hline 922 & 12 & -1.724998 & -1.887263 & -0.494503 & -0.649035 & -0.472771 & \\
\hline 923 & 1 & 1.532986 & 1.540284 & 0.624796 & 0.848140 & 1.118639 & \\
\hline 23 & 2 & -0.411307 & -0.597022 & -0.177162 & -1.076554 & 26 & \\
\hline 23 & 3 & & & & & & \\
\hline 192 & 4 & & & & & & \\
\hline 1923 & 5 & 0.413185 & 0.44 & -0 & -0.9 & 22 & \\
\hline 1923 & 6 & 0.0 & 0.0 & -0 & -0 . & $-0.3^{\prime}$ & \\
\hline 1923 & 7 & -1.088012 & -1.071328 & -0.64 & -0.339665 & -0.40 & \\
\hline 923 & 8 & -0.035924 & 0.108282 & -0.63 & -0.762570 & -0.30 & \\
\hline 923 & 9 & & & -0.15 & & & \\
\hline 23 & 10 & -0 . & & & & & \\
\hline 923 & 11 & -0 . & -0 & & & & \\
\hline 1923 & 12 & 90 & 1.44 & 144 & 652 & & \\
\hline 1924 & 1 & 0.714455 & 0.66 & 0.89 & 0.91 & 98 & \\
\hline 1924 & 2 & -1.790608 & -1.847782 & -0.37 & -1.13 & 0.73 & \\
\hline 924 & 3 & -2.42 & -2.37 & -0.5 & -0 . & & \\
\hline 924 & 4 & 0.0 & -0.0 & & & & \\
\hline 24 & 5 & $0 . \varepsilon$ & & & & & \\
\hline 1924 & 6 & -0 . & -0.9 & -0.40 & & & \\
\hline 1924 & 7 & 0.450624 & 0.42 & -0.94 & -0.57 & -0.0 & \\
\hline 1924 & 8 & -0.605413 & -0.681289 & -0.742969 & -0.565730 & -0.15 & \\
\hline 924 & 9 & 1.6 & 163 & & & & \\
\hline & 10 & & -0 . & & & & \\
\hline & 1 & -1 & -1 & -1 & & & \\
\hline 24 & 12 & -0 . & & & & & \\
\hline 925 & 1 & -1.599496 & -1.610697 & -1.46 & -1 & -1 & \\
\hline 25 & 2 & 1.91 & 761 & 2.60 & 2.26 & 45 & \\
\hline 92 & 3 & 0.6 & 0. & 1.6 & & & \\
\hline & 4 & -0.8 & & & -1 & & \\
\hline & 5 & & & & & & \\
\hline & 6 & -0 . & & & & & \\
\hline 925 & 7 & 1.0 & 0 . & & & -0 . & \\
\hline 725 & 8 & 0.2 & 803 & 1. & 1.0 & -0 . & \\
\hline 192 & 9 & 0.6 & 322 & -0.01 & -0.1 & -0.31 & \\
\hline 1 & 10 & -0.2 & -0.2 & & & & \\
\hline & 1. & & & & & & \\
\hline & 12 & & & & & & \\
\hline & 1 & & -0. & & -1 & -0 . & \\
\hline 1926 & 2 & -0.23 & -0.1 & 0.23 & 0.07 & $0 . \varepsilon$ & \\
\hline 1926 & 3 & -1.032 & -0.99 & -0.996618 & -0.952521 & -0.516327 & \\
\hline 1926 & 4 & 0.62 & 3468 & -1.09 & -0.79 & -0.56 & \\
\hline 192 & 5 & $-0.7 \varepsilon$ & -0.74 & $-1.25 c$ & -1.525 & -0.724509 & \\
\hline 192 & 6 & -0.1 & -0 . & & -0 . & & \\
\hline 192 & 7 & -0 & -0 . & & & & \\
\hline & 8 & & & & & & \\
\hline & 9 & & -0.85 & & & 0.928947 & \\
\hline 192 & 10 & & & 0.40 & 0.235721 & -0.639182 & \\
\hline 192 & $1]$ & 0.672949 & 0.631406 & & 0.653494 & 0.864618 & \\
\hline 192 & 12 & -1.372438 & -1.298155 & -0.233535 & 0.122784 & 0.212968 & \\
\hline & 1 & & & & 0.178432 & -0.027368 & \\
\hline & 2 & & & & -0.2 & & \\
\hline
\end{tabular}




\begin{tabular}{|c|c|c|c|c|c|c|c|}
\hline 1927 & 3 & 1.455435 & 1.412411 & -1.301882 & -1.806245 & -1.621336 & -1 \\
\hline 1927 & 4 & -0.929202 & -0.866317 & -1.105568 & -0.964205 & -0.420715 & -1 \\
\hline 927 & 5 & 1.037940 & 0.985610 & 0.489378 & 1.194412 & 0.020525 & \\
\hline 1927 & 6 & 0.106575 & 0.082776 & 0.586191 & -0.161005 & 67 & \\
\hline 192 & 7 & -0.12504 & -0.0873 & -0.0358 & 0.6462 & & \\
\hline 1927 & 8 & 1.852194 & 1.877301 & 1.224536 & 0.961752 & & \\
\hline 7 & 9 & 0.250722 & 0.232623 & 0.350955 & -0.230514 & -0.124334 & \\
\hline 7 & 10 & 75610 & 0.928755 & 1.494467 & & 2.188876 & \\
\hline 927 & 1 & 06817 & 0.523745 & 0.569314 & 0.517678 & 56258 & \\
\hline 7 & 12 & 59187 & 1.153151 & 0.398720 & 0.563100 & & \\
\hline & 1 & -0.249693 & -0.24 & -0.925424 & -0.853198 & -0.872693 & \\
\hline 928 & 2 & -0.0640 & & & & & \\
\hline 1928 & 3 & -0 . & -0 . & -1.5 & -1 & & \\
\hline 192 & 4 & 0. & 0.1 & 0.42 & 0 & & \\
\hline 1928 & 5 & 1.1 & 1.14 & 0.41 & 703 & & \\
\hline 928 & 6 & 1.5 & 1.52 & 0.98 & 652 & & \\
\hline 928 & 7 & 0.2 & 0.34 & 1.24 & 861 & 61 & \\
\hline 928 & 8 & 0.73 & 0.75 & 0.67 & 275 & & \\
\hline & 9 & 884 & -0.0 & & & & \\
\hline 1928 & 10 & 2 & -1. & -0 . & -0 . & & \\
\hline 192 & 11 & $-1 \cdot 3$ & -1.35 & -0.97 & -1. & -0 . & - \\
\hline 1928 & 12 & -0.4 & -0.6 & -0.72 & -0.9 & -0. & \\
\hline 929 & 1 & 0.4 & 0.43 & 0.69 & 268 & 0 & \\
\hline 929 & 2 & -0.0 & -0.16 & 1.16 & 1.2 & 27 & \\
\hline & 3 & & & & & & \\
\hline & 4 & & & & & & \\
\hline & 5 & & & & & & \\
\hline 929 & 6 & -0.7 & -0.8 & -0.1 & -0.3 & -0 . & -1 \\
\hline 29 & 7 & -0.2 & -0.27 & -0.7 & -0.6 & -0 . & -1 \\
\hline 29 & 8 & -0.6 & -0.6 & -0.7 & $-0.7-7$ & -0 . & \\
\hline & 9 & & $-0.2-2$ & & & & \\
\hline & 10 & & & & & & \\
\hline & 11 & -0 . & -0 . & -0 & & & \\
\hline 2 & 12 & & 0.2 & & 385 & -0 . & \\
\hline 30 & 1 & 0.2 & 0.20 & -0.0 & -0.7 & 39 & \\
\hline 30 & 2 & 0.5 & $0.4 \xi$ & -0.2 & $-0.7-7$ & 0 . & \\
\hline 3 & 3 & & 0.3 & -0.3 & -0 . & 56 & \\
\hline & 4 & -1 & -1 & -0.5 & -0 . & & \\
\hline & 5 & -1 & -1 & & -1 & & \\
\hline 1 & 6 & 1.7 & 1.76 & 0.2 & 0 & & \\
\hline 30 & 7 & -1.56 & -1.53 & -0.13 & 664 & -0 & - \\
\hline 30 & 8 & -0.54 & -0.3 & -0.6 & -0.7 & $-0.8-8$ & - \\
\hline 3 & 9 & & -0.0 & -0.52 & -0. & -1 & \\
\hline & 10 & -1.1 & -1 & -0.4 & -1 & -0 . & \\
\hline & 11 & -0 & & & & & \\
\hline & 12 & & & & & & \\
\hline 19 & 1 & -1 & -1.5288 & -0.1 & -0.03 & -0 . & -1 \\
\hline 1931 & 2 & -1.254712 & -1.156043 & -0.38 & -0.383765 & -0.3 & - \\
\hline 1931 & 3 & -0.949 & -0.856236 & -1.541 & -0.59 & -0.5 & - \\
\hline 193 & 4 & 0.636909 & 0.645484 & 0.03 & -0.40 & 75434 & \\
\hline 193 & 5 & & 0.9 & 0.6 & 0.4 & -0.106707 & \\
\hline 193 & 6 & & 0.0 & & & & \\
\hline 1 & 7 & & & & & & \\
\hline & 8 & & & -0.87 & -0.70 & -0.074326 & \\
\hline 193 & 9 & -0.62 & -0.53 & -0.585332 & -0.268344 & -1.150260 & - \\
\hline 1931 & 10 & -0.82563 & -0.8198 & -0.630440 & -0.729864 & -0.583103 & - \\
\hline & 11 & -1.51474 & -1.528620 & -1.1787 & -1.250881 & -1.337693 & \\
\hline & 12 & & 0.494171 & -0.889249 & -0.613012 & -1.087457 & \\
\hline & 1 & 1.589090 & 1.518325 & 0.618321 & 0.821052 & 1.346552 & \\
\hline
\end{tabular}




\begin{tabular}{|c|c|c|c|c|c|c|c|}
\hline 1932 & 2 & 0.600757 & 0.425806 & -0.427792 & -1.008012 & -0.387155 & \\
\hline 1932 & 3 & -2.069361 & -2.203327 & -0.795107 & -0.386982 & 0.527247 & \\
\hline 932 & 4 & 0.084954 & -0.168756 & 0.488718 & 0.133330 & 0.017663 & \\
\hline 932 & 5 & 36257 & -0.743465 & -0.539042 & -0.494872 & -1.04 & \\
\hline & 6 & 0.854825 & 0.892101 & -0.669290 & -0.639040 & -0.27 & \\
\hline & 7 & 12339 & -0.084740 & -0.189093 & -0.506475 & $-0.61 s$ & \\
\hline & 8 & 44867 & -0.307417 & -0.736846 & -0.888325 & -0.716035 & \\
\hline & 9 & -1.02 & -1.013902 & -0.367063 & -0.006063 & 0.144896 & \\
\hline 932 & 10 & 1.91 & 1.958507 & 0.881036 & 1.324418 & 017 & \\
\hline 932 & 1 & 0.072228 & 02889 & 2.015234 & 260 & 856 & \\
\hline 932 & 12 & -1.87 & -1.84 .09 & & -0.7 & & \\
\hline 193 & 1 & & 0.5 & -0 . & -0 . & 87 & \\
\hline 1933 & 2 & -0.2 & -0.3 & -0 . & -0. & -0 . & \\
\hline 9 & 3 & -0.3 & -0.3 & 0 & & & \\
\hline 1933 & 4 & 0.7 & 0.686688 & 0.996976 & 0.74 & 002 & \\
\hline 3 & 5 & -1.26 & -1.230565 & -0.025180 & $0.0^{\circ}$ & 284 & \\
\hline & 6 & -0.23 & -0.208293 & $-0.68 c$ & -0.6 & -0.0 & \\
\hline & 7 & -0 . & -0 . & -0 . & -0 . & -0 & \\
\hline & 8 & 2 & & & & & \\
\hline 1933 & 9 & 0.3 & 0.2 & 1. & 1. & & \\
\hline 1933 & 10 & -0.7 & -0.6 & -0. & -0.6 & -0 & \\
\hline 1933 & & -0.6 & -0.581985 & -1.44 & -1.28 & -1.0 & \\
\hline 17 & 12 & -0.5 & -0. & -0.88 & -0.8 & -0.7 & \\
\hline & 1 & $0 . \epsilon$ & & & & & \\
\hline & 2 & -1 & -1 & & -2 . & & \\
\hline & 3 & -0 & -0 . & & & & \\
\hline 193 & 4 & $-0.2 x-2$ & -0 & & & & \\
\hline 1934 & 5 & -1.4 & -1.49 & -0.00 & -0.1 & 97 & \\
\hline 193 & 6 & -0.2 & -0.19 & 0.3 & 0.3 & -0.1 & \\
\hline & 7 & & & -0 & -0 & -0 . & \\
\hline & 8 & & -0 . & & & & \\
\hline & $\subseteq$ & & & & & & \\
\hline 19 & 0 & -0 & $-0.4+5$. & 0 . & & & \\
\hline 193 & & 0.1 & 0.2 & -0.8 & -0.6 & -0 . & \\
\hline 193 & 12 & 0.6 & 0.6 & & & -0 . & \\
\hline 19 & 1 & 0. & 0.6 & -0 & -0 . & -0 . & \\
\hline & 2 & -0 . & -0 . & & -0 . & & \\
\hline & 3 & & & & -1 & & \\
\hline & 4 & -1. & -1 & -1 & -0 . & -0 . & \\
\hline 193 & 5 & 0. & -0. & -1.0 & $-0.5-5$ & -0 & \\
\hline 193 & 6 & -0.4 & -0.4 & 0. & 726 & & \\
\hline 193 & 7 & 0. & 0.6 & 2.3 & 1.9 & 37 & \\
\hline & 8 & -0 . & -0 . & -0 & -0 & -0 & \\
\hline & s & -0 & & & & & \\
\hline & & & & & & & \\
\hline & & & & & & & \\
\hline 19 & 12 & -0. & -0.6 & -0.62 & -0.7 & -0 & \\
\hline & 1 & 0.2 & 0.2 & 1.167 & 589 & 541 & \\
\hline 193 & 2 & -0.8 & $-0.82 \varepsilon$ & -0.90 & $-0 . \varepsilon$ & -0 . & \\
\hline & 3 & & 1. & & & & \\
\hline 19 & 4 & & 0.7 & -0 . & -0 & -0 & \\
\hline & 5 & -1 & -1 & -1 & -0 & -0 . & \\
\hline & 6 & & & & & & \\
\hline & 7 & -0.9 & -0.990399 & -0.77 & & -0.57 & \\
\hline & 8 & 0.6 & 0.718650 & -0.41 & -0.4 & -0.618160 & \\
\hline & 9 & -0.520853 & -0.584430 & -0.662301 & -0.538173 & 0.208531 & \\
\hline & 10 & 0.595156 & 0.641226 & 0.1107 & 0.455423 & 0.469926 & \\
\hline & 11 & -0.120435 & -0.156814 & -0.89 & 2111 & -1.134136 & \\
\hline & 12 & 70 & & & 669 & 37675 & \\
\hline
\end{tabular}




\begin{tabular}{|c|c|c|c|c|c|c|c|}
\hline 193 & 1 & .413526 & 1.407977 & 1.268477 & 1.168073 & 0.878085 & \\
\hline & 2 & .149896 & 1.028223 & 0.473813 & 0.174319 & -0.026354 & \\
\hline & 3 & 1.723307 & -1.838253 & -1.064978 & -1.131504 & -0.969527 & \\
\hline & 4 & -0.007342 & -0.214381 & 0.478145 & 0.487937 & 0.372387 & \\
\hline & 5 & 1.143569 & 0.212655 & 0.754067 & & & \\
\hline 7 & 6 & -0.048422 & & & & & \\
\hline & 7 & 0.3 & 26721 & -0.1 & & & \\
\hline & 8 & 1.76 & 52281 & 0.605 & & & \\
\hline 7 & 9 & 0.40 & 0.476368 & -0.642313 & -0.766828 & -0.258996 & \\
\hline & 10 & 0.36 & 0.811545 & 0.870137 & 0.514087 & 0.697241 & \\
\hline & & -0.27 & -0.457271 & 0.596665 & 0.522 & 659721 & \\
\hline & & -0.33 & -0.463397 & -0.456810 & $-0.470 s$ & -0.526676 & \\
\hline 938 & 1 & & & & & & \\
\hline 1938 & 2 & & & & & & \\
\hline 1938 & 3 & -0 . & & -1 & -1 & 272 & \\
\hline 1938 & 4 & -0.9 & $-0 . \varepsilon$ & -0.23 & -0.1 & 260380 & \\
\hline 938 & 5 & -0.5 & -0.48 & -0.35 & -0.29 & 348222 & \\
\hline 938 & 6 & 1.3 & 1.14 & 1.59 & $1 . \varepsilon$ & 2921 & \\
\hline 938 & 7 & 1.2 & & & & 6973 & \\
\hline 938 & 8 & & & -0.1 & -0 . & -0 & \\
\hline 1938 & 9 & & & & & & \\
\hline 193 & 10 & -1 & -1 & -0 . & -0 . & -0 . & \\
\hline 1938 & 11 & 0.0 & 0.3 & -1.0 & $-0 . \varepsilon$ & -0 . & \\
\hline 1938 & 12 & 1.26 & 1.092053 & 1.16 & 1.0484 & 4414 & \\
\hline 939 & 1 & -0.9 & -1.062708 & -0.27 & -0.31 & 0608 & \\
\hline 939 & 2 & & & & & & \\
\hline 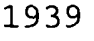 & 3 & & & & & & \\
\hline 9 & 4 & & & & & & \\
\hline 1939 & 5 & -1.7 & -1.3 & -0.7 & -0. & -0 . & \\
\hline 939 & 6 & -0.8 & -0.8 & -0.7 & -0.6 & 154447 & \\
\hline 935 & 7 & -0. & -0. & -0.5 & -0. & 5333 & \\
\hline 935 & 8 & -0 & & -0.3 & -0 & & \\
\hline & 9 & & & -0 . & -0 & & \\
\hline & 10 & & & -0 . & & & \\
\hline & & & & -0 . & -0 . & 272 & \\
\hline 939 & 12 & $-0 . \varepsilon-1-1$ & -0 & -1.2 & -1.5 & 4396 & \\
\hline 1940 & 1 & -1.0 & $-0 . \varepsilon-\varepsilon$ & -0.9 & -1.2 & 3969 & \\
\hline 340 & 2 & -1.6 & -1 & -0.7 & -0 . & -0 . & \\
\hline 4 & 3 & -0 . & -1 & & & & \\
\hline & 4 & & & & & & \\
\hline & 5 & & & & & 3068 & \\
\hline 940 & 6 & & 988 & 1.25 & 1.0 & 07914 & \\
\hline 940 & 7 & -0.2 & 165 & -1.15 & -0.652622 & 8330 & \\
\hline 4 & 8 & -0.5 & -0.9 & -0.5 & -0.488270 & -0 . & \\
\hline 4 & 9 & & & & & & \\
\hline & & -1. & -1 & -0.5 & -0 . & -0 & \\
\hline & & & & & & & \\
\hline & 12 & & & & & & \\
\hline & 1 & -0 . & & -0.3 & $-0.4 x-4$ & 1142 & \\
\hline & 2 & -0.56 & -0.3 & -0.2958 & -0.199121 & 0.026618 & \\
\hline 194 & 3 & -1.9 & -2. & -0.8165 & -0.68 & -0.012395 & \\
\hline & 4 & -0.3 & -1.0 & -0.62 & -0.44 & -0.2 & \\
\hline 15 & 5 & -1.8 & -2.53 & -1.42 & -1.39 & -1.064611 & \\
\hline 194 & 6 & -0.2 & & 0.67 & 0.346343 & 0.789508 & \\
\hline 194 & 7 & & -0.5 & 0.1 & & & \\
\hline 194 & 8 & & & -0.0 & -0.2 & 398 & \\
\hline & 9 & -1.034622 & -0.571015 & -1.065583 & -0.977621 & -1.350698 & \\
\hline & 10 & -0.5 & -0.63 & -0.55 & -0.597765 & -1.034950 & \\
\hline & 11 & -0.549216 & -0.29 & -0.281544 & -0.256735 & -0.033817 & \\
\hline
\end{tabular}




\begin{tabular}{|c|c|c|c|c|c|c|c|}
\hline 1941 & 12 & 0.028940 & 0.566580 & 0.063849 & 0.261706 & 0.116444 & \\
\hline 1942 & 1 & -0.126876 & -0.246245 & -0.368214 & -0.620055 & -0.866460 & \\
\hline 1942 & 2 & -0.905865 & -0.339002 & 0.094153 & 0.122937 & -0.259862 & \\
\hline 1942 & 3 & 0.748345 & 0.248840 & 0.258146 & 0.855461 & 0.511466 & \\
\hline 1942 & & -0.195595 & -0.780058 & -0.887363 & -1.073976 & -1.079990 & -1 \\
\hline 1942 & & -0.510528 & 0.467444 & -0.239336 & -0.914800 & -0.987795 & 0 \\
\hline 1942 & & 0.420866 & 0.831568 & -0.206955 & -0.043490 & -0.062603 & 1 \\
\hline 1942 & & -0.680046 & -0.683196 & 0.766035 & 0.613262 & 0.386966 & 0 \\
\hline 1942 & $\varepsilon$ & 0.349919 & 0.775831 & 2.303096 & 2.402787 & 1.855533 & 1 \\
\hline 1942 & 9 & 1.299219 & 1.513751 & -0.000785 & 0.167102 & -0.636673 & 1 \\
\hline 1942 & 11 & 0.172556 & -0.012575 & -0.046412 & 0.123274 & 0.435240 & 0 \\
\hline 1942 & 12 & 0.372470 & 0.376230 & 0.623370 & 0.659757 & 0.605132 & 1 \\
\hline 1943 & 1 & 0.159531 & 0.038970 & -0.134613 & -0.434043 & -0.727393 & 0 \\
\hline 1943 & 2 & 0.669420 & 0.320704 & 0.379164 & 0.286784 & -0.163309 & 0 \\
\hline 1943 & 3 & 0.887018 & 1.037942 & -0.575837 & -0.557433 & -1.082510 & 0 \\
\hline 1943 & 4 & -0.077302 & 0.026220 & -0.814500 & -0.869940 & -1.337626 & -1 \\
\hline 1943 & 5 & 1.667181 & 1.878347 & 1.144223 & 1.262918 & 1.212560 & 1 \\
\hline 1943 & 6 & 0.240118 & 0.005752 & 0.322055 & 0.156485 & -1.282 & 0 \\
\hline 1943 & 7 & -1.126925 & -0.422738 & -0.380635 & 0.112135 & 0.457347 & -1 \\
\hline 1943 & 8 & -0.481494 & -0.560451 & -0.636283 & -0.663058 & -1.449830 & -1 \\
\hline 1943 & 9 & -0.829286 & -0.629306 & -0.662758 & -0.5297 & -0.907389 & -1 \\
\hline 1943 & 10 & 0.634667 & 0.955169 & 0.978082 & 1.090855 & 0.797245 & 1 \\
\hline 1943 & 11 & 0.452912 & 0.356009 & 0.517556 & 0.385017 & 0.655259 & 1 \\
\hline 1943 & 12 & -1.602528 & -2.075146 & -1.337263 & -1.433504 & -1.713151 & -1 \\
\hline 44 & 1 & -1.191296 & -1.158227 & $1: 030669$ & 1.120222 & 1.536309 & 0 \\
\hline 44 & 2 & -0.800532 & -1.142609 & 0.168429 & 0.004892 & 0.106737 & 0 \\
\hline 44 & 3 & -0.020474 & -0.289554 & 0.949719 & 1.479701 & 1.578084 & 1 \\
\hline 944 & 4 & -0.186430 & 0.195347 & 0.544312 & 0.451540 & 0.814561 & 0 \\
\hline 1944 & 5 & -0.829350 & -0.967386 & -0.419711 & -0.578710 & -0.394843 & -1 \\
\hline 1944 & 6 & -0.245610 & -0.277552 & -0.2505 & 0.020438 & 0.27 & 0 \\
\hline 44 & 7 & -0.131179 & -0.394676 & -0.965476 & -1.012190 & -1.19 & -1 \\
\hline 44 & 8 & -0.353552 & -0.839493 & -0.907915 & -0.847112 & -1.227731 & -1 \\
\hline 44 & 9 & 0.561918 & 0.232634 & 0.140822 & 0.614797 & 2.318523 & 1 \\
\hline 44 & 10 & -0.387393 & -0.587378 & -0.707975 & -0.779421 & -1.583517 & -1 \\
\hline 1944 & 11 & -0.525798 & -0.661409 & 0.671408 & 1.059068 & 1.146648 & 0 \\
\hline 1944 & 12 & 0.017135 & -0.060225 & 0.079770 & -0.202502 & 0.05 & 0 \\
\hline 45 & 1 & 0.742012 & 0.324934 & 0.032235 & 0.022483 & -0.54 & 0 \\
\hline 45 & 2 & 0.163728 & -0.206884 & 0.588765 & 0.492502 & 0.809449 & 0 \\
\hline 45 & 3 & 1.895655 & 1.705242 & 0.690013 & 0.578615 & -0.471465 & 1 \\
\hline 1945 & 4 & -0.691686 & -0.095037 & -0.763865 & -0.6885 & -1.014552 & -1 \\
\hline 1945 & 5 & 1.174559 & 1.246678 & 1.147539 & 1.208325 & 0.804604 & 1 \\
\hline 1945 & 6 & 0.455224 & 0.324672 & 0.413764 & -0.107285 & -0.708183 & 0 \\
\hline 1945 & 7 & 1.349904 & 2.084671 & 1.756322 & 1.152745 & 1.51 & 1 \\
\hline & 8 & 0.457872 & -0.224418 & 0.179878 & 0.332197 & -0.224 & 0 \\
\hline & 9 & 0.115583 & 0.503844 & 0.089917 & 0.212099 & 1.249427 & 1 \\
\hline & 10 & 0.764808 & 0.538768 & -0.517424 & -0.321149 & -0.803891 & 0 \\
\hline & 11 & 0.125147 & 0.272487 & 0.508513 & 0.505289 & 0.740795 & 1 \\
\hline 1945 & 12 & -0.602210 & -0.880336 & 0.485842 & 0.686557 & 0.852863 & 0 \\
\hline 1946 & 1 & 1.132135 & 0.763645 & 0.214301 & -0.087531 & -0.518756 & 1 \\
\hline & 2 & -0.896326 & -0.762187 & -1.262208 & -1.421625 & -2.005800 & -1 \\
\hline & 3 & 0.539951 & 0.591659 & -0.793287 & -0.313655 & -1.019310 & 0 \\
\hline & 4 & -2.658707 & -2.819943 & -1.296432 & -1.429037 & -1.906671 & -1 \\
\hline & 5 & 0.265024 & 0.591692 & 1.020464 & 1.424803 & 0.573060 & 1 \\
\hline & 6 & 0.976935 & 0.579973 & 1.655092 & 1.353757 & 1.754263 & 1 \\
\hline & 7 & -0.116361 & -0.371744 & -0.128254 & 0.222525 & 0.141586 & 0 \\
\hline 1946 & 8 & -0.142703 & -0.399833 & -0.456748 & -0.664410 & -0.309348 & -1 \\
\hline 1946 & 9 & -0.025214 & 0.637323 & -0.610049 & -0.380027 & -0.507885 & 0 \\
\hline 1946 & 10 & 0.261045 & 0.070152 & -0.120865 & -0.210356 & -0.621548 & 0 \\
\hline
\end{tabular}




\begin{tabular}{|c|c|c|c|c|c|c|c|}
\hline 1946 & 11 & -1.361657 & -1.206403 & -0.889453 & -0.995212 & -1.061830 & -1 \\
\hline 1946 & 12 & -1.016400 & -1.057977 & -0.851978 & -0.914830 & -0.769251 & 1 \\
\hline 947 & 1 & 1.365487 & 1.374872 & 0.685876 & 0.799765 & & \\
\hline 1947 & 2 & -0.016412 & .362629 & -0.862097 & -1.2 & 822 & -1 \\
\hline 19 & 3 & 45 & -0.06 & -0.153814 & -0.0 & & \\
\hline 194 & 4 & 0.673205 & 0.648931 & 9614 & 0661 & & \\
\hline 947 & 5 & 1.350304 & 1.327009 & 2.003247 & 1.845413 & & \\
\hline 94 & 6 & -0.068249 & -0.160916 & 0.621496 & 0.261902 & -0. & \\
\hline 47 & 7 & 0.353576 & 1.34 & -0.271434 & -0.278217 & -0 & \\
\hline 47 & 8 & -0.311 & 275 & -0.322894 & -0.29 & & \\
\hline 47 & 9 & -0.13 & -0.17 & & -0.4 & & \\
\hline 1947 & 10 & -1 & -1 & & & & \\
\hline 19 & 1 & & & & & & \\
\hline 94 & 12 & -0 . & -0.9 & -0.890686 & -1 & & - \\
\hline 948 & 1 & -1.05 & -1.0 & -0.382973 & -0.3 & 395 & - \\
\hline 948 & 2 & 0.75 & -0.3 & 0.897218 & 1.202451 & 62 & \\
\hline & 3 & 2.10 & 1.7 & 1.085258 & 1.49 & & \\
\hline & 4 & 0.63 & & & & & \\
\hline & 5 & & & & & & \\
\hline & 6 & & & & & & \\
\hline 948 & 7 & -0.08 & -0.3 & -0.428493 & -0. & -0 . & -1 \\
\hline 948 & 8 & -0.3 & -0.3 & -0.434026 & -0.3 & 0 & \\
\hline & 9 & -0.87 & -1.1 & -0.6 & -0.7 & 541 & - \\
\hline 948 & 10 & -0.44 & -0.4 & -0.3 & -0 . & & \\
\hline & 11 & & & -0.2 & -0 . & & \\
\hline & 12 & & & & & & \\
\hline 1 & 1 & & & & & & \\
\hline 949 & 2 & 0.5 & 0.7 & 0.7 & 0 . & & \\
\hline 94 & 3 & -1.1 & -0 & -0.885442 & -0. & -0 . & \\
\hline 4 & 4 & -1.9 & -1 & & & & \\
\hline & 5 & & & & & & \\
\hline & 6 & & & & 70 & & \\
\hline & 7 & -0 & -0 & -0 & -0 & & \\
\hline 940 & 8 & -0. & -0.6 & -0 . & -0 . & -0 . & - \\
\hline & 9 & $0 . c$ & 0. & -0.269656 & $-0.2+3$ & & \\
\hline 949 & 10 & -0.3 & -0. & -0.53 & -0.5 & -0 & \\
\hline & 1 & -0 & -0 . & -0.9 & -1 & & \\
\hline & 12 & & & & & & \\
\hline & 1 & & & & -0 & & \\
\hline 95 & 2 & $-0.2+x$ & -0.1 & 0.8 & 0 & & \\
\hline 95 & 3 & 0.2 & -0.3 & 0.169820 & -0. & & \\
\hline 95 & 4 & 0.4 & 0.4 & -0.358953 & -0.745124 & -1 & \\
\hline 195 & 5 & -0 . & & & & -0 & \\
\hline & 6 & & & & & & \\
\hline & 7 & & & & -0 & & \\
\hline & 8 & & & & & & \\
\hline & 9 & & -0 . & -0.24 & -0.2 & -0.1 & \\
\hline 195 & 10 & -0.65 & -0.86 & -0.456720 & -0.565914 & -0.604921 & - \\
\hline 195 & 11 & 1.62 & 1.6 & 0.969978 & 1.031842 & 0 & \\
\hline 195 & 12 & 0.9 & 0.5 & 1.08 & 0.7 & 7266 & \\
\hline 195 & 1 & 0.2 & 0.4 & -0.03 & -0.155756 & -0.0 & \\
\hline 195 & 2 & & & & & & \\
\hline 195 & 3 & & & & & & \\
\hline & & & & & & & \\
\hline 195 & 5 & -1.3 & -1.22 & -0.7 & -0.5 & -0.413197 & \\
\hline & 6 & 0.72 & 0.2 & 0.657820 & 0.376277 & 0.139132 & \\
\hline & 7 & & $0.6^{\circ}$ & 1.077825 & 1.064627 & -0.517498 & \\
\hline & 8 & -0.05 & -0.30 & 0.127194 & & 1.015010 & \\
\hline 1951 & 9 & 0.042673 & 0.015573 & -0.549156 & -0.638680 & -1.343478 & \\
\hline
\end{tabular}




\begin{tabular}{|c|c|c|c|c|c|c|c|}
\hline & 10 & 543729 & 0.492775 & 74456 & .775336 & 0.798211 & \\
\hline & 11 & 87709 & 0.837367 & 648304 & 1.241058 & 1.561277 & \\
\hline 19 & 12 & 0.041943 & 0.458438 & 486517 & 0.650152 & 895917 & \\
\hline 1952 & 1 & 0.956634 & 09767 & 507840 & 0.481957 & 40713 & \\
\hline 1 & 2 & -0.021206 & 0.582155 & 102260 & -0.012296 & -0 . & \\
\hline 1 & 3 & -0.206934 & -0.001656 & 38450 & 0.582536 & 0.390 & \\
\hline 95 & 4 & 18180 & 0.876376 & & 308709 & 0.518 & \\
\hline 952 & 5 & $0.1+x-1$ & 0.67 & 0.58 & 0.883351 & & \\
\hline 952 & 6 & 0.62 & & 0.671404 & 586 & & \\
\hline 952 & 7 & -0.124916 & & -0.309100 & -0.383071 & & \\
\hline 52 & 8 & -0.539100 & -1 & -0 & -0.124882 & & \\
\hline 952 & 9 & 0.474970 & & & 0.914574 & & \\
\hline 52 & 10 & -1.235925 & -1.325928 & -1.18 & -1.204759 & & \\
\hline 52 & 11 & 0.2 & 0.76 & & 0.552406 & & \\
\hline 52 & 12 & 1.3 & $1.31^{\circ}$ & 0 . & 878 & & \\
\hline 53 & & 0.7 & 0.6 & 0 . & & & \\
\hline 953 & 2 & 0.7 & & -0 & -0 . & & \\
\hline 1953 & 3 & 0.7 & & & 1.28 & & \\
\hline 1953 & 4 & 0.0 & 0.3 & & 0.673 & & \\
\hline 1953 & 5 & 0.9 & 1.1 & & 0.100942 & -0 & \\
\hline 195 & 6 & -1.0 & -0.8 & -0 . & -0.629 & -0 & \\
\hline 953 & 7 & 0.0 & -0.4 & -0 . & -0.5 & -0 . & 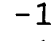 \\
\hline 53 & $\varepsilon$ & -0.3 & -1.0 & -0 & -0. & -0 . & \\
\hline 5 & $s$ & -0.2 & -0.1 & -0 & -0.7 & & \\
\hline & & -0.4 & -0.7 & -0 & -0.1 & & \\
\hline & & 0.0 & -0.3 & & -0.6 & -0 & \\
\hline & 12 & & 1.3 & & 0. & & \\
\hline 54 & 1 & -0.0 & $-0.5 c$ & -1 & -1.3 & -1 & -1 \\
\hline 54 & 2 & 0.9 & 1.3 & -1 & -1 & -2 & -1 \\
\hline 54 & 3 & -0.0 & 0.1 & -1.2 & -0.9 & -1 & -1 \\
\hline & 4 & -1.0 & -0.8 & -1 & -0.9 & & -1 \\
\hline & 5 & 0.7 & 0.6 & & 0.735 & & \\
\hline & 6 & -0.5 & -0.9 & -1 & -1.1244 & -1 & -1 \\
\hline & 7 & -0.6 & -0.7 & -0. & -0 & -1 & \\
\hline & 8 & -0.1 & -0.8 & 0 & & 0 & \\
\hline & 9 & & & 0. & & & \\
\hline & 1 & -0.1 & & $-0 . \varepsilon$ & -0.8 & -1 & -1 \\
\hline & & 0.9 & 1.0 & & 1.0 & & \\
\hline & 12 & 0.2 & 0.3 & 0. & 0.187 & 0 & 0 \\
\hline & 1 & -0.2 & -0.1 & -0 & -0.7 & -0. & \\
\hline & 2 & & -0.0 & -0.4 & & -0. & \\
\hline & 3 & & & -0.7 & 59 & -0 & 0 \\
\hline & 4 & -0.4 & -0.1 & -1.2 & -1.2 & -1 & -1 \\
\hline & 5 & -1.45 & -1.4 & -1.1 & -1.1 & -1 & -1 \\
\hline & $\epsilon$ & 0.15 & & & -0.007 & & 1 \\
\hline & 7 & -1.1 & -1.3 & -0.6 & -0.943734 & -1 & -1 \\
\hline & $\varepsilon$ & & & & & 3. & \\
\hline & 9 & -1.33 & -0.8 & -1.0 & -1.221 & -0.9 & -1 \\
\hline & & 2.12 & & & 2.209489 & 2.4 & \\
\hline & & -0.54 & -0.49 & -0.4 & -0.391235 & -0.6 & -1 \\
\hline & 1 & -1.674580 & -1.643207 & -14 & -1.487980 & -2.0 & \\
\hline & & 0.178043 & -0.103463 & -0.8 & -0.8932 & -0.1 & 0 \\
\hline & 2 & & & & 0.951371 & & 1 \\
\hline & 3 & $.2650 \varepsilon$ & -0.542655 & 0.26 & 0.881135 & 1.62 & 1 \\
\hline & 4 & & 1.4012 & 0.9679 & 0.552653 & & \\
\hline & 5 & 0.349089 & & 0.004156 & 0.200004 & -0.409514 & \\
\hline & 6 & -0.124913 & & & -0.1094 & & \\
\hline & 7 & -0.175658 & & & 0.363753 & -0.315601 & \\
\hline & 8 & -0.849465 & -0.690371 & -0.760397 & -0.676247 & & \\
\hline
\end{tabular}




\begin{tabular}{|c|c|c|c|c|c|c|c|}
\hline 1956 & 9 & 0.976232 & 0.842336 & 0.798317 & 1.333276 & -0.335910 & \\
\hline 1956 & 10 & -0.403544 & -0.456979 & -0.327103 & -0.339854 & -0.528942 & \\
\hline 1956 & 11 & .135013 & .285159 & 0.080315 & .206997 & & \\
\hline 956 & 12 & 63391 & 655938 & 0.693607 & 0.642170 & & \\
\hline 957 & 1 & 0.125799 & 35698 & -0.835413 & -1.171242 & -1. & \\
\hline 95 & 2 & -0.514003 & -0.135411 & -0.393835 & -0.437589 & -0.719736 & \\
\hline 957 & 3 & -1.006959 & -0.601472 & -1.831017 & -1.456250 & -1.276186 & - \\
\hline 957 & 4 & -0.543924 & -0.391187 & 1.734879 & 1.521008 & 1.096190 & \\
\hline 57 & 5 & -0.063198 & -0.695076 & -0.538094 & -0.638874 & -1.280528 & \\
\hline 957 & 6 & -0.691563 & -0.661368 & & -0.608895 & -0.871570 & \\
\hline & 7 & -0 . & -0 . & -0 . & -0.8 & -1 & \\
\hline 957 & 8 & $-0.8-2$. & -0.89 & -0 . & -0.8 & -0 . & \\
\hline 957 & 9 & -0.4 & -0.64 & -0 . & -0.43 & -0 . & \\
\hline 957 & 10 & -0 & -0.34 & -0 . & -0.285854 & -0.723 & \\
\hline 957 & 11 & -0.468361 & -0.039946 & -0.14 & -0.425124 & -0.798255 & \\
\hline 957 & 12 & 1.631567 & 2.083863 & 1.72 & 1.885482 & 1.662206 & \\
\hline 958 & 1 & -0.360371 & -0.394194 & 0.68 & 0.625851 & 0.567725 & \\
\hline & 2 & -1 & -1 & & -0.0 & & \\
\hline 958 & 3 & -1 & -1.5 & & & & \\
\hline 1958 & 4 & 1.5 & 0.6 & 0 . & 0.8 & 46 & \\
\hline 1958 & 5 & 0.4 & 0.236954 & 0.68 & 0.805617 & 806573 & \\
\hline 958 & 6 & -0.0 & -0.886937 & -1.13 & -1.015965 & -1.272241 & \\
\hline 958 & 7 & -0.3 & 0.156366 & -0.39 & 0.076686 & 0.717256 & \\
\hline & 8 & -0. & -0.16 & -0.5 & -0.2 & $-0.4 t$ & \\
\hline & 9 & & & & & -0 & \\
\hline 58 & 10 & & 0.2 & & 1.2 & & \\
\hline 958 & 11 & 0.4 & 0.1 & -0 & -0.3 & -0. & \\
\hline 1958 & 12 & -0.84 & -0.752070 & -0.54 & -0.762264 & -0.572 & - \\
\hline 959 & 1 & 0.9 & 0.70 & -0. & -0.052629 & -0.25 & \\
\hline & 2 & -0.2 & & -0 . & -0.4 & -0 & - \\
\hline & 3 & -0 . & -0 & & -0 . & -0 & \\
\hline & 4 & & & & -0 . & -0 & \\
\hline 1959 & 5 & -1 & -1.3 & -0 . & -0.4 & -1. & -1 \\
\hline 1959 & 6 & -0.6 & -0.9 & 0 & 59182 & 0.3 & \\
\hline 959 & 7 & -0.4 & 0.2 & -0 & -0.549856 & 0. & \\
\hline & 8 & -0.5 & -0.4 & & 0.5 & & \\
\hline & 9 & & & & -0 & & \\
\hline & & & & & 0 & -0 & \\
\hline & 11 & 0. & 0.4 & -0 . & -0.0 & 63 & \\
\hline 1959 & 12 & & 0. & 0 & 0.9 & 0.78 & \\
\hline 1 & 1 & 0. & 0.0 & 0.4 & 0.266466 & 0. & \\
\hline 1 & 2 & 0.549333 & & 0.3 & 0.274839 & 0 . & \\
\hline & 3 & -0 & -1.4 & & -1.4 & 08 & \\
\hline & & & & & & & \\
\hline & 5 & -0 . & -0 . & -0 & -0 . & -0 & \\
\hline & 6 & & & -0 . & -0.4 & -0 & \\
\hline 196 & 7 & -0.2 & -0.6 & 0 & 0.6 & 1.20 & \\
\hline & 8 & 0.3 & 0.3 & 0.29 & 0.448451 & 0.37 & \\
\hline 1 & 9 & 1.94 & 1.652213 & 1.558436 & 1.127141 & 1.652832 & \\
\hline & 10 & -1.0 & -1.2 & -0. & -0.66 & -0.39 & \\
\hline & 11 & -0. & -0.4 & -0 & -0.8 & & \\
\hline & 12 & -1 & -1 & & -0 . & -0 . & - \\
\hline & 1 & -1 & -1.19 & -0.2 & 0.5 & & \\
\hline & 2 & & 1.44 & & 1.4 & & \\
\hline 196 & 3 & 0.74 & 0.69862 & 1.44 & 1.654645 & 1.875971 & \\
\hline & 4 & 0.925 & 0.9943 & 0.710554 & 0.543334 & 0.730518 & \\
\hline & 5 & 0.491094 & 0.558689 & & 0.045702 & 0.054506 & \\
\hline & 6 & & & -0.830018 & -0.523920 & -0.716284 & \\
\hline & 7 & & 564 & & 0.362188 & 1.022941 & \\
\hline
\end{tabular}




\begin{tabular}{|c|c|c|c|c|c|c|c|}
\hline 1961 & 8 & -0.151515 & 0.086956 & 0.221120 & 0.051272 & 1.026875 & \\
\hline & 9 & -0.707852 & -0.858206 & -0.728636 & -0.796054 & -0.566373 & \\
\hline 1961 & 10 & 1.049859 & -0.806369 & -0.655447 & -0.571477 & 270 & \\
\hline 1961 & 1 & -0.975894 & .454627 & -0.480525 & 50981 & & -1 \\
\hline 1 & 12 & -1.323806 & -0.936313 & -0.301107 & -0.324313 & & -1 \\
\hline 1962 & 1 & 1.193270 & 1.293442 & 0.730754 & 0.641992 & 2895 & \\
\hline 1962 & 2 & -0.877096 & -1.163275 & 0.335378 & 0.674966 & 0.811359 & \\
\hline & 3 & -0.811496 & -0.500484 & 0.713212 & 0.985447 & 1.364735 & \\
\hline 62 & 4 & 0.654443 & 0.716089 & 0.254029 & 353828 & 0.548698 & \\
\hline & 5 & -1.125628 & -1.474901 & -1.064666 & -0.853732 & -1.133919 & \\
\hline & 6 & & -0 . & & & & - \\
\hline & 7 & 343 & -0.66 & -0. & & & -1 \\
\hline 96. & 8 & 49 & -0.8 & 0 & 112 & 316 & \\
\hline 00 & 9 & -0.8 & -0.83 & -0. & -0.2 & 320 & -1 \\
\hline 962 & 10 & 0.2 & -0.13 & 0.18 & 0.142620 & -0.103644 & \\
\hline 96 & 11 & 0.0 & -0.01 & 0.72 & 0.582434 & 1.039456 & \\
\hline 2 & 12 & -0.1 & -0.45 & -0.64 & -1.063850 & 695 & -1 \\
\hline & 1 & & -0.7 & & & & -1 \\
\hline & 2 & -1.4 & -0.8 & -1 & -0 . & & -1 \\
\hline 1963 & 3 & 0.2 & 0.2 & $0 . \varepsilon$ & 1.21 & 796 & \\
\hline 1963 & 4 & -0.306 & 0.17 & -2.22 & -2.227323 & -2.23 & -1 \\
\hline 1963 & 5 & -1.273 & -0.44 & -0.88 & $-0.5 \varepsilon$ & -2.12 & -1 \\
\hline & 6 & 0.3 & -0.0 & -0.68 & -0.6 & -0.5 & \\
\hline & 7 & -0.1 & & & & & -1 \\
\hline & 8 & & & & & & \\
\hline 1. & 9 & -0 & -1.0 & & & & \\
\hline 1963 & 10 & -0.7 & -0.5 & -1.4 & -0 . & -0 . & -1 \\
\hline 1963 & 11 & 0.8 & 0.3 & 0.6 & 1.09 & 0.805892 & \\
\hline 1963 & 12 & 0.1 & -0.15 & -0 . & -0.47 & -0.70 & \\
\hline & 1 & & & & & & \\
\hline & 2 & & -0 . & & & & \\
\hline 196 & 3 & 1. & 0. & & -0 & -0 & \\
\hline 1964 & 4 & -0.0 & -0.1 & & 630 & 726 & \\
\hline 1964 & 5 & -1.5 & -1.0 & -0.56 & -0.0 & -0.1 & -1 \\
\hline & 6 & -1 & -0.5 & & -0 . & -1.33 & -1 \\
\hline & 7 & & -0.7 & & -0 & & \\
\hline & 8 & & & & & & -1 \\
\hline & 9 & -0 & -1.0 & -0 . & -1 & -0 & -1 \\
\hline 1964 & 10 & -0.8 & -0.8 & -0 . & -0 & -0 . & -1 \\
\hline 1964 & 17. & -2.9 & -2.3 & -0 . & -0 . & -1.2 & -1 \\
\hline & 12 & $-0 . \varepsilon$ & -0.1 & -0 . & 6604 & 0.556 & \\
\hline & 1 & & -0 . & -0 . & -1 & -0.5 & -1 \\
\hline & 2 & & & & & & \\
\hline & 3 & & & & & & - \\
\hline & 4 & & -0.6 & -0 . & -0 . & 01 & -1 \\
\hline 1 & 5 & -1.16 & -1.5 & -1.0 & -0.7 & -1.2 & -1 \\
\hline & 6 & -1.4 & -0.55 & $-0.7-7$ & -0.83 & -0.973298 & -1 \\
\hline 196 & 7 & -0.4 & -0.87 & -0.3 & -0.472180 & 0.1 & -1 \\
\hline 196 & 8 & -0.0 & & $-0.5-5$ & $-0.4^{2}$ & -0.37 & \\
\hline & 9 & & & & & -0.4 & \\
\hline & 10 & & & & & & \\
\hline & 11 & & & & -1 & & \\
\hline 196 & 12 & -0.4 & -0.205676 & -0 & -1.0 & $-1.7 c$ & -1 \\
\hline 196 & 1 & -0.315168 & -0.426219 & -0.396 & -0.605455 & -0.696238 & -1 \\
\hline & 2 & & & 0.045 & 0.140356 & 1.394326 & \\
\hline 1966 & 3 & 0.784897 & .609265 & 0.128499 & 0.069841 & -0.016352 & \\
\hline & 4 & & -1.391399 & -1.403481 & -1.023537 & -1.584902 & - \\
\hline & 5 & -0.289384 & & & -0.011299 & & \\
\hline & 6 & & & & & & \\
\hline
\end{tabular}




\begin{tabular}{|c|c|c|c|c|c|c|c|}
\hline 1966 & 7 & -1.092791 & -1.168777 & -0.900902 & -1.708941 & -1.736459 & \\
\hline 1966 & 8 & -0.980221 & -0.930148 & -0.607589 & -0.523182 & -1.237768 & \\
\hline 1966 & 9 & 0.272378 & -0.172872 & 0.038643 & 0.612433 & 1.824422 & \\
\hline 196 & 10 & -0.088481 & -0.287521 & 0.551056 & 0.381791 & 1.368655 & \\
\hline 966 & 11 & -0.162171 & 0.003747 & -0.0285 & -0.06608 & -0.9435 & \\
\hline 966 & 12 & -0.662735 & -0.433411 & -0.430338 & -0.423210 & -0.032128 & \\
\hline 96 & 1 & 0.593669 & 0.611058 & 0.615950 & 0.316184 & 0.316389 & \\
\hline 96 & 2 & 0.159695 & 0.020872 & -0.120826 & -0.409083 & -0.349184 & \\
\hline 1967 & 3 & -0.708855 & -1.100861 & 1.296493 & 1.028412 & 1.210618 & \\
\hline 1967 & 4 & 0.384502 & 0.326171 & -0.829294 & -0.693514 & -1.155836 & \\
\hline 967 & 5 & 0.177061 & 0.052964 & 0.572218 & 0.771916 & 0.714847 & \\
\hline 7 & 6 & 0.098642 & & -1.03 & -0.505543 & -0.80 & \\
\hline 1967 & 7 & 0.2 & -0.1 & 0 & 0.37 & 0.8 & \\
\hline 967 & 8 & -0.2 & 0.73 & 1.3 & 0.75 & 1.4 & \\
\hline 967 & 9 & -0.43 & -0.65 & -1.0 & $-0.7 s$ & -0.6 & \\
\hline 196 & 10 & 0.82 & 0.668 & 0.1 & -0.05 & 0.1 & \\
\hline 96 & 11 & 0.041166 & 0.105922 & -0.23 & -0.01 & -0.53 & \\
\hline 967 & 12 & 0.449397 & 0.439536 & 0.83 & 0.83 & 1.38 & \\
\hline 96 & 1 & -1.06 & -1.283 & -0.46 & -0.28 & -0.2 & \\
\hline 196 & 2 & -0.3 & -0 . & -0 . & -0.8 & -1 & \\
\hline 1968 & 3 & 0.7 & & -0 . & -0.6 & -0 & \\
\hline 1968 & 4 & -0.6 & -0.8 & -0 & -0.55 & -1.9 & \\
\hline 968 & 5 & 0.62 & 0.54 & 0.5 & $1.05 \xi$ & 0.84 & \\
\hline L96 & 6 & 1.09 & 1.00 & 1.27 & 1.13 & 1.1 & \\
\hline 96 & 7 & -0.36 & -0.54 & $-0.5-5$ & -1.12 & -1.3 & \\
\hline 8 & 8 & -0 . & -0 . & -0 & -0.8 & & \\
\hline 196 & 9 & -0 & -0 . & -0 . & -0.4 & -0 . & \\
\hline 1968 & 10 & -0.2 & -0 & -0 & -0.22 & $-0 . \varepsilon-\gamma$ & \\
\hline 1968 & 11 & 0.80 & 0.726 & 0.2 & 0.099805 & 0.58 & \\
\hline 1968 & 12 & 0.33 & 0.09 & 0. & 0.02 & 0.25 & \\
\hline 196 & 1 & & & -0 . & $-0.5^{\prime}$ & -0 . & \\
\hline & 2 & & & & -1 & -1 & \\
\hline 1969 & 3 & -1.3 & -0 . & -1 & -1.2 & -0 . & \\
\hline 1969 & 4 & 0.1 & & & 0.5 & -0 . & \\
\hline 1969 & 5 & -0.3 & -0.04 & -0.3 & 0.23 & -0.9 & \\
\hline 1969 & 6 & 0.0 & & $-0.8+2$. & -0.19 & -0.171058 & \\
\hline 196 & 7 & & & & 0.35 & & \\
\hline & 8 & & & & & & \\
\hline & 9 & -0 . & -1 & & -0.0 & & \\
\hline 196 & 10 & -0.7 & -0 & -0 . & $-0.2 \epsilon$ & -1.4 & \\
\hline 196 & 11 & 1.68 & & 0 & 0.166732 & -0.55 & \\
\hline 1969 & 12 & -0.2 & 0.00 & & 0.35 & 0.78 & \\
\hline 197 & 1 & -1.6 & -1.150473 & -0 & -1.05 & $-0.7 s$ & \\
\hline & 2 & & & & & & \\
\hline & 3 & -1 . & & & -1.4 & -1 & \\
\hline 19 & 4 & & & & 1.7 & & \\
\hline $19^{\circ}-(-2$ & 5 & -0.2 & & -0 & -0.9 & -0.3 & \\
\hline 197 & 6 & -0.7 & -0.8 & 0 & 0.02 & 0.7 & \\
\hline 197 & 7 & 0.5 & 599 & -0.1 & 0.24 & -0.92 & \\
\hline 197 & 8 & -0.6 & 84296 & 725 & -0.135693 & 0.023103 & \\
\hline 197 & 9 & & & -0. & -1.27 & -0.9 & \\
\hline 197 & 10 & & & & 0.8 & & \\
\hline & 1 & -0 . & 0 . & & 0.58 & & \\
\hline 197 & 12 & -1.1 & -1.0 & -0 . & -0.53 & -0.3 & \\
\hline & 1 & -0.1 & -0.9 & & 0.05 & -0.27 & \\
\hline & 2 & 0.554686 & & & 1.505734 & 1.180267 & \\
\hline & 3 & 0.672722 & 0.036098 & & 0.959522 & 0.508131 & \\
\hline & 4 & & & & -0.479474 & & \\
\hline & 5 & & & & 11 & 88 & \\
\hline
\end{tabular}




\begin{tabular}{|c|c|c|c|c|c|c|c|}
\hline 1971 & 6 & -1.646141 & -1.442566 & -0.347667 & -0.378363 & -1.119417 & -1 \\
\hline & 7 & -0.035411 & -0.306937 & -0.175210 & 0.015417 & -0.093571 & \\
\hline 1971 & 8 & .981683 & 1.526825 & 2.002408 & 937470 & & \\
\hline 1971 & 9 & -0.119751 & -0.723986 & 0.7707 & 1.28 & 567 & \\
\hline 1 & 10 & -0.221540 & 0.021953 & -0.003106 & -0.178027 & & \\
\hline 1 & 11 & -0.702755 & -0.536851 & 0.364857 & 0.248660 & 0.322680 & \\
\hline 971 & 12 & 1.574569 & 1.387670 & -0.321158 & -0.271701 & -0.339810 & \\
\hline 172 & 1 & -0.165664 & -0.213953 & -0.176654 & -0.310857 & -0.279307 & \\
\hline & 2 & -1.268404 & -0.773529 & -0.307647 & -0.120289 & 0.562957 & \\
\hline 17 & 3 & 301 & 0.023049 & 0.2 & 822 & & \\
\hline 2 & 4 & 652 & 1.08 & -0 . & -0 . & & \\
\hline & 5 & & 0.7 & & & & \\
\hline 19 & 6 & .267048 & 1.74 & 2.5 & 2.0 & 98 & \\
\hline 1972 & 7 & 0.274358 & -0.344122 & -0.29 & -0.32 & -0.14 & \\
\hline 972 & 8 & -0.898963 & -0.259839 & -1.153859 & -1.070434 & -1.460058 & \\
\hline 7 & 9 & -0.674154 & -0.852792 & -0.122935 & 0.081639 & -1.025 & \\
\hline 72 & 10 & 0.2 & -0.01 & & -0.2 & & \\
\hline 72 & 11 & 1. & 1.80 & & 1.82 & & \\
\hline & 12 & & 1.0 & & & & \\
\hline 973 & 1 & 0.317284 & 0.65 & -0. & -0.1429 & -0.03 & \\
\hline $9 / 3$ & 2 & 0.240644 & 0.530755 & 0.762553 & 1.256305 & 0.876832 & \\
\hline 913 & 3 & -0.375173 & 0.123726 & -0.677105 & -0.311615 & -0.176667 & \\
\hline 7 & 4 & -0.099997 & -0.212799 & 1.02 & 0.91 & 1.59 & \\
\hline 73 & 5 & 1. & 1.2 & & & & \\
\hline & 6 & & & & & & \\
\hline 1973 & 7 & 0.391510 & -0.401070 & 0.42 & 0.5 & 33 & \\
\hline 973 & 8 & -0.517075 & 0.152936 & 0.477279 & 0.387803 & 0.133099 & \\
\hline 973 & 9 & -0.619962 & -0.626285 & -0.802426 & -0.517944 & -0.864892 & \\
\hline & 10 & $-0.4 \varepsilon$ & -0.5 & & & & \\
\hline 973 & 11 & -0 . & -0.1 & -0 & -0 . & -0 & \\
\hline & 12 & & & & & & \\
\hline 1974 & 1 & 0. & -0.0 & -0. & -0.26 & -0 . & \\
\hline 1974 & 2 & 0.286242 & 0.398923 & -0.662084 & -0.822268 & -1.520912 & -1 \\
\hline 1974 & 3 & -0.150283 & 0.121354 & -0.801281 & -0.768440 & -0.732607 & \\
\hline & 4 & & & & & & \\
\hline & 5 & -0 . & & & -0 . & -0 & \\
\hline & 6 & & & & -0 & & \\
\hline & 7 & & -0.4 & -0 . & -0 . & -0 . & \\
\hline 974 & 8 & 0.950141 & -0.026790 & 0.42 & 0.28 & 0.729836 & \\
\hline 1974 & 9 & 0.9 & 1.36 & 1.66 & 0.92 & 1.1 & \\
\hline 7 & 10 & -0.2 & -0.5 & -0 . & & -0 & \\
\hline & 11 & & & -0 & -0 . & -0 & \\
\hline & 12 & & & & & & \\
\hline & 1 & & & & & & \\
\hline & 2 & 760640 & 0.97 & 560622 & 0.86 & 0.491552 & \\
\hline 975 & 3 & -0.21 & 0.536 & 0.4 & 0.71 & 0.036274 & \\
\hline 97 & 4 & -0.50 & -0.134012 & -0.33 & -0.797714 & -0.247848 & \\
\hline 1 & 5 & & & & $0.4-4$ & 1.17 & \\
\hline 1 & 6 & & & & & 1.2 & \\
\hline & 7 & & -0 . & & & & \\
\hline & 8 & & & & -0 . & 33 & \\
\hline & 9 & & & & & & \\
\hline 97 & 10 & 0.63 & 0.108373 & 0.484831 & 0.622104 & 0.662669 & \\
\hline 197 & 11 & -0.397732 & 0.015925 & -0.204697 & -0.127584 & 0.094498 & \\
\hline 197 & 12 & -0.571051 & -0.518615 & -0.534339 & -0.464235 & -0.474514 & \\
\hline 197 & 1 & 1.315790 & 1.402813 & 1.363807 & 1.407513 & 1.098474 & \\
\hline 1976 & 2 & 1.698861 & 1.655523 & 0.809862 & 0.914889 & 0.772234 & \\
\hline 97 & 3 & 0.38 & 0.739690 & -0.518408 & -0.451020 & -0.491090 & \\
\hline & 4 & -0.144988 & -0.805797 & -0.285706 & -0.284345 & -0.461017 & \\
\hline
\end{tabular}




\begin{tabular}{|c|c|c|c|c|c|c|c|}
\hline 1976 & 5 & 0.866507 & 0.589127 & 0.055508 & 0.029342 & 0.298548 & \\
\hline 1976 & 6 & -0.182424 & -0.402547 & 0.030930 & 0.012455 & -0.633387 & \\
\hline 1976 & 7 & 0.549820 & 1.394298 & -0.065371 & -0.081208 & -0.695894 & \\
\hline 76 & 8 & 0.242752 & 0.151321 & -0.383896 & -0.3926 & 0.1137 & \\
\hline 976 & 9 & -0.556401 & -0.298455 & 0.123979 & 0.128478 & -0.952425 & \\
\hline 1976 & 10 & 1.586407 & 1.632696 & 1.135649 & 1.127246 & 0.967710 & \\
\hline 1976 & 11 & -0.939232 & -0.959991 & -0.779833 & -0.824195 & -1.144770 & \\
\hline 1976 & 12 & -0.519105 & -1.092486 & -0.369735 & -0.373531 & -1.178336 & \\
\hline 1977 & 1 & -1.784185 & -1.414977 & -0.717240 & -0.726963 & -1.478669 & \\
\hline 1977 & 2 & -0.769015 & -0.60 & 0.341874 & 0.290457 & -0.263704 & \\
\hline 97 & 3 & 2.250434 & 2.166250 & 1.848524 & 1.787825 & 7852 & \\
\hline 977 & 4 & & & & & & \\
\hline 1977 & 5 & 0.6 & & $-0.8-8$ & -0 . & -1.7 & \\
\hline 197 & 6 & -1.315 & -1.4 & 0.17 & & -0.0 & \\
\hline 197 & 7 & -0.308935 & -0.0 & -0.680197 & -0.705529 & & \\
\hline 197 & 8 & 0.455489 & 0.08 & 0.085664 & 0.098336 & 0.24 & \\
\hline 197 & 9 & 2.170453 & 1.71 & 0.074821 & 0.056236 & -0.314879 & \\
\hline 97 & 10 & 0.601750 & 0.63 & 0.985183 & 1.081243 & & \\
\hline 97 & 1 & & -0 . & & & & \\
\hline 1977 & 12 & 0 . & & & & & \\
\hline 197 & 1 & 1.2 & 1. & 0.7 & 0.9 & 0.9 & \\
\hline 1978 & 2 & -0.5 & -0.8 & -0.76 & -0.4 & -2.03 & \\
\hline 1978 & 3 & -0.3 & -0.64 & 0.43 & 0.717299 & 0.73 & \\
\hline 197 & 4 & 0.074778 & 0.15 & -0.72 & -0.78 & -1.36 & \\
\hline & 5 & & & & & & \\
\hline & 6 & & -0 . & -0 & -0 . & -0 . & \\
\hline 197 & 7 & 0. & & -0 . & -0 . & $-0.2+x$ & \\
\hline 1978 & 8 & 0.5 & -0.3 & 0. & 0 & 0.6 & \\
\hline 1978 & 9 & -0.2 & -0.4 & -0.403209 & -0.468082 & -0.12 & \\
\hline 197 & 10 & & & -0.55 & -0.94 & -1.03 & \\
\hline & 11 & -0 . & -0 & -0. & & -0 & \\
\hline & & -0 . & & & & & \\
\hline 197 & 1 & & & & & & \\
\hline 1979 & 2 & -0.6 & $-0.3+2$ & 1.5 & 1.7 & 1. & \\
\hline 197 & 3 & 1.4 & 1.3 & 1.384754 & 1.694520 & 1.20 & \\
\hline 197 & 4 & -0.1 & -0.2 & -0.219514 & -0.360472 & -0.37 & \\
\hline & 5 & & & & & & \\
\hline & 6 & & & & & & \\
\hline & 7 & -0 & -0 . & $-0.4-5$ & -0 & -0 . & \\
\hline $19^{\circ}$ & 8 & & & & 0 & 0.7 & \\
\hline 197 & 9 & 1.2 & 1.4 & 1.568134 & 0.875594 & 0.90 & \\
\hline 197 & 10 & 0.3 & 0.1 & 0.59 & 0.475444 & 1.51 & \\
\hline & 1. & & & -0. & -0.2 & -0. & \\
\hline & 12 & $-c$ & & & & & \\
\hline & 1 & -0 . & -0 . & -0 . & -0 . & -0 & \\
\hline & 2 & -2 & -1 & -1.8 .2 .0 & -1 & -2 . & \\
\hline & 3 & 0.5 & 0.47 & 0.3 & 0.73 & 0.42 & \\
\hline 198 & 4 & 0.109 & 0.1 & 0.76 & 0.936718 & 0.850004 & \\
\hline $19 \varepsilon$ & 5 & -0.7 & -1.1 & -0.22 & $-0.1-1 \quad-x$ & -0.27 & \\
\hline & 6 & -0.585 & -0.4 & -0.3 & -0 . & -1.17 & \\
\hline & 7 & & & -0 & -0 . & -0 . & \\
\hline & 8 & -0 & & & & & \\
\hline & & -0.7 & -1. & -0.85 & -1. & -1.3( & \\
\hline & 10 & -0.2 & $-0.2+x$ & & & & \\
\hline 19 & 11 & -0.5 & -0.45 & -0.30 & -0.54 & -0.23 & \\
\hline & 12 & -0.7 & -0.69 & -1.36 & -1.86 & -1.49 & \\
\hline & 1 & -1.6327 & -1.75 & -1.340498 & -1.602594 & -1.822852 & \\
\hline & 2 & & & & 0.186952 & -0.099229 & \\
\hline & 3 & & 2 & 948 & -2 & -2.26 & \\
\hline
\end{tabular}




\begin{tabular}{|c|c|c|c|c|c|c|c|}
\hline 1981 & 4 & -1.336193 & -1.518114 & 0.032695 & -0.007649 & 0.294358 & \\
\hline 1981 & 5 & 0.969149 & 1.277596 & 2.316412 & 2.015465 & 1.139210 & \\
\hline 981 & 6 & -1.123344 & -1.520813 & -0.870227 & -0.783805 & -0.961123 & \\
\hline 981 & 7 & & 0.391821 & 0.359384 & 0.424908 & & \\
\hline & 8 & -0.4 & -0.5893 ? & -0 . & -1.0 & 41 & \\
\hline 81 & 9 & 0.388314 & -0.3 & -0.035347 & -0.0068 & -0.112 & \\
\hline 981 & 10 & 0.837607 & 0.971161 & 0.090740 & 0.307882 & 545 & \\
\hline 981 & 11 & -0.578910 & -0.687820 & -0.809762 & -1.291243 & $-0.48^{\circ}$ & \\
\hline 981 & 12 & -1.106795 & -1.165010 & 0.362055 & -0.018608 & 0.715265 & \\
\hline 982 & 1 & 0.161909 & 0.210268 & 0.776635 & 1.241865 & 552 & \\
\hline 982 & 2 & 0.805029 & 0.747738 & 1.916222 & 2899 & 496 & \\
\hline 982 & 3 & 0.066391 & & -0.481 & -0 . & & \\
\hline 1982 & 4 & 0.544 & 1.339 & & & & \\
\hline 1982 & 5 & -1.702 & -1.09 & -0.26 & & -0 . & \\
\hline 982 & 6 & 1.883 & 1.31 & 1.619383 & & 96 & \\
\hline 982 & 7 & -0.151 & -0.74 & -0.560 & -0 . & $-0.2+2$ & \\
\hline 2 & 8 & -0.917 & $-0.59^{\circ}$ & -0.073 & -0 & -0.92 & \\
\hline 982 & 9 & -0.608211 & -0.663662 & -0.39 & -0 . & -0.52 & \\
\hline 2 & 10 & -0.61 & $-0.9 c$ & -0.51 & -0 . & -0.8 & \\
\hline ? & & -0.2 & -0.0 & & -0 & & \\
\hline 198 & 12 & -0.10 & 0.4 & -0 . & -0 & -0 & \\
\hline 983 & 1 & -0.00 & 0.212 & 0.5 & & & \\
\hline 1983 & 2 & 0.646378 & 0.860612 & 1.873851 & 0. & 62 & \\
\hline 198 & 3 & 0.971 & $0.62^{\circ}$ & 1.94 & & 308 & \\
\hline & 4 & 1.59 & & & & & \\
\hline & 5 & 0.9 & 0.8 & & & & \\
\hline 98 & 6 & -0.5 & 0.4 & & & 31 & \\
\hline 198 & 7 & -0.584 & -0.6 & -0.8 & -0 . & -0 & \\
\hline 198 & 8 & -0.351092 & -0.754 & -0.2 & -0 & -0 & \\
\hline 198 & 9 & -0.75 & -0.5 & -0.6 & -0 . & -0. & \\
\hline & & -0.5 & -0.5 & & & & \\
\hline & & -0 & 0.2 & & & & \\
\hline 19 & 12 & 1.7 & 1.6 & & & & \\
\hline 198 & 1 & -1.227668 & -1.41 & $-0 . \varepsilon-\gamma$ & -0 & -1 & \\
\hline 198 & 2 & 1.338918 & 1.8 & 0 & & -0 . & \\
\hline 19 & 3 & -0.997601 & -0.7 & -0. & & & \\
\hline & 4 & 1.0 & & & & & \\
\hline & 5 & 1.5 & & & & & \\
\hline & 6 & -0.0 & -0. & & & & \\
\hline 19 & 7 & -0.0 & 0.3 & & & & \\
\hline $19 \varepsilon$ & 8 & 0.36 & -0.55 & -0.8 & -0 . & -0 . & \\
\hline & 9 & -0.4 & -0.7 & -0.3 & -0 & -0 . & \\
\hline & & -0.5 & -0 . & & & & \\
\hline & & -0 . & -0 & & & & \\
\hline & & & & & -0 & & \\
\hline & 1 & -0.7 & -0 & -0 . & -0 & -1 & \\
\hline & 2 & -0.45 & -0.2 & $-0.2-2$ & -0 . & -0 . & \\
\hline & 3 & -0.850404 & -0.4 & -1.9 & -2.1 & -3.45 & \\
\hline 19 & 4 & -1.913274 & -2.2 & -1.064095 & -1.2 & -1.405 & \\
\hline & 5 & -1.74 & -1.4 & 1.0 & 0 & & \\
\hline 19 & 6 & 0.469 & -0.0 & 0.3 & & 516 & \\
\hline 19 & 7 & -0.0 & & & -0 . & -0.5 & \\
\hline & $\varepsilon$ & & & -0 . & -0 & & \\
\hline & 9 & 1.014 & 0.998778 & & & 423 & \\
\hline 198 & 10 & 0.156997 & 0.009241 & -0.28 & -0. & 361 & \\
\hline & $\perp$ & 0.53 & 0.5 & & 1.0 & 0.96 & \\
\hline 198 & 12 & -0.0532 & -0.033816 & -0.170604 & -0.466518 & -0.32 & \\
\hline & 1 & -0.2270 & & & & & \\
\hline & 2 & 0.250 & & 37 & & & \\
\hline
\end{tabular}




\begin{tabular}{|c|c|c|c|c|c|c|c|}
\hline & 3 & 1.638385 & 1.461595 & 172740 & -0.006785 & -0.968105 & \\
\hline & 4 & -1.168944 & -1.005436 & 0.437689 & 0.673320 & & \\
\hline 86 & 5 & 0.525025 & 0.430632 & -0.339152 & -0.478113 & -1.483896 & \\
\hline 986 & 6 & 1.233390 & 0.323460 & 0.286472 & -0.199865 & -0.660408 & \\
\hline 6 & 7 & 0.108508 & -0.219127 & 0.041272 & & & \\
\hline & 8 & 1.035630 & 1.1172 & 0.697968 & 0.612382 & & \\
\hline & 9 & -1.485010 & -1.281535 & -0.548716 & -0.314280 & -0.3 & \\
\hline & 10 & 0.196529 & 0.700313 & -0.418991 & -0.58 & & \\
\hline & 11 & 0.959912 & 0.977151 & 1.060896 & 1.202778 & 8030 & \\
\hline & 12 & -0.214288 & -0.215604 & 0.774315 & 0.885014 & 1.049777 & \\
\hline & 1 & -0.942582 & -0.990579 & -0.437750 & 81935 & -0.06 & \\
\hline & 2 & -1.976486 & -1.370399 & -1.416130 & -1.300406 & -1.093881 & \\
\hline 987 & 3 & -0.048324 & -0.016903 & -0.595572 & -0.588723 & -0.978404 & \\
\hline 98 & 4 & 1.32 & 0 & & & & \\
\hline 1987 & 5 & -2.09 & -1.88 & -0 . & -0 . & -0 . & \\
\hline 987 & 6 & 0.0 & -0.2 & -0 . & -0 . & & \\
\hline 987 & 7 & 1.353020 & 1.16 & 5864 & 925 & 1.6 & \\
\hline 987 & 8 & 0.688673 & -0.19 & 7438 & -0.164549 & -0.0 & \\
\hline 987 & 9 & 1.299359 & 1.79 & 9443 & 1.283473 & -0.3 & \\
\hline 987 & 10 & 0.226244 & -0.39 & & & & \\
\hline 987 & 11 & -0.4 & -0 . & -0 . & -0 & -0 . & \\
\hline 987 & 12 & -0.6 & -0 . & -0 . & -0 & -0 . & \\
\hline 988 & 1 & -0.87 & $-0 . \varepsilon$ & -0 . & -0 . & -0 . & \\
\hline 988 & 2 & 0.55 & 0.2 & 0. & 0 & 0 & \\
\hline 988 & 3 & -0.02 & 0.41 & -0 . & -0 & -0 & \\
\hline 988 & 4 & -1.164999 & -1.30 & -1 & -1.1 & -0.6 & \\
\hline 988 & 5 & & -0.15 & & & & \\
\hline 8 & 6 & -0.7 & -0 & -0 . & -0 & -0 . & \\
\hline 88 & 7 & 0.7 & 0 & & & & \\
\hline 988 & 8 & 0.0 & -0.1 & -0 . & -0 & -0 & \\
\hline 88 & 9 & -0.5 & -0.3 & 0 & -0 . & -0 . & \\
\hline 8 & 10 & -0.3 & -0.6 & -0.4 & -0 & -0 . & \\
\hline & & & & & & & \\
\hline & 12 & -1.3 & -1 & & -0 & -1 & \\
\hline 3 & 1 & -0.7 & -0 . & -0. & -0 & -0 . & \\
\hline 89 & 2 & -0.4 & -0 & -0 . & -0 & & \\
\hline 85 & 3 & -1.5 & -0.5 & -1.2 & -0 & -0 . & \\
\hline & 4 & -1.1 & -1.0 & & 0. & 4787 & \\
\hline & 5 & & & & & & \\
\hline & 6 & & & & & & \\
\hline & 7 & 0.1 & -0 . & -0 & -0 & & \\
\hline 98 & 8 & -0.5 & -0 . & -0 & -0 . & -0 . & \\
\hline & 9 & 0.7 & & & & & \\
\hline 89 & 10 & 0.7 & 0.6 & 020 & 1. & 4768 & \\
\hline & 11 & -0.2 & -0.3 & -0 . & -0 & -0 . & \\
\hline & 12 & -1.7 & -1. & -1 & -1 & -1 & \\
\hline & 1 & & & & & & \\
\hline & 2 & & & & & & \\
\hline & 3 & & & & -0 . & -0 . & \\
\hline & 4 & -0.4 & -0.6 & -0 . & & & \\
\hline & 5 & 1.2 & & & & & \\
\hline 19 & 6 & -0.74 & -1.2 & & $-0 .($ & -0 & \\
\hline & 7 & 0.51 & 0.5 & -0 & -0 . & -0 . & \\
\hline & 8 & 0.74 & 1.2 & & 789 & 6183 & \\
\hline 1990 & 9 & $-0.5 s$ & -0.7 & -0.6 & -0.6 & -0 . & \\
\hline & 10 & 0.95 & & & 1.044526 & 0.664545 & \\
\hline 1990 & 11 & 0.5 & 0.256204 & -0. & -0.1 & -0.4 & \\
\hline & 12 & 0.479501 & & & & & \\
\hline & 1 & -0.099849 & -0.125054 & 0.161557 & 0.243739 & 0.679303 & \\
\hline
\end{tabular}




$\begin{array}{rrrrrrrr}1991 & 2 & 0.211327 & 0.329718 & -0.585762 & -0.447829 & -0.951710 & 0 \\ 1991 & 3 & -0.184240 & 0.189147 & -0.518059 & -0.466600 & -0.018605 & 0 \\ 1991 & 4 & -0.787385 & -1.742588 & -0.199558 & -0.179750 & 0.118946 & -1 \\ 1991 & 5 & -0.710863 & -1.320490 & 0.112204 & 0.102719 & -0.387401 & 0 \\ 1991 & 6 & -1.277508 & -1.009632 & -0.569999 & -0.970803 & -0.536033 & -1 \\ 1991 & 7 & -0.233958 & -0.528864 & -0.197771 & -0.404773 & 0.307150 & 0 \\ 1991 & 8 & 0.202322 & -0.424791 & -0.392858 & 0.102300 & 0.859420 & 0 \\ 1991 & 9 & -0.298876 & -0.522149 & 0.323632 & 0.303485 & -0.297519 & 0 \\ 1991 & 10 & 0.172654 & 0.310555 & -0.371932 & -0.088378 & -0.426450 & 0 \\ 1991 & 11 & 0.450681 & 0.321894 & -0.546060 & -0.740087 & -0.701081 & 0 \\ 1991 & 12 & 0.276553 & 0.009662 & 0.020699 & -0.006777 & 0.337557 & 0 \\ 1992 & 1 & 0.146069 & 0.200799 & -0.392770 & -0.437346 & -0.695885 & 0 \\ 1992 & 2 & -0.782105 & -0.594187 & -1.169707 & -1.508015 & -2.043290 & -1 \\ 1992 & 3 & -0.711564 & -0.368944 & -0.930647 & -0.828512 & -2.027584 & -1 \\ 1992 & 4 & -0.346303 & -0.267739 & -0.612322 & -0.612014 & -0.876354 & -1 \\ 1992 & 5 & -0.418245 & -0.520459 & -0.593608 & -0.441529 & -0.893633 & -1 \\ 1992 & 6 & 1.105515 & 1.540966 & 2.209049 & 2.324837 & 2.142472 & 1 \\ 1992 & 7 & -1.080874 & -0.997221 & -0.320409 & -0.421938 & -0.956231 & -1 \\ 1992 & 8 & 0.149256 & 0.936618 & -0.188443 & -0.228232 & -0.091928 & 0 \\ 1992 & 9 & -0.115754 & -0.350450 & -0.081770 & -0.328333 & -0.497210 & 0 \\ 1992 & 10 & -0.103379 & 0.278804 & -0.472539 & -0.216348 & -0.819923 & 0 \\ 1992 & 11 & 0.634800 & 0.776546 & 1.152476 & 1.097872 & 0.643273 & 1 \\ 1992 & 12 & 0.016589 & -0.163840 & 0.604119 & 0.805369 & 1.649392 & 1 \\ 1993 & 1 & 1.261229 & 1.102808 & -0.146802 & -0.075703 & -0.685308 & 0 \\ 1993 & 2 & -1.490302 & -1.245320 & -0.903271 & -0.561991 & -1.244618 & -1 \\ 1993 & 3 & -0.214649 & -0.561130 & 0.930750 & 1.417512 & 1.136659 & 1 \\ 1993 & 4 & 1.718656 & 1.505442 & 0.670535 & 0.345575 & 0.154764 & 1 \\ 1993 & 5 & -1.201656 & -1.050625 & -0.946370 & -1.114816 & -1.540363 & -1 \\ 1993 & 6 & -1.029967 & -0.576982 & -0.420319 & -0.217977 & -0.136542 & -1 \\ 1993 & 7 & -0.542723 & -0.722243 & -0.657478 & -0.728207 & 0.080943 & -1 \\ 1993 & 8 & -0.736880 & -0.467191 & -0.124088 & -0.147720 & -0.183724 & 0 \\ 1993 & 9 & 0.048231 & 0.097317 & 0.586688 & 0.252517 & 0.728429 & 1\end{array}$

